\title{
ANÁLISE DE LIGAÇÃ̃ NA SÍNDROME DE MARFAN
}

\author{
Lúcia Valéria da Silva Teixeira
}

Tese (Doutorado) apresentada ao Programa de Pós-Graduação Interunidades Biotecnologia USP/ Instituto Butantã/IPT, para obtenção do Titulo de Doutor em Biotecnologia.

São Paulo 


\section{ANÁLISE DE LIGAÇÃO NA SÍNDROME DE MARFAN}

\section{Lúcia Valéria da Silva Teixeira}

Tese (Doutorado) apresentada ao Programa de Pós-Graduação Interunidades Biotecnologia USP/ Instituto Butantã/IPT, para obtenção do Titulo de Doutor em Biotecnologia.

Área de concentração

Biotecnologia

Orientadora:

Profa. Dra. Lygia da Veiga Pereira Carramaschi

Co-orientadora:

Profa. Dra. Ana Beatriz Alvarez Perez 
Teixeira, Lúcia Valéria da Silva.

Análise de ligação na síndrome de Marfan / Lúcia Valéria da Silva Teixeira. -- São Paulo, 2009.

Orientador: Lygia da Veiga Pereira Carramaschi.

Tese (Doutorado) - Universidade de São Paulo. Instituto de Ciências Biomédicas. Programa de Pós-Graduação Interunidades em Biotecnologia USP/IPT/Instituto Butantan. Área de concentração: Biotecnologia. Linha de pesquisa: Genética.

Versão do título para o inglês: Linkage analysis Marfan syndrome.

Descritores: 1. Marfan 2. Análise de ligação 3. Heterogeneidade genética I. Carramaschi, Lygia da Veiga Pereira II. Universidade de São Paulo. Instituto de Ciências Biomédicas. Programa de PósGraduação em Biotecnologia III. Título. 


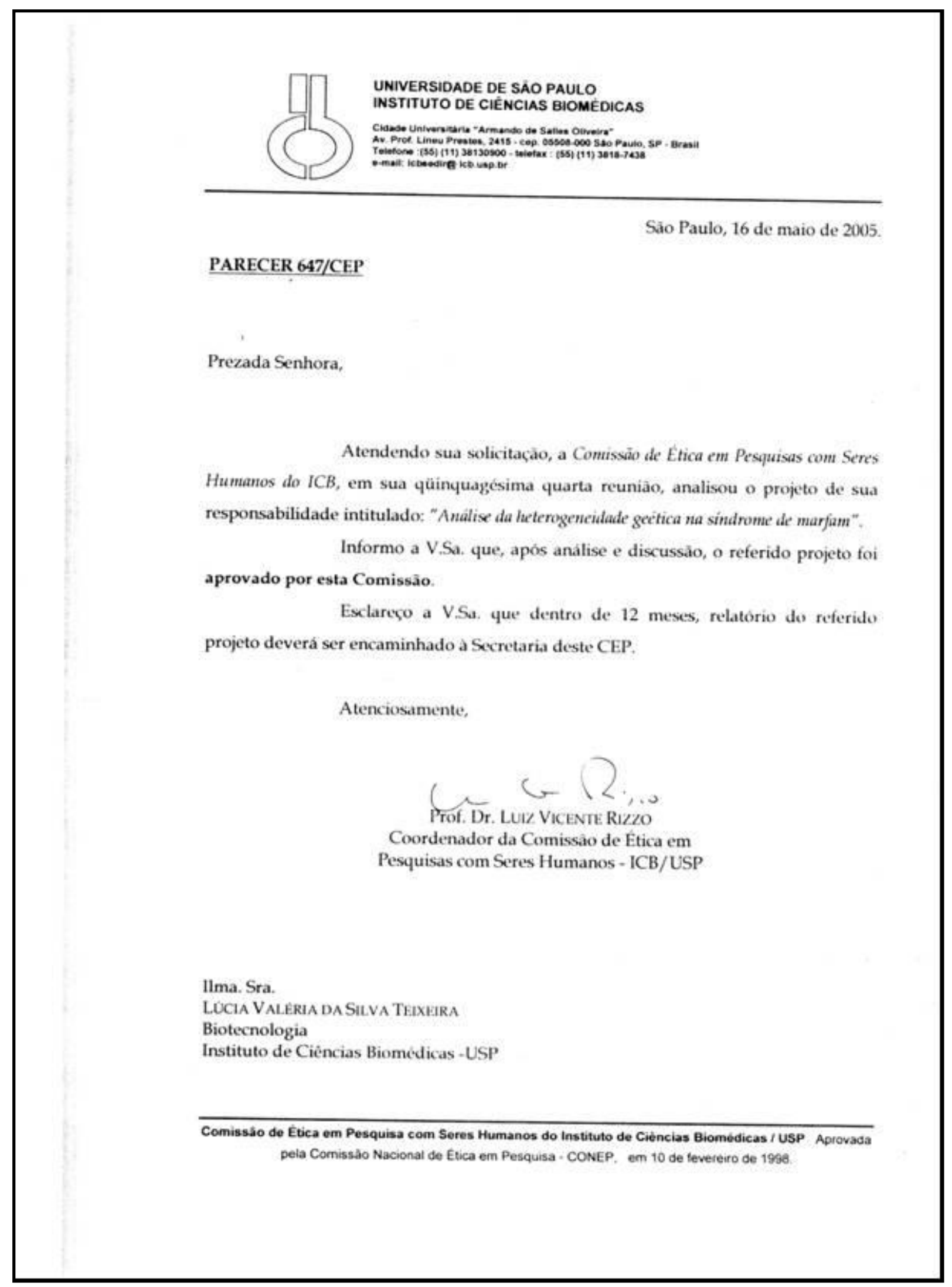


Às famílias com síndrome de Marfan, em especial a memória de Silvia Melo Ferreira e Moises Alves dos Santos 


\section{AGRADECIMENTOS}

A Deus porque sem ele nada seríamos.

À Profa. Dra. Lygia da Veiga Pereira Carramaschi e a Profa. Dra. Ana Beatriz Alvarez Perez pela oportunidade em desenvolver esta pesquisa e pela orientação.

À Dra. Karina Lezirovitz pelo auxílio com cálculos de Lod score e pelos conselhos científicos.

À Prof(a). Dra. Maria Regina Madruga da Faculdade de Estatística da Universidade Federal do Pará (ICEN/UFPA) pelo auxílio nos testes estatísticos.

Aos meus pais, Maria J. C. da Silva Teixeira e José F. Teixeira por todo o carinho e apoio que sempre me oferecem.

Aos meus irmãos Rainner A. da S. Teixeira, Rômulo A. da S. Teixeira e Ricardo A. da S. Teixeira pelo apoio nos momentos difíceis.

A meu esposo Marcelo da R. Machado pelo auxilio no decorrer deste trabalho.

À Tamine Manzin pela revisão de texto.

Aos meus colegas de bancada do laboratório de genética da UNIFESP e USP, em especial Mariana e Joana Carvalho, respectivamente.

À Fundação de Amparo à Pesquisa do Estado de São Paulo (FAPESP), pelo apoio financeiro. 
Coisas Que Eu Sei

Composição: Dudu Falcão

Eu quero ficar perto

De tudo que acho certo

Até o dia em que eu

Mudar de opinião

A minha experiência

Meu pacto com a ciência

Meu conhecimento

É minha distração... 


\section{RESUMO}

TEIXEIRA, L. V. S. Análise de ligação na síndrome de Marfan. 2009. 70 f. Dissertação (Doutorado em Biotecnologia) - Instituto de Ciências Biomédicas, Universidade de São Paulo, São Paulo, 2009.

A síndrome de Marfan (MFS) é uma doença autossômica dominante do tecido conjuntivo que afeta o coração, vasos sanguíneos, pulmões, olhos, ossos e os ligamentos. Mutações no gene codificante da fibrilina 1 (FBN1) causa a síndrome de Marfan e doenças relacionadas do tecido conjuntivo. FBN-1 é o componente principal das microfibrilas de 10-12nm encontrados na matriz extracelular (ECM). A ECM tem um papel estrutural na organização específica do tecido e participa na regulação de várias citosinas e fatores de crescimento. Uma quantidade crescente de evidências demonstra um relacionamento entre FBN-1 e o receptor do fator de transformação do crescimento (TGF- $\beta$ ). A Homologia entre FBN-1 e TGF- $\beta$ latente (LTGF) permite que os microfibrilas sirvam de reservatório para esta citosina. Recentemente foram descritos nos pacientes com MFS, mutações nos genes receptores I e II do TGF- $\beta$ (TGFBRI/II). O objetivo deste estudo foi analisar a heterogeneidade genética da síndrome de Marfan. Nós realizamos análises de ligação para 6 marcadores dos gene FBN1 e TGFBRII em 34 famílias e sequenciamos o TGFBRI e TGFBRII. A análise de ligação dos haplótipos em relação aos marcadores do gene FBN1 indicou co-segregação em 70,58\%, exclusão em 17,64\% e homozigozidade em 11,76\%; em relação aos marcadores do gene TGFBRII indicou co-segregação em uma família. Conseguimos demonstrar a heterogeneidade de lócus e a utilidade do teste diagnóstico na assistência das famílias pré-sintomáticas com manifestações atípicas ou ambíguas da MFS.

Palavras-chave: Síndrome de Marfan. Heterogeneidade genética. Análise de segregação. 


\begin{abstract}
TEIXEIRA, L. V. S. Linkage analysis in Marfan syndrome. 2009. $70 \mathrm{f}$. Ph. D. Thesis (Biotecnology) - Instituto de Ciências Biomédicas, Universidade de São Paulo, São Paulo, 2009.

Marfan syndrome is an autosomal dominant disorder of connective tissue that can affect the heart, blood vessels, lungs, eyes, bones, and ligaments. Mutations in the gene encoding fibrillin 1 (FBN1) cause Marfan syndrome (MFS), and related connective tissue disorders. Fibrillin-1 (FBN-1) is the main component of the 10-12 nm microfibrils found in the extracellular matrix (ECM). ECM displays a structural role in the tissue-specific organization and takes part in the regulation of various cytokines and growth factors. A growing body of evidence supports a narrow relationship between FBN-1 and TGF-beta. Homology between FBN-1 and latent TGF-beta (LTGF) allows microfibrils to be a reservoir for this cytokine. Recently, mutations in the gene for transforming growth factor-beta (TGF- $\beta$ ) receptor type I and II (TGFBRI/II) have been described in patients with MFS. The aim of this study was to analyze the genetic heterogeneity of Marfan syndrome. We have performed linkage analysis for 6 FBN1 and TGFBRII gene markers in 34 families and sequenced both TGFBRI and TGFBRII. The haplotype linkage analysis concerning the FBNl gene markers indicated cosegregation at $70.58 \%$, exclusion at $17.64 \%$ and homozygosity at $11.76 \%$; in relation to the TGFBRII gene markers, it indicated co-segregation in one family. We were able to demonstrate the heterogeneity of locus and the utility of the diagnostic test in the assistance of the daily pre-symptomatic families with atypical or ambiguous manifestations of MFS.
\end{abstract}

Key Words: Marfan syndrome. Genetic heterogeneity. Segregation analysis. 


\section{LISTA DE ILUSTRAÇÕES}

Figura 1. Representação esquemática da molécula da Fibrilina ..............................................27

Figura 2. Representação esquemática do gene TGFBRII .............................................................. 34

Figura 3. Representação esquemática do gene TGFBRII .......................................................... 34

Figura 4. Gráfico da análise dos marcadores de microsatélites ..............................................41 


\section{LISTA DE TABELAS}

Tabela 1. Famílias em que a doença co-segrega com haplótipos dos marcadores do gene FBN1

Tabela 2. Famílias em que foi excluída co-segregação com haplótipo dos marcadores do gene FBN1 . .48

Tabela 3. Famílias que apresentam haplótipo não informativo ............................................. 48

Tabela 4 Valores de lod score obtidos com o microssatélites do gene FBN1 ............................ 49

Tabela 5. Valores de lod score obtidos com os microssatélites do gene TGFBRII ...................50

Tabela 6. Famílias que apresentaram no mínimo 1 sinal maior e demonstraram segregação ou

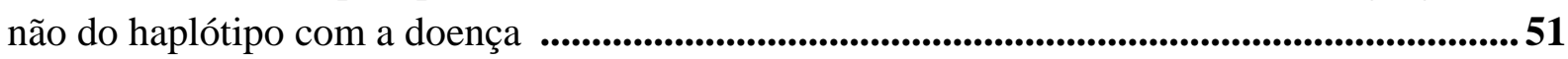




\section{LISTA DE QUADROS}

Quadro 1. Critérios diagnósticos e nosologia de Ghent .............................................................21

Quadro 2. Sinais clínicos maiores e menores na Síndrome de Marfan ......................................... 22

Quadro 3. Doenças que apresentam quadros semelhantes aos da Síndrome de Marfan ........... 24

Quadro 4. Seqüência de oligonucleotídeos para amplificação dos marcadores utilizados ....... 39

Quadro 5. Condições ideais de amplificação para os marcadores estudados .............................. 40 


\section{LISTA DE ABREVIATURAS}

$\mathrm{AD}=$ AUTOSSÔMICA DOMINANTE

AR $=$ AUTOSSÔMICA RECESSIVA

$\mathrm{CCA}=$ Aracnodactilia Contratural Congênita

cbEGF $=$ Fator de crescimento epidérmico ligado ao cálcio

DNA = Ácido desoxirribonucléico

D3S3727 = Marcador para o gene TGFBRII

D3S3567 = Marcador para o gene TGFBRII

LLC $=$ Complexo latente grande

LTBP-1 = Complexo latente de ligação a proteína do TGF- $\beta 1$

LTBP-2 = Complexo latente de ligação a proteína do TGF- $\beta 2$

LX $=$ LIGADA AO X

MTS-1 = Marcador para o gene FBNI

MTS-2 = Marcador para o gene FBN1

MTS-3 = Marcador para o gene FBNI

MTS-4 = Marcador para o gene FBNI

TGF- $\beta 1=$ Proteína do fator de crescimento transformante $\beta 1$

TB $=$ Proteínas ligantes do TGF- $\beta$

T $\beta$ RII = Proteína transmembrânica II

TGFBRI = gene do beta receptor 1 do fator de crescimento de transformação

TGFBRII = gene do beta receptor 2 do fator de crescimento de transformação

FBN1 = Gene da Fibrilina 1

UNIFESP = Universidade Federal de São Paulo 


\section{SUMÁRIO}

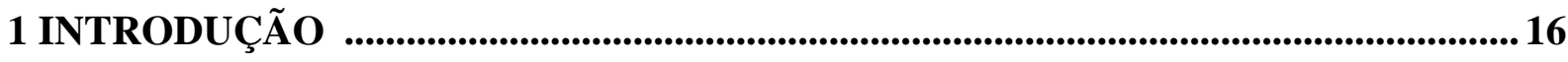

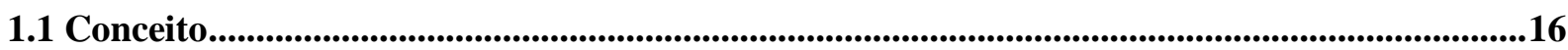

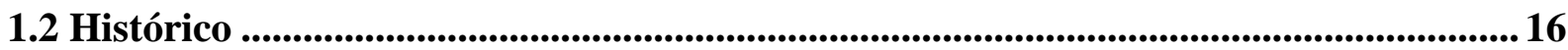

2 QUADRO CLINICO ............................................................................................................................ 17

2.1 Manifestações Esqueléticas............................................................................................................................17

2.2 Manifestações Oculares....................................................................................................................... 18

2.3 Manifestações Cardiovasculares ................................................................................................18

2.4 Outras Manifestações ........................................................................................................ 19

3 CRITÉRIOS DIAGNÓSTICOS....................................................................................... 21

3.1 Critérios Diagnósticos da Síndrome de Marfan ........................................................................................21

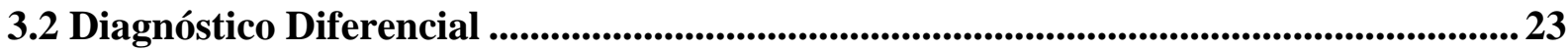

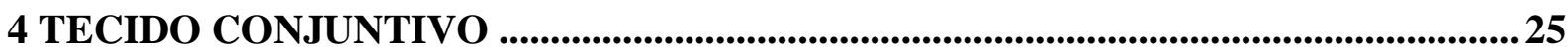

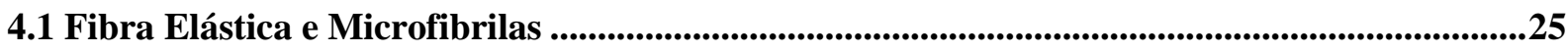

4.2 Estudos Bioquímicos e Imunohistoquímicos ............................................................ 25

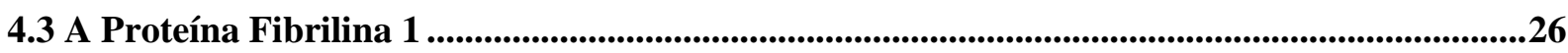

5 MAPEAMENTO E IDENTIFICAÇÃO DO GENE FBN 1 .....................................28

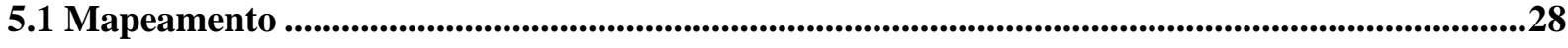

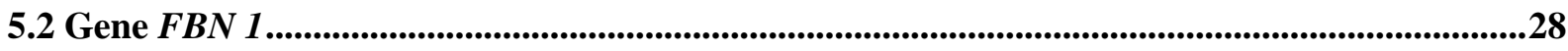

6 MUTAÇÕES E MECANISMOS PATOGÊNICOS NO FBN 1..................................... 29

7 CORRELAÇÃO GENÓTIPO/FENÓTIPO........................................................................ 31

8 HETEROGENEIDADE GENÉTICA NA SÍNDROME DE MARFAN ......................... 32

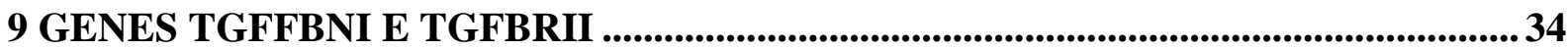

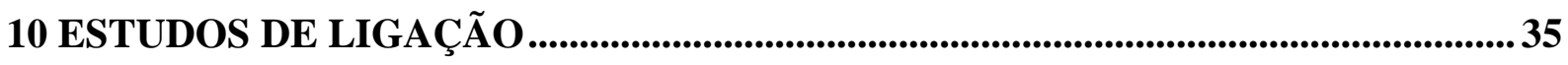

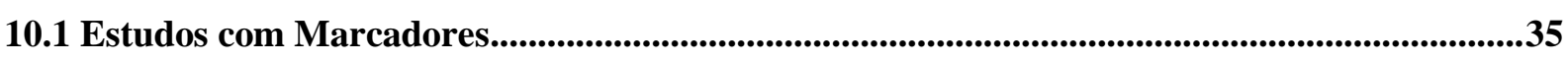

10.2 Estudos de Ligação na Síndrome de Marfan ...................................................... 35

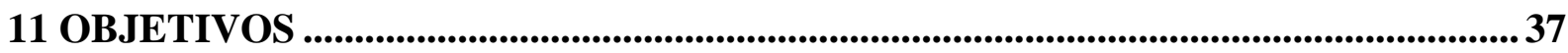

11.1 Objetivo Geral ......................................................................................................................................37

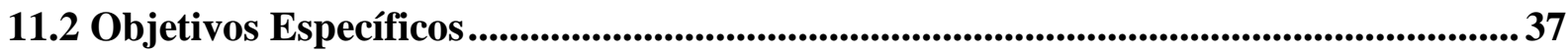

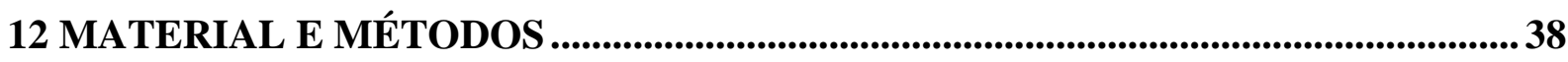

12.1 Grupo de Pacientes.................................................................................................................................................38

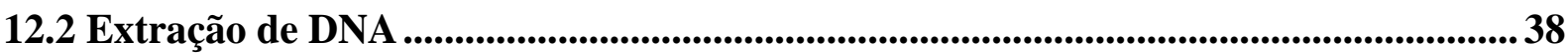

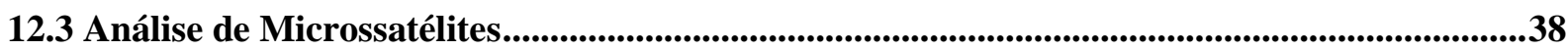


12.4 Condições de Amplificação.

12.5 Eletroforese e Análise dos Fragmentos .............................................................................................40

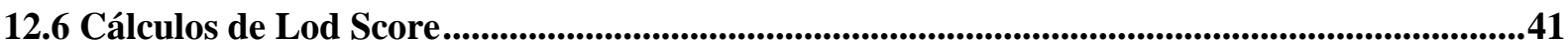

12.7 Sequenciamento ........................................................................................................................................42

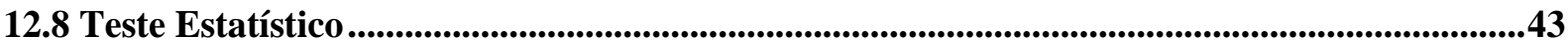

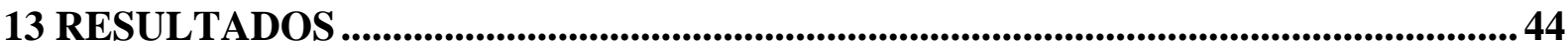

13.1 Estudo das manifestações clínicas de uma amostra brasileira de pacientes com síndrome de Marfan com o quadro clínico clássico e fenótipos associados ......................................................44

13.2 Análise da segregação de marcadores moleculares intragenicos aos genes FBN-1 e TGFBRII nos casos familiais de síndrome de Marfan...........................................................................44

13.3 Correlação genótipo-fenótipo dos genes $F B N-1$ e $T G F B R I I$ versos a gravidade da

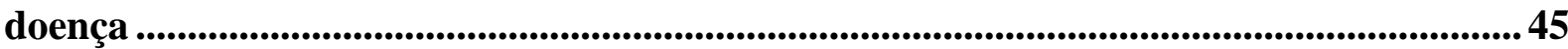

13.4 Seqüenciamento do gene TGFBRII nos casos que co-segregam com o gene e seqüenciamento do gene TGFBRI nos casos que excluíram ligação com o gene TGFBRII ......................................46

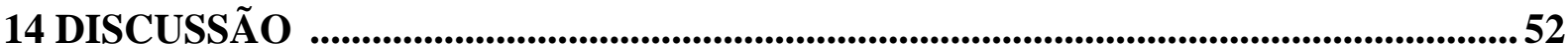

14.1 Estudo das manifestações clínicas de uma amostra brasileira de pacientes com síndrome de Marfan com o quadro clínico clássico e fenótipos associados ........................................................52

14.2 Análise da segregação de marcadores moleculares intragênicos aos genes $F B N$-1 e TGFBRII nos casos familiais de síndrome de Marfan ..............................................................................................53

14.3 Correlação genótipo-fenótipo dos genes $F B N 1$ e TGFBRII versos a gravidade da doença ..55

14.4 Sequenciamento do gene TGFBRII nos casos que co-segregaram com o gene e seqüenciamento do gene TGFBRI nos casos que excluíram ligação com o gene TGFBRII ...........56

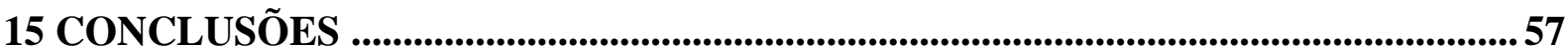

15.1 Estudo das manifestações clínicas de uma amostra brasileira de pacientes com síndrome de Marfan com o quadro clínico clássico e fenótipos associados

15.2 Análise da segregação de marcadores moleculares intragênicos aos genes $F B N$-1 e TGFBRII nos casos familiais de síndrome de Marfan ...........................................................................57

15.3 Correlação genótipo-fenótipo dos genes FBN1 e TGFBRII versos a gravidade da doença ..57

15.4 Sequenciamento do gene TGFBRII nos casos que co-segregaram com o gene e seqüenciamento do gene TGFBRI nos casos que excluíram ligação com o gene TGFBRII ...........58

15.5 Conclusão geral ..............................................................................................................................................................58

REFERÊNCIAS BIBLIOGRÁFICAS .......................................................................... 59

ANEXO A. Heredogramas das familias estudadas com marcadores do gene $F B N 1$ (MTS-1, MTS-2, MTS-3 e MTS-4) .......................................................................... 70

ANEXO B. Heredogramas das familias estudadas com marcadores do gene TGFBRII (D3S3727 E D3S3567) 


\section{INTRODUÇÃO}

\subsection{Conceito}

A síndrome de Marfan é uma doença hereditária do tecido conjuntivo. Apresenta herança autossômica dominante, pleiotropia, expressividade variável, penetrância completa e incidência de 2-3 por 10.000 indivíduos sem predileção por gênero, raça ou etnia (PYERITZ et al., 1993). As características clínicas envolvem principalmente os sistemas esquelético, ocular e cardiovascular. Outros órgãos, incluindo pulmão, pele ou tegumento e dura-máter também podem apresentar alterações (PYERITZ et al., 1993). Mutações no gene FBN1 são responsáveis por $90 \%$ dos casos de síndrome de Marfan e mutações nos genes TGFBRI e TGFBRII são responsáveis por 5-10\% dos casos (SAKAI et al., 2006).

\subsection{Histórico}

A síndrome de Marfan foi primeiramente descrita em 1896 pelo pediatra francês, Antoine Bernard Marfan, em uma menina de 5 anos e 6 meses, que apresentava dolicostenomelia (membros longos e finos), múltiplas contraturas articulares e escoliose. Em 1972, Hecht e Beals denominaram essa condição clínica de Aracnodactilia Contratural Congênita (CCA).

Weve em 1931 e Apert em 1938 foram os primeiros a sugerirem a herança autossômica dominante na síndrome de Marfan. O comprometimento da aorta foi descrito em 1943 por Baer et al., 1943, Etter e Glover, 1943 e o extenso envolvimento cardiovascular foi descrito detalhadamente em 1955 por Mckusick. Posteriormente Mckusick demonstrou que o defeito existente no tecido conjuntivo envolvia a aorta e a zônula ocular (MCKUSICK, 1955, 1956, 1991). Em 1972 foi esclarecido o papel da aorta na diminuição da expectativa de vida (MURDOCH et al., 1972). 


\section{QUADRO CLÍNICO}

\subsection{Manifestações Esqueléticas}

A maior parte dos indivíduos apresenta estatura elevada (acima do percentil 97) e membros longos. O segmento inferior é maior do que o superior e a envergadura é maior do que a estatura, caracterizando a dolicostenomelia. Essas proporções variam de acordo com a idade durante o crescimento normal, mas na pessoa afetada pela Síndrome de Marfan, a relação segmento superior e inferior está geralmente abaixo do $2^{\circ}$ desvio padrão para a idade, raça e sexo (PYERITZ, 1990; BEIGHTON et al., 1993).

A aracnodactilia se refere à presença de dedos longos, é um sinal característico, sendo considerado importante realizar as medidas das mãos e dos dedos médios. Essas medidas ultrapassam o percentil 97\% (PYERITZ, 1990; BEIGHTON et al., 1993).

Manobras simples para avaliar a aracnodactilia são clássicas, tais como o sinal do polegar positivo e o sinal do punho positivo. Essas manobras são úteis, porém têm um valor subjetivo por refletirem mais uma frouxidão ligamentar longitudinal das mãos do que a aracnodactilia (PYERITZ, 1990; BEIGHTON et al., 1993).

Outra característica clinica é o alongamento do tórax, exibindo deformidades e assimetrias produzidas pelo crescimento longitudinal excessivo das costelas e pela presença do peito escavado ou carenado isoladamente, ou combinados com o estreitamento do diâmetro ântero-posterior do tórax e escoliose. O peito escavado pode ser um sinal precoce da síndrome na criança e indica a necessidade de se procurar por outras anomalias (PYERITZ, 1990; BEIGHTON et al., 1993).

Escoliose ou cifoescoliose, algumas vezes com uma curvatura ântero-posterior significativa, ocorre em 30-60\% dos pacientes. Esta anormalidade é variável, mas alguns indivíduos são gravemente afetados e o prognóstico da escoliose tem sido relatado como pior do que nas escolioses idiopáticas. A cifose torácica está associada a deficiências pulmonares, incluindo capacidade vital e volume residual reduzidos. A escoliose aumenta rapidamente durante os anos de maior crescimento ósseo e consequentemente das vértebras, dos 11 aos 15 anos de idade, sendo importante à detecção precoce, quando a possibilidade de correção é maior (DEMETRACOPOULOS e SPONSELLER, 2007).

A protrusão acetabular é um achado freqüente. Está associada à escoliose e é mais comum no sexo feminino. 
São também observadas frouxidão ligamentar, pés planos, hálux alongado e valgo, contraturas dos dedos dos pés, hipotonia e hipotrofia muscular e gordura subcutânea escassa (PYERITZ, 1990; BEIGHTON et al., 1993; DEAN, 2007).

\subsection{Manifestações Oculares}

A subluxação do cristalino ou ectopia lentis ocorre em 50 a $80 \%$ dos casos e é usualmente bilateral, raramente progressiva, causando um prejuízo discreto da visão. O mais comum é que as lentes sejam deslocadas para cima. As zônulas ou ligamentos suspensórios do cristalino, quando visualizados, são redundantes, atenuados e freqüentemente rotos, porém a acomodação é possível. Quando a lente é deslocada totalmente fica caracterizada, então, a luxação do cristalino. Uma lente subluxada não pode ser visualizada com o oftalmoscópio comum, devendo sempre ser examinada com lâmpada de fenda. A iridodonese, ou o tremor da lente, é sugestivo do deslocamento (MAUMENEE, 1981).

O comprimento axial do globo ocular é aumentado, o que contribui para a miopia, em $80 \%$ dos casos, bem como para um risco maior de descolamento de retina e subluxação das lentes. Estudos da forma da córnea (ceratometria) mostram que aproximadamente todos os pacientes apresentam córneas achatadas. Além disso, frequentemente é observada a megalocórnea (PYERITZ, 1990; BEIGHTON et al., 1993; DEAN, 2007).

\subsection{Manifestações Cardiovasculares}

A Síndrome de Marfan é a principal causa de aneurisma dissecante em pessoas com menos de 40 anos, quase sempre conseqüente à dilatação da raiz da aorta. Em geral, o quadro clínico do aneurisma dissecante nestes pacientes difere pouco daqueles que não tem a síndrome, exceto pelo fato de que nos primeiros a regurgitação aórtica é mais comum e resulta de uma dilatação prévia na primeira porção da aorta. O aneurisma da aorta não é congênito, mas se desenvolve progressivamente no decorrer da vida. A dilatação da aorta em geral se inicia na primeira porção da aorta ascendente e a dissecção ocorre após a dilatação exceder o diâmetro de 5,5 a 6,0 cm. A pulsação e especialmente a pressão na aorta ascendente são os principais fatores na patogênese da dissecção da aorta. A anormalidade na túnica média pode resultar na dilatação difusa da aorta ascendente ou da artéria pulmonar, em aneurisma dissecante, numa combinação de dilatação e dissecção, ou em aneurismas mais distais da 
aorta e de seus ramos. O ecocardiograma é o método de escolha para o diagnóstico e o acompanhamento das anomalias da aorta torácica enquanto que o ultrasom de abdômen é útil na avaliação da aorta abdominal. A ressonância magnética é útil para uma visualização mais extensa da aorta tóraco-abdominal, obtendo-se uma visão panorâmica de toda a aorta que permite observar pontos com pequenas alterações que necessitam maior acompanhamento (SUMMERS et al., 2006; DEAN, 2007).

Em pacientes pediátricos, o prolapso da válva mitral com insuficiência mitral grave é a manifestação usual de maior morbidade. Embora as manifestações cardiovasculares na infância sejam mais sutis e menos graves, elas ainda representam a maior causa de óbito em pacientes jovens. A morte nestes casos é em geral atribuída à insuficiência cardíaca congestiva, pela lesão valvar, podendo ainda haver, em menor número, casos de expansão rápida da aorta com sua rotura e óbito por tamponamento cardíaco (PHORNPHUTKUL et al., 1973; SISK et al., 1983; CHEN et al., 1985; GEVA et al., 1987; GEVA et al., 1990; EL HABBAL, 1992). Entretanto, Lopez et al. (2005), diferentemente da maior parte da literatura, encontraram proporção significante de dilatação de aorta ascendente em crianças préescolares e escolares (76\% de ectasia ânulo aórtica).

\subsection{Outras Manifestações}

A manifestação pulmonar mais freqüente em pacientes com Síndrome de Marfan é o pneumotórax espontâneo, que ocorre em aproximadamente 5\% das pessoas afetadas (DWYER e TRONCALE, 1965; PYERITZ e MCKUSICK, 1979; HALL et al., 1984).

Estrias cutâneas nos ombros, dorso e coxas são comuns. São chamadas de striae atrophica ou distensae e aparecem por volta da segunda década de vida, não estando relacionadas à perda de peso. Hérnias inguinais, femorais e incisionais são achados frequentes, provavelmente associadas à flacidez do tecido conjuntivo. Também existem relatos de hérnia diafragmática (BEIGHTON et al., 1993).

Tem sido aceito que os pacientes com Síndrome de Marfan não apresentam comprometimento da função cerebral e o desenvolvimento intelectual e motor está dentro da média. Entretanto, metade dos pacientes mostra uma ou mais manifestações neuropsicológicas, incluindo dificuldade de aprendizado escolar ou de atenção, com ou sem hiperatividade, imaturidade emocional e discrepância verbal e de comportamento (BEIGHTON et al., 1993). 
A ectasia dural é caracterizada pelo estreitamento dos pedículos vertebrais, alargamento das distâncias interpediculares e um entalhamento dos corpos vertebrais. A maioria dos pacientes é assintomática, mas alguns podem referir dores lombares e nos membros inferiores. Atualmente, esta anomalia é melhor avaliada através da tomografia computadorizada ou ressonância magnética de região lombo-sacra (OOSTERHOF et al., 2001; AHN et al., 2001; KNIRSH et al., 2005; HABERMANN et al., 2005; JONES et al., 2005). 


\section{CRITÉRIOS DIAGNÓSTICOS}

\subsection{Critérios Diagnósticos da Síndrome de Marfan}

Em 1986 foi realizado um Workshop durante o $7^{\circ}$ Congresso de Genética Humana em Berlim. Neste evento, Pyeritz et al., estabeleceram os critérios diagnósticos modificados para a Síndrome de Marfan, que foram publicados por Beighton et al. (1988). Neste trabalho foram listados os sinais clínicos, dentre eles os considerados sinais maiores, ou seja, aqueles com maior frequência e especificidade (luxação do cristalino, dilatação da aorta ascendente, dissecção da aorta e ectasia dural).

Posteriormente, De Paepe et al. (1996) revisaram os critérios de Pyeritz et al. (1986a) e fizeram algumas modificações motivadas pelas descobertas de achados moleculares e de sua correlação com o fenótipo, hoje conhecidas como critérios de Ghent (Quadro 1 e Quadro 2).

Quadro 1 - Critérios diagnósticos e nosologia de Ghent.

\section{CASO ISOLADO}

Critérios maiores em dois ou mais órgãos diferentes e o envolvimento de um terceiro órgão. Se a mutação já tiver sido identificada em um indivíduo afetado, uma manifestação maior e algum outro órgão afetado.

\section{CASO FAMILIAL}

Manifestações em dois sistemas, sendo pelo menos uma manifestação maior, dependendo do fenótipo familial.

Fonte: De Paepe et al., 1996. 
Quadro 2 - Sinais clínicos maiores e menores na Síndrome de Marfan.

\begin{tabular}{|c|c|c|}
\hline CRITÉRIO & MANIFESTAÇÃO MAIOR & MANIFESTAÇÃO MENOR \\
\hline $\begin{array}{c}\text { SISTEMA } \\
\text { ESQUELÉTICO }\end{array}$ & $\begin{array}{ll}\text { - } & \text { Peito carenado } \\
\text { - } & \text { Escavado - no caso de } \\
& \text { necessitar cirurgia; } \\
\text { - } & \text { Envergadura > altura; } \\
\text { - } & \text { Sinais de punho (Walker- } \\
& \text { Murdoch) e polegar } \\
& \text { (Steinberg); } \\
\text { - } & \text { Escoliose > 20 ou } \\
& \text { espondiolistese; } \\
\text { - } & \text { Extensão limitada do } \\
& \text { cotovelo < } 170^{\circ} ; \\
\text { - Pé plano; } \\
\text { - Protrusão acetabular; } \\
\text { No mínimo 4 dos sinais presentes. }\end{array}$ & $\begin{array}{l}\text { Aparência facial: } \\
\text { dolicocefalia, hipoplasia } \\
\text { malar, retrognatia; } \\
\text { - Hipermobilidade articular; } \\
\text { - Peito ecscavado } \\
\text { moderado; } \\
\text { - Palato altamente arqueado. } \\
\text { No mínimo 2 dos sinais maiores } \\
\text { presentes ou no mínimo } 1 \text { sinal } \\
\text { maior e } 2 \text { sinais menores presentes. }\end{array}$ \\
\hline $\begin{array}{l}\text { SISTEMA } \\
\text { OCULAR }\end{array}$ & $\begin{array}{l}\text { • Luxação do cristalino. } \\
\text { Luxação do cristalino presente. }\end{array}$ & $\begin{array}{l}\text { - Miopia; } \\
\text { - Córnea plana; } \\
\text { - Hipoplasia muscular de } \\
\text { íris ou ciliar. } \\
\text { No mínimo } 2 \text { dos sinais menores } \\
\text { presentes. }\end{array}$ \\
\hline $\begin{array}{c}\text { SISTEMA } \\
\text { CARDIOVASCULAR }\end{array}$ & 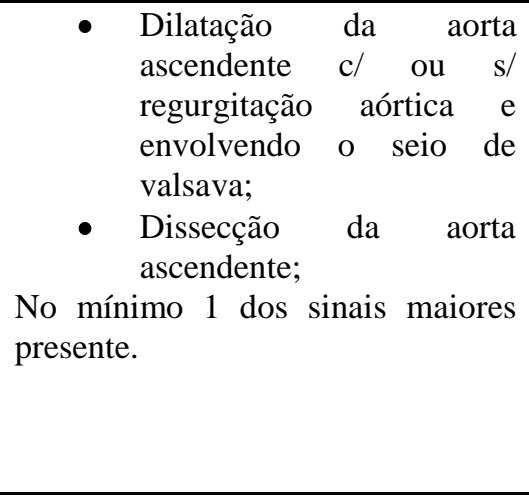 & 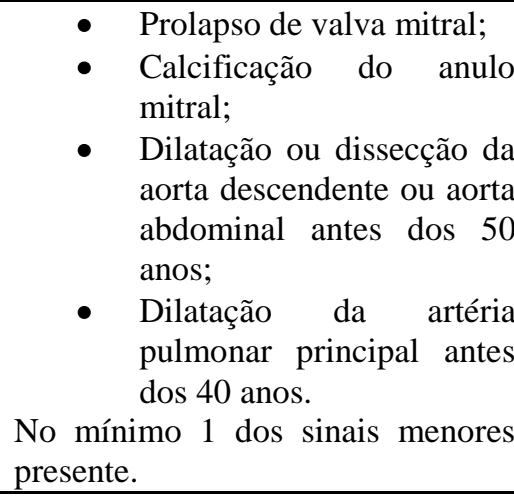 \\
\hline $\begin{array}{l}\text { SISTEMA } \\
\text { PULMONAR }\end{array}$ & & $\begin{array}{l}\text { - Pneumotórax; } \\
\text { Bolhas apicais. } \\
\text { No mínimo } 1 \text { dos sinais menores } \\
\text { presente. }\end{array}$ \\
\hline $\begin{array}{c}\text { PELE } \\
\text { /TEGUMENTO }\end{array}$ & & $\begin{array}{l}\text { - Estrias atroficas s/ causa } \\
\text { aparente; } \\
\text { - Hérnia recorrente ou } \\
\text { incisional. } \\
\text { No mínimo } 1 \text { dos sinais menores } \\
\text { presente. }\end{array}$ \\
\hline DURAL & $\begin{array}{r}\bullet \quad \text { Ectasia lombosacral. } \\
\text { Ectasia lombosacral presente. }\end{array}$ & \\
\hline FAMILIA & $\begin{array}{l}\text { - Membro familiar de grau } \\
\text { independente } \\
\text { diagnóstico completo; } \\
\text { - Mutação patogênica do } \\
\text { FBN1. } \\
\text { No mínimo } 1 \text { dos sinais maiores } \\
\text { presente. }\end{array}$ & \\
\hline
\end{tabular}

Fonte: De Paepe et al., 1996. 
Estes critérios foram revistos e comparados por Rose et al. (2000). Os autores perceberam que a ectasia dural era o segundo sinal maior mais comumente diagnosticado e que a procura pela ectasia dural estabelecia o diagnóstico da Síndrome de Marfan em 23\% dos pacientes sob os critérios de Ghent.

Dean, em 2007, reforçou que os critérios de Ghent confirmam ou excluem o diagnóstico da Síndrome de Marfan em $86 \%$ dos casos. Além disso, confirmou que o aparecimento de algumas características depende da idade e que os critérios diagnósticos devem ser utilizados com cuidado em crianças.

Recentemente, em um grande estudo realizado por um consórcio internacional foram analisados 1009 probandos com uma mutação no gene FBNl conhecida. Nesse estudo, os pacientes foram classificados da seguinte maneira: os que preenchiam e os que não preenchiam os critérios diagnósticos. Os autores demonstraram clinicamente que $79 \%$ dos adultos tinham diagnóstico da Síndrome de Marfan sendo que, quando considerada a mutação no gene FBN1, 90\% deles preenchiam os critérios diagnósticos. Para as crianças, estes números foram de $56 \%$ e $85 \%$ respectivamente. A dilatação da aorta ocorreu mais tardiamente em indivíduos que não preencheram os critérios diagnósticos (FAIVRE et al., 2008).

\subsection{Diagnóstico Diferencial}

Os principais diagnósticos diferenciais da síndrome de Marfan a serem considerados incluem alguns quadros semelhantes aos da síndrome de Marfan e outros ocasionados por genes diferentes (Homocistinuria, síndrome de Stickler, Aracnodactilia Contratural Congênita, síndrome de Ehlers-Danlos) e também pelos fenótipos chamados associados. Estes últimos constituem-se por doenças que apresentam combinações diferentes das alterações observadas na Síndrome de Marfan, também com herança autossômica dominante, como o fenótipo MASS, a Ectasia Anulo aórtica, a Ectopia lentis, a Síndrome do Aneurisma Aórtico de Loeys-Dietz e o Hábito familial semelhante ao da Síndrome de Marfan, nas quais já foram encontradas mutações no gene FBNl (Quadro 3) (JUDGE e DIETZ, 2005). 
Quadro 3 - Doenças que apresentam quadros semelhantes aos da síndrome de Marfan.

\begin{tabular}{|c|c|c|}
\hline DOENÇA & QUADRO CLÍNICO & HERANÇA \\
\hline HOMOCISTINÚRIA & $\begin{array}{l}\text { Estatura elevada, dolicostenomelia, } \\
\text { aracnodactilia, deformidade torácica, luxação do } \\
\text { cristalino (para baixo), miopia, retardo mental, } \\
\text { tromboembolia }\end{array}$ & $\begin{array}{c}\text { AR } \\
\text { (def. da } \\
\text { cistationina } \beta \\
\text { sintetase) }\end{array}$ \\
\hline $\begin{array}{l}\text { ARACNODACTILIA } \\
\text { CONTRATURAL } \\
\text { CONGENITA }\end{array}$ & $\begin{array}{l}\text { Estatura elevada, aracnodactilia, deformidade } \\
\text { torácica, escoliose, contraturas congênitas, PVM, } \\
\text { miopia, ceratocone, orelhas pregueadas }\end{array}$ & $\begin{array}{c}\mathrm{AD} \\
\text { FIBRLINA } 2\end{array}$ \\
\hline $\begin{array}{l}\text { S. EHLERS-DANLOS } \\
\text { (ESPECIALMENTE } \\
\text { O TIPO VI) }\end{array}$ & $\begin{array}{l}\text { Aracnodactilia, escoliose, PVM, descolamento de } \\
\text { retina, miopia, ceratocone, hipermobilidade } \\
\text { articular, luxações articulares, hematomas }\end{array}$ & $\begin{array}{c}\mathrm{AR} \\
\text { COL } 5 A 1 \\
\text { COL } 5 A 2 \\
\text { COL } 3 A 1\end{array}$ \\
\hline $\begin{array}{l}\text { S. DO PROLAPSO } \\
\text { DE VALVA MITRAL }\end{array}$ & $\begin{array}{l}\text { Deformidade torácica, cifose, PVM, defeitos de } \\
\text { septo atrial }\end{array}$ & $\begin{array}{c}\mathrm{AD} \\
\text { FIBRLINA } 1\end{array}$ \\
\hline S. STICKLER & $\begin{array}{l}\text { Estatura elevada, dolicostenomelia, deformidade } \\
\text { torácica, hipermobilidade articular, fenda } \\
\text { palatina, hipoacusia, artropatia, miopia, } \\
\text { descolamento de retina }\end{array}$ & $\begin{array}{c}\mathrm{AD} \\
C O L 2 A 1\end{array}$ \\
\hline $\begin{array}{l}\text { RDNPM E HÁBITO } \\
\text { MARFANÓIDE }\end{array}$ & $\begin{array}{l}\text { Estatura elevada, dolicostenomelia, hipotrofia } \\
\text { muscular, deformidade torácica, aracnodactilia, } \\
\text { face plana, hipertelorismo ocular, sinófris }\end{array}$ & $\begin{array}{c}\text { AR } \\
\text { FIBRLINA } 1\end{array}$ \\
\hline $\begin{array}{l}\text { DMLX COM } \\
\text { HÁBITO } \\
\text { MARFANÓIDE }\end{array}$ & $\begin{array}{l}\text { Estatura elevada, face longa e estreita, } \\
\text { macrocefalia, palato alto, retardo mental, } \\
\text { convulsão, micrognatia, defeito de septo atrial }\end{array}$ & $\begin{array}{c}\text { LX } \\
\text { FMRI }\end{array}$ \\
\hline $\begin{array}{l}\text { S. SHPRINTZEN- } \\
\text { GOLDBERG }\end{array}$ & $\begin{array}{l}\text { Aracnodactilia, escoliose, deformidade torácica, } \\
\text { cranioestenose, hipertelorismo ocular, } \\
\text { micrognatia, palato arqueado, deficiência mental, } \\
\text { PVM, miopia }\end{array}$ & $\begin{array}{c}\mathrm{AD} \\
\text { FIBRLINA } 1\end{array}$ \\
\hline $\begin{array}{c}\text { S. } \\
\text { HIPERMOBILIDADE } \\
\text { MARFANÓIDE }\end{array}$ & $\begin{array}{l}\text { Estatura elevada, hipermobilidade articular e da } \\
\text { pele, escoliose, deformidade torácica, palato alto }\end{array}$ & $\begin{array}{c}\mathrm{AD} \\
\text { FIBRLINA } 1\end{array}$ \\
\hline $\begin{array}{l}\text { ECTASIA ANULO } \\
\text { AÓRTICA }\end{array}$ & Dilatação da aorta & $\begin{array}{c}\mathrm{AD} \\
\text { FIBRLINA } 1\end{array}$ \\
\hline ECTOPIA LENTIS & Luxação do cristalino & $\begin{array}{c}\mathrm{AD} \\
\text { FIBRLINA } 1\end{array}$ \\
\hline FENÓTIPO MASS & $\begin{array}{l}\text { Miopia, PVM, dilatação discreta da aorta, } \\
\text { alterações da pele e do esqueleto }\end{array}$ & $\begin{array}{c}\mathrm{AD} \\
\text { FIBRLINA } 1\end{array}$ \\
\hline $\begin{array}{l}\text { HÁBITO FAMILIAL } \\
\text { SEMELHANTE AO } \\
\text { DA S. MARFAN }\end{array}$ & $\begin{array}{l}\text { Estatura elevada, dolicostenomelia, } \\
\text { aracnodactilia, deformidade torácica, escoliose }\end{array}$ & $\begin{array}{c}\mathrm{AD} \\
\text { FIBRLINA } 1\end{array}$ \\
\hline
\end{tabular}

Fonte: DEAN, 2007 (com modificações). AD= autossômico dominante; $\mathrm{AR}=$ autossômico recessivo; $\mathrm{LX}=$ ligado ao cromossomo X; PVM = prolapso de valva mitral; DMLX=deficiência mental ligada ao cromossomo $\mathrm{X}$; def.=deficiência; RDNPM=retardo de desenvolvimento neuropsicomotor. 


\section{TECIDO CONJUNTIVO}

\subsection{Fibra Elástica e Microfibrilas}

As fibras elásticas estão presentes no tecido conjuntivo de vários locais, tais como aorta, outros vasos, pulmão, derme, dura máter, vários tendões e ligamentos.

Fisiologicamente são responsáveis pela elasticidade dos tecidos (UITO, 1979; PYERITZ et al., 1993). Por meio de microscopia eletrônica foi demonstrado que as fibras elásticas consistem de dois componentes: um amorfo e o outro fibrilar (VARADI, 1976 e ROSS et al., 1977). O componente amorfo é composto pela proteína elastina. A elastina é sintetizada por células do tecido conjuntivo. Inicialmente a tropoelastina é traduzida pelas moléculas de RNAm, codificantes do polipeptídio da tropoelastina, a qual vai para o retículo endoplasmático rugoso (RER) destas células. Após a tradução, o polipeptídio de tropoelastina é novamente sintetizado para dentro das cisternas do RER, de maneira similar ao que ocorre com outras proteínas do colágeno e de outras proteínas destinadas ao meio extracelular. Os polipeptídios de tropoelastina são então transferidos do RER para o meio extracelular, onde se polimerizam por ligações cruzadas entre resíduos de lisina, originando a elastina (ROSEMBLOOM et al., 1993; UITO, 1979).

O componente amorfo é rodeado pelo componente fibrilar, que é constituído por distintas estruturas fibrilares $10-12 \mathrm{~nm}$. Análises imunológicas e químicas da microfibrila revelaram a síntese de duas microfibrilas distintas: microfibrilas de $8-10 \mathrm{~nm}$ e microfibrilas de 3 - 5 nm (LOW, 1961; LOW, 1962; UITO, 1979). O componente fibrilar representa a proteína microfibrilar da fibra elástica. A proteína microfibrilar contém várias glicoproteínas, incluindo a fibrilina (CLEARY, 1983; SAKAI et al., 1986).

As microfibrilas de $8-10 \mathrm{~nm}$ são filamentos lineares espaçados por estruturas globulares semelhantes a um colar de contas, estão associadas à membrana basal e, juntamente com as fibras elásticas, encontram-se na maioria dos tecidos. As microfibrilas menores de $3-5 \mathrm{~nm}$ estão conectadas a grânulos de proteoglicanas (FREDERICKSON et al., 1971; HAY 1978).

\subsection{Estudos Bioquímicos e Imunohistoquímicos}

Perejda et al., em 1985, ao examinar as fibras elásticas de tecidos da aorta de indivíduos com síndrome de Marfan notaram perda focal ou fragmentação das fibras elásticas. 
Outros autores observaram fibras elásticas anormais, em tecidos do pulmão e pele de indivíduos com síndrome de Marfan (HOLBROOK et al., 1982; SAYERS et al., 1975). Posteriormente foi sugerido que o componente protéico das microfibrilas, associadas às fibras elásticas, era candidato ao produto gênico alterado causador da síndrome de Marfan. Em 1990, Hollister et al., comprovaram em estudo realizado em indivíduos com síndrome de Marfan, que esse produto gênico era a fibrilina 1 anormal.

Estudos bioquímicos em fibroblastos da derme de pacientes com síndrome de Marfan, comprovaram que a diminuição da fibrilina 1 causava problemas em três vias metabólicas da sua formação: síntese celular, secreção e processamento (MCGOOKEY et al., 1989; MILEWICZ et al., 1992).

\subsection{A Proteína Fibrilina 1}

A fibrilina foi primeiramente isolada em 1986 por Sakai et al., a partir da cultura do fibroblasto, usando um anticorpo monoclonal contra as microfibrilas. Os autores demonstraram que se tratava de uma proteína de $350 \mathrm{kD}$, principal componente estrutural da classe das microfibrilas, estando presente nas microfibrilas associadas à elastina e nas microfibrilas sem morfologia definidas. A fibrilina também é encontrada nas microfibrilas presentes na membrana basal da junção derme/epiderme, no tecido periférico das fibras elásticas da pele, em tecidos elásticos como aorta e cartilagem da orelha e nos tecidos pobres em elastina como córnea, tendão e zônula ciliar (SAKAI et al., 1986).

A proteína fibrilina 1 é codificada pelo gene $F B N 1$, processada e secretada, formando as microfibrilas $(10-12 \mathrm{~nm})$ na matriz extracelular em associação com outras moléculas extracelulares. As microfibrilas podem funcionar sozinhas ou juntamente com a elastina para formar a base das fibras elásticas. A fibrilina 1 é rica em cisteína, contendo 47 repetições homólogas ao fator de crescimento epidermal (EGF), 43 dos quais são domínios do fator de crescimento epidérmico ligado ao cálcio (cbEGF). Cada repetição contém 6 cisteínas, entre as cisteinas 1-3, 2-4 e 5-6 existem pontes de sulfeto, que estabilizam a ligação. Além disso, a proteína tem repetições homólogas aos domínios encontrados na proteína ligante ao fator transformante beta-1 (TGF- $\beta 1$ ). Esses domínios também são ricos em cisteína, contendo 8 cisteínas cada (FIG 1). A fibrilina contém também outros domínios ricos em cisteína, que são variantes de módulos da proteína ligantes do EGF e TGF- $\beta 1$, também encontrados em outras moléculas que interagem com as microfibrilas, as fibulinas 1 e 2 e as proteínas ligantes da forma latente do TGF- $\beta 1$ e 2 (LTBP-1 e LTBP-2). O TGF $\beta$ é expresso como um precursor, 
sendo necessária sua clivagem para ser ativado. O complexo LTBP1 e TGF- $\beta$, conhecido como complexo latente grande (LLC), é ligado aos elementos da matriz extracelular, incluindo fibrilina 1 e outras fibrilas. Posteriormente o TGF- $\beta$ é liberado em resposta aos sinais moleculares e ambientais (KANZAKI et al., 1990; PEREIRA et al., 1993; 1994; RAMIREZ e PEREIRA, 1999; BIERY et al., 1999).

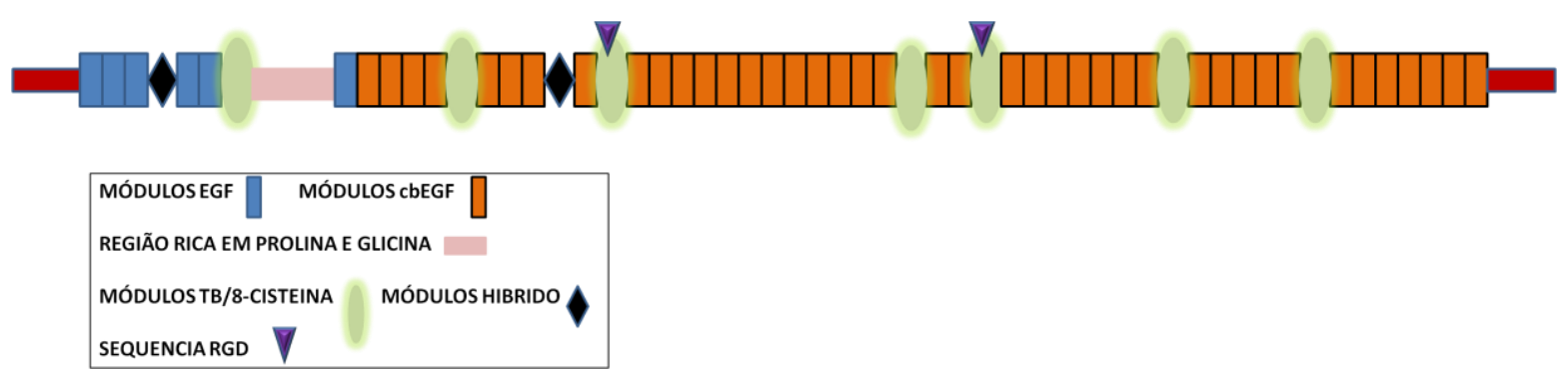

FIG. 1. Representação esquemática da molécula da Fibrilina. 


\section{MAPEAMENTO E IDENTIFICAÇÃO DO GENE FBN 1}

\subsection{Mapeamento}

Por meio de estudos de ligação, realizado em indivíduos afetados de famílias finlandesas e usando marcadores específicos, estabeleceu-se uma ligação entre a síndrome de Marfan e o cromossomo 15, na região cromossômica 15q22. Os autores obtiveram um lod score de 3,92 $(\theta=0,0 \pm 0,11)$ com os marcadores utilizados nessa região (KAINULAINEM et al., 1990). Posteriormente, em outro estudo conduzido em famílias americanas, confirmou-se a ligação do lócus da síndrome de Marfan no cromossomo 15, definindo com maior precisão a região, mapeada em 15q15 - q21.3 (DIETZ et al., 1991; TSIPOURAS et al., 1991; LEE et al., 1991).

Tsipouras et al., em 1992, estudaram 28 famílias com síndrome de Marfan. Os autores analisaram um marcador intragênico nestas famílias e obtiveram um lod score de 25,6.

Em 1993, Pereira et al., completaram a estrutura primária da fibrilina, elucidando a organização exon/intron do gene.

\subsection{Gene FBN1}

FBN1 é um gene de $230 \mathrm{~Kb}$ com 65 exons (MASLEN et al., 1991). O gene FBN1 é transcrito em um RNAm de $10 \mathrm{~Kb}$, contendo 9663 nucleotídeos, um quadro de leitura aberto (open reading frame - ORF) de 8613 nucleotídeos e as extremidades 5'e 3' não traduzidas tem 134 e 916 nucleotídeos respectivamente. O RNAm codifica a proteína fibrilina 1 que contém 2871 aminoácidos, excluindo peptídeo-sinal (PEREIRA et al., 1993; MASLEN et al., 1991). 


\section{MUTAÇÕES E MECANISMOS PATOGÊNICOS NO FBN1}

Dietz et al. (1991) demonstraram que mutações no gene $F B N 1$, que codifica a glicoproteína fibrilina 1, principal componente da microfibrila extracelular, ocasionam a síndrome de Marfan Clássica. Desde então mais de 800 mutações já foram descobertas nesse gene, em indivíduos com síndrome de Marfan (FAIVRE et al., 2007).

A primeira mutação patogênica encontrada no gene $F B N 1$, foi descrita por Dietz et al., em 1991. Os autores identificaram mutações de sentido trocado na região codificadora do gene FBN1 após análise de dois pacientes com Síndrome de Marfan.

Em 1995, foi criado um banco de dados, Universal Mutation Database (UMD) (http://www.umd.be), com o objetivo de estimar a quantidade de mutações encontradas em alguns genes. Ao todo, são apresentadas 601 mutações para o gene FBN1. Porém, em trabalho realizado por Faivre et al. (2007) foram descritas 803 mutações, entre elas 114 recorrentes. As mutações mais freqüentes listadas para esse gene são as mutações de ponto, deleções, inserções e as encontradas em sítio de splice (ROBINSON et al., 2006).

As mutações no gene FBN1 compreendem assim, três categorias funcionais:

1. Mutações "Missense", substituições de um aminoácido por outro, alteram os domínios do cbEGF, TB e módulos de fibrilina (Fib);

2. Mutações de sentido trocado inibem a maioria das atividades relacionadas à ligação do cálcio e criam um sinal prematuro para o término da tradução - são responsáveis por $60,3 \%$ dos casos;

3. Deleções internas e encurtamento da região carboxil-terminal que interferem na polimerização da proteína, originando uma proteína truncada.

Atualmente, em uma das maiores pesquisas já realizada com pacientes afetados da síndrome de Marfan (1009 indivíduos registrados entre 1995 a 2005), foram descritas várias mutações distribuídas por todo o gene $F B N 1$, sendo $77 \%$ delas localizadas no domínio do EGF, $15 \%$ no domínio do fator de crescimento transformante $\beta 1$ ligado à proteína (TGF $\beta 1$ BP), $20 \%$ nos exons $24-32,29 \%$ na região 5' (exons 1-21) e 37\% na região 3' (exons 43-65) (FAIVRE et al., 2008).

Foram encontradas deleções grandes no exon 1 do gene $F B N 1$, na região do códon de iniciação da tradução (ATG), causando a completa perda de expressão de um alelo haploinsuficiência (MÁTYÁS et al., 2007). Foram também encontradas mutações na região 5' "upstream" do gene FBN1 em 6 pacientes que preenchiam os critérios diagnósticos estabelecidos pela nosologia de Ghent ou, no mínimo, apresentavam um sinal maior 
envolvendo dois sistemas. Estas mutações são conservadas em humanos e outros primatas (SINGH et al., 2006b; SINGH et al., 2008a).

A constatação de que diferentes níveis de transcritos mutantes pudessem originar fenótipos variáveis sugeriram o mecanismo dominante-negativo. O mecanismo dominante/negativo, no qual o alelo mutante interfere na ação do alelo normal, é uma hipótese que pode explicar a polimerização anormal da proteína fibrilina 1 no interior das moléculas de microfibrilas. Vários estudos examinaram a correlação entre o nível de expressão do RNAm mutante produzido por mutações no códon de terminação prematura (PTC) e a gravidade clínica da doença (DIETZ et al., 1993; SCHRIJVER et al., 2002; ADES et al., 2004). Entretanto, este fato é controverso, pois é possível que diferentes níveis de expressão encontrados nos alelos normais do gene FBN1 causem diferentes fenótipos em membros da família que compartilham a mesma mutação PTC (HUTCHINSON et al., 2003). 


\section{CORRELAÇÃO GENÓTIPO/FENÓTIPO}

As mutações distribuídas ao longo do gene $F B N 1$ não apresentam uma correlação aparente genótipo/fenótipo. No entanto, há exceções em algumas regiões, as quais são normalmente causadas por mutações pontuais ou pequenas deleções nos exons 24-32 no quadro de leitura do EGF, as quais são relacionadas com o fenótipo neonatal (MILEWICZ e DUVIC, 1994; WANG et al., 1996; SINGH et al., 2006).

Algumas outras correlações também são descritas, tais como:

a) mutações que causam perda ou ganho da sequiência codificante central por meio de deleções, inserções ou erros na formação do RNAm maduro (Splice) estão associadas à doença mais grave;

b) mutações que criam um código de terminação prematuro e resultam em rápida degradação do transcrito mutante podem estar associadas a condições menos graves, as quais podem passar despercebidas (DIETZ et al., 1993; TYNAN et al., 1993; HAYWARD et al., 1994; NIJBROEK et al., 1995);

c) indivíduos com mutações na região C-terminal apresentando alterações no processamento do propeptídio têm mostrado predominância de manifestações esqueléticas (MILEWICZ et al., 1995);

d) mutações que causam substituições de cisteína são mais frequentes em pacientes portadores do sinal ocular maior (luxação do cristalino) (LOEYS et al., 2004; FAIVRE et al., 2007);

e) foi descrito que mutações nos primeiros 15 exons também estão correlacionadas com luxação do cristalino (COMEGLIO et al., 2002; COMEGLIO et al., 2007).

Em um estudo recente, os autores realizaram uma nova tentativa de correlação genótipo fenótipo. Avaliaram 113 pacientes, incluindo portadores de síndrome de Marfan e fibrilinopatias. Por meio de técnicas de DHPLC (cromatografia líquida de alta performance denaturante) e MLPA (amplificação de múltiplas sondas dependentes de ligação) encontraram 53 mutações no gene FBN1 (41 novas e 12 recorrentes) e realizaram a correlação genótipo fenótipo baseados no "teste exato de Fisher" ou no "qui-quadrado". Através deste estudo, os autores concluíram que o aconselhamento genético, em particular a habilidade de predizer a correlação genótipo fenótipo na síndrome de Marfan, permanece limitado e sugeriram que há outros fatores modificadores para o fenótipo da doença (TURNER et al., 2009). 


\section{HETEROGENEIDADE GENÉTICA NA SÍNDROME DE MARFAN}

Estudos sugerem que a deficiência genética da fibrilina 1 na Síndrome de Marfan e a degradação das microfibrilas na matriz extracelular, observados nos indivíduos que tem aneurisma da aorta ascendente, podem induzir um aumento anormal do TGF- $\beta 1$ latente e causar uma ativação excessiva do TGF- $\beta 1$ na parede vascular (DIJKE et al., 2007; ROBINSON et al., 2006).

O TGF- $\beta$ é uma citoquina multifuncional relacionada à morfogênese embrionária, diferenciação celular, apoptose e integridade da matriz extracelular (CORDENONSI et al., 2003; BONYHADI et al., 1997; OWENS et al., 1997). Estes efeitos resultam da ligação do TGF- $\beta 1$ e dos receptores transmembrana tipos I e II (TGFBRI e TGFBRII) ao domínio serina treonina quinase citoplasmático. Os genes TGFBRI e TGFBRII ativam várias vias metabólicas, regulando a síntese dos componentes da matriz (DERYNCK et al., 2003). Em estudo realizado na parede aórtica de indivíduos com mutações encontradas em TGFBRI e TGFBRII foi detectado um aumento na via de sinalização do TGF- $\beta$ (LOEYS et al., 2005; LOEYS et al., 2006; MALESZEWSKI et al., 2009).

A heterogeneidade genética na síndrome de Marfan vem sendo discutida desde 1991, quando Boileau et al., realizaram estudo de ligação em uma grande família francesa com características clínicas esqueléticas e cardiovasculares da síndrome de Marfan, porém sem sinais oculares maiores nos afetados, e descobriram que a doença nesta família não estava ligada ao gene da fibrilina, região 15q21 (BOILEAU et al., 1991). Em 1994, Collod et al., utilizando essa mesma família, confirmaram um segundo loco para a síndrome de Marfan na região cromossômica 3p24.2-p25, obtendo um lod score de 4,89 $(\theta=0,05)$. Posteriormente, Mizuguchi et al. (2004) descreveram também em um paciente com síndrome de Marfan, uma translocação equilibrada envolvendo o ponto de quebra 3p24.1. O achado de mutações localizadas na região 3p24.2-p25, na qual foi posteriormente mapeado o gene do receptor do fator beta de transformação do crescimento II (TGFBRII), estabeleceu a heterogeneidade genética (MIZUGUCHI et al., 2004).

Entretanto, ainda discutia-se a possibilidade de outro quadro clínico distinto, denominado de síndrome de Marfan tipo 2, cujos afetados não apresentavam sinais oculares maiores. Esta hipótese foi descartada por Mizuguchi et al. (2004), ao demonstrarem a presença de luxação do cristalino em um dos afetados da família francesa descrita por Boileau et al. (1991). 
Em 2006, foram encontradas mutações no gene TGFBRII em pacientes de síndrome de Marfan sem os sinais oculares maiores e sem mutação no gene FBN1 (DISABELLA et al., 2006). Na mesma época, outros autores demonstraram, em estudos realizados com famílias não relacionadas, a presença de mutações de sentido trocado em aminoácidos conservados evolutivamente no domínio serina/treonina quinase dos genes TGFBRI e TGFBRII, confirmando a heterogeneidade genética na Síndrome de Marfan (MATYAS et al., 2006a; SINGH et al., 2006; SAKAI et al., 2006). 


\section{GENES TGFBRI E TGFBRII}

Em estudos realizados entre 1994 - 1995 foram mapeados o gene TGFBRI na região 9q33-q34 e o gene TGFBRII na região cromossômica 3p22. O gene TGFBRI contém 31kb e 9 exons (FIG 2) e o TGFBRII contém 7 exons (FIG 3), que codificam uma proteína de 565 aminoácidos, com 65kD (JOHNSON et al., 1995; TAKENOSHITA et al., 1996; VELLUCCI e REISS, 1997).

Os genes TGFBRI e TGFBRII são receptores serina/treonina quinases transmembrânicas. A proteína transmembrânica II (TßRII), serina / treonina quinase, codificada pelo gene TGFBRII, tem o papel de supressor tumoral e inibidor da proliferação celular (MATHEW et al., 1994; TEM DIJKE e ARTHUR, 2007).

A proteína de ligação à membrana codificada pelo gene TGFBRI liga-se ao TGF- $\beta$ e forma um complexo heterodimérico com o TGFBRII. A ligação do TGFBRI é dependente da co-expressão com o TGFBRII, entretanto o TGFBRII pode ligar-se sozinho a membrana, mas depende do TGFBRI para ativação da sua função quinase (FRANZEN et al., 1993; JOHNSON et al., 1995).

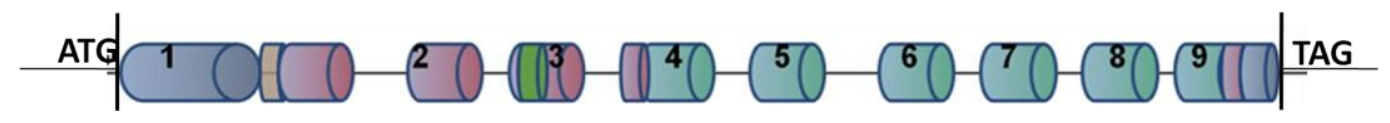

FIG 2. Representação esquemática do gene $T G F B R I$. Os diferentes exons estão numerados.

(representam os exons que codificam o domínio extracelular do receptor ;

Dóminio transmembrana;

Dóminio serina treonina quinase.

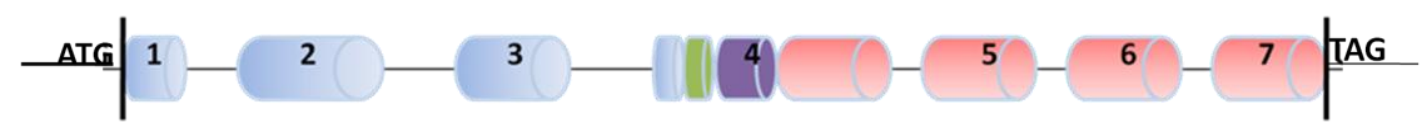

FIG 3. Representação esquemática do gene TGFBRII.

Os diferentes exons estão numerados.

representam os exons que codificam o domínio

extracelular do receptor ;

Dóminio transmembrana;

Dóminio serina treonina quinase. 


\section{ESTUDOS DE LIGAÇÃO}

\subsection{Estudos com Marcadores}

A análise de ligação é um teste indireto do DNA, realizado com sequências polimórficas que estão próximas ou dentro de um gene de interesse. Uma de suas funções é revelar em uma família quais os indivíduos são prováveis portadores de uma mutação causadora de uma determinada doença em questão.

Podemos dividir o estudo da análise de ligação em três passos:

1. Estabelecer haplótipos de cada indivíduo: escolher múltiplos marcadores do DNA que se encontram próximos ao gene de interesse, e testá-los para determinar o haplótipo comum a cada membro de uma família;

2. Estabelecer a fase por comparação de haplótipos entre os membros da família: comparando os haplótipos dos membros da família, cujo quadro clínico ou fenótipo é conhecido, e desta maneira associar o haplótipo com o alelo causador da doença;

3. Determinar todos os membros afetados na família: uma vez que o haplótipo relacionado à doença é estabelecido na família, é possível determinar outros membros da família acometidos (PAGON et al., 2008).

Os marcadores moleculares utilizados em estudo de ligação podem ser: isoenzimas, RFLPs (polimorfismos no comprimento de fragmentos de restrição), minissatélites ou VNTRs (variação do número da repetição em tanden), SNPs (polimorfismo de nucleotídeo único), microssatélites, etc. Os marcadores de microssatélites constituem a classe mais polimórfica de marcadores moleculares existentes (STRACHAN et al., 1999).

$\mathrm{Na}$ análise de ligação é possível avaliar em uma só fase o DNA de vários membros de uma família, afetados e não afetados, sendo útil para diagnóstico oligossintomático e aconselhamento de pessoas com manifestações atípicas pertencentes a famílias com doenças clássicas, como a Síndrome de Marfan.

\subsection{Estudo de Ligação na Síndrome de Marfan}

O diagnóstico molecular para a síndrome de Marfan tem evoluído rapidamente desde o mapeamento do gene $F B N 1$ em 1990. A diversidade das mutações no gene $F B N 1$ é alta e não há uma relação genótipo/fenótipo para todas as mutações encontradas até o momento. Além 
disso, existe a heterogeneidade alélica e gênica, já mencionada, que implica no mesmo quadro clínico. Devido a esses fatores, o método de análise de ligação pode ser mais rápido e útil na identificação de indivíduos afetados e na identificação de qual gene a doença pode estar associada.

Vários estudos foram realizados com o uso de marcadores intragênicos em pacientes com síndrome de Marfan, demonstrando que os mesmos auxiliam no diagnóstico dos indivíduos afetados e também no diagnóstico genético pré-implantação de embriões a partir de ancestrais afetados (MOTTES et al., 2000; VALIEV et al., 2006; SPITS et al., 2006; LLEDÓ et al., 2006).

Rantamäki et al. (1994) realizaram estudo com dois marcadores intragênicos (FBN1a e FBN1b) e outros dois (D15S103 e CYP19) que flanqueavam o gene FBN1. Este trabalho demonstrou que os marcadores polimórficos foram informativos para as diferentes famílias analisadas e que os mesmos eram úteis para o diagnóstico da síndrome de Marfan.

Em 1994, Pereira et al., descreveram quatro marcadores do tipo microssatélites intragênicos (MTS-1 a MTS-4) que podem ser utilizados para análise de segregação de haplótipos. Lee et al. (2005) estudaram seis famílias com síndrome de Marfan, um total de 18 pacientes, utilizando estes marcadores. Os haplótipos em todos os membros das famílias puderam ser estabelecidos e não foi observada recombinação entre os marcadores e a doença. Esse estudo mostrou-se bastante útil no diagnóstico e aconselhamento destas famílias.

Vários autores utilizaram os mesmos marcadores descritos por Pereira et al., 1994, entre eles, Robert et al. (1998), os quais estudaram uma família com síndrome de Marfan. O estudo revelou que três crianças aparentemente afetadas não apresentavam alelo comum com os dois pacientes que completavam o diagnóstico da síndrome de Marfan. Em outro estudo, também realizado com os mesmos marcadores e outros marcadores polimórficos para $F B N 1$, concluiu-se que o uso de marcadores moleculares é bastante útil no diagnóstico de famílias com indivíduos portadores de características atípicas ou em famílias com um alto grau de variação clínica da síndrome de Marfan (JUDGE et al., 2001).

Em 2004 Mizuguchi et al., utilizaram marcadores gênicos do TGFBRII (D3S1609 e D3S3727 - intragênicos; D3S3567 e D3S1619 - flanqueadores), em duas famílias com síndrome de Marfan não relacionadas, as quais não apresentavam mutações no gene $F B N 1$, demonstrando por análise de ligação a segregação de haplótipos com a presença da mutação $1524 \mathrm{G}-\mathrm{A}$ 


\section{OBJETIVOS}

\subsection{Objetivo Geral}

Avaliar a heterogeneidade genética da síndrome de Marfan na população brasileira, utilizando marcadores polimórficos intragênicos para o estudo da análise de segregação do fenótipo Marfan/marfanóide com os diferentes genes associados a estas condições.

\subsection{Objetivos Específicos}

1 - Estudar as manifestações clínicas de uma amostra brasileira de pacientes com síndrome de Marfan com o quadro clínico clássico e fenótipos associados;

2 - Estabelecer a frequência de segregação de marcadores moleculares intragênicos aos genes FBN-1 e TGFBRII com a síndrome de Marfan nos casos familiais;

3 - Estabelecer a correlação genótipo-fenótipo dos genes $F B N-1$ e $T G F B R I I$ e a gravidade da doença;

4 - Realizar o seqüenciamento do gene TGFBRII nos probandos dos casos em que o fenótipo apresentou co-segregação com os marcadores desse gene e o sequenciamento do gene TGFBRI nos casos em que foi possível excluir ligação com o gene TGFBRII. 


\section{MATERIAL E MÉTODOS}

Em 2004, foi criado o Grupo de Estudos da Síndrome de Marfan na Universidade Federal de São Paulo (UNIFESP). Desde então, o grupo tornou-se um centro de referência para pacientes portadores da SMF, e estes vêm sendo acompanhados sistematicamente nas clínicas de apoio, diagnóstico e tratamento, contando atualmente com mais de 160 famílias catalogadas. Em consequência deste grupo de estudos, criou-se também a Associação Marfan Brasil (www.marfan.com.br) que presta assistência e orientação médica aos pacientes e seus familiares. Todos os sinais e sintomas são reconhecidos, incluindo principalmente o comprometimento cardiovascular, oftalmológico e esquelético, inclusive a presença da ectasia dural.

\subsection{Grupo de Pacientes}

Até o momento foram avaliadas 358 pessoas, resultando em um total de 47 famílias avaliadas. Todos esses indivíduos foram avaliados no Centro de Genética Médica, Departamento de Morfologia e Genética da Universidade Federal de São Paulo, pela Dra. Ana Betriz Alvarez Perez, médica geneticista da Universidade Federal de São Paulo. Todos foram avaliados de acordo com os critérios da Nosologia de Ghent revisados por De Paepe et al. (1996). Os pacientes afetados ou os que apresentaram algum sinal clínico correspondente à síndrome de Marfan foram encaminhados para realizarem exames complementares.

\subsection{Extração de DNA}

Após avaliação clínica e assinatura do termo de consentimento livre e esclarecido pelos pacientes ou responsáveis, foram coletados $10 \mathrm{ml}$ de sangue de cada paciente em tubo contendo 0,4 ml de EDTA 5\%. A extração do DNA foi realizada a partir dos linfócitos do sangue periférico seguindo o protocolo de Miller et al. (1988).

\subsection{Análise de Microssatélites}

Para o estudo de ligação do gene $F B N$-1 foram escolhidos os marcadores moleculares do tipo microssatélites MTS-1, MTS-2, MTS-3 e MTS-4 (PEREIRA et al., 1994) e para o gene TGFBR2, os marcadores de microssatélites D3S37227 e D3S3567 (MIZUGUCHI et al., 
2004) (Quadro 4). Os marcadores MTS-1, MTS-2 e MTS-4 são repetições de dinucleotídeos $(\mathrm{CA})_{\mathrm{n}}$, enquanto o MTS-3 contém repetições de pentanucleotídeos (TAAAA)n. Os marcadores D3S3727 e D3S3567 são repetições de dinucleotídeos (CA $)_{n}$. Os oligunucleotídeos, diretos ou reversos, foram marcados com fluorescência (FAM).

Quadro 4 - Sequência de oligonucleotídeos para amplificação dos marcadores utilizados.

\begin{tabular}{|c|c|l|l|}
\hline MARCADOR & GENE & LOCAL & \multicolumn{1}{|c|}{ SEQÜENCIA } \\
\hline MTS-1 & $F B N 1$ & INTRON 1 & $\begin{array}{l}\text { Direto: 5'FAM caacaaagaaggagaaacag3' } \\
\text { Reverso: 5'gctctggaatacattgtc3' }\end{array}$ \\
\hline MTS-2 & $F B N 1$ & INTRON 5 & $\begin{array}{l}\text { Direto: 5'gtagttgttatcttgcaga3' } \\
\text { Reverso: 5'FAMtcttagagtcctagagggcag3' }\end{array}$ \\
\hline MTS-3 & $F B N 1$ & INTRON 28 & $\begin{array}{l}\text { Direto: 5'FAMgagtacatagagttttaggg3' } \\
\text { Reverso: 5'gggagttgaatggtagccagg3' }\end{array}$ \\
\hline MTS-4 & $F B N 1$ & INTRON 43 & $\begin{array}{l}\text { Direto: 5'gatgtccctattgccatcaccac3' } \\
\text { Reverso: 5'FAMcttgtcttacctgcacagg3' }\end{array}$ \\
\hline D3S3727 & $T G F B R 2$ & $3 \mathrm{p} 22$ & $\begin{array}{l}\text { Direto: 5'FAMctagtacgggccgggt3' } \\
\text { Reverso: 5'ggtaggtagttccagtgtgaaa3' }\end{array}$ \\
\hline D3S3567 & $T G F B R 2$ & $3 \mathrm{p} 22$ & $\begin{array}{l}\text { Direto: 5'FAMctgtgaaatgcttgccc3' } \\
\text { Reverso: 5'aacccactttgttatcaatgtttag3', }\end{array}$ \\
\hline
\end{tabular}

\subsection{Condições de Amplificação}

Foram testadas três concentrações diferentes $(1,5 \mathrm{mM} ; 2,0 \mathrm{mM}$ e 3,0 mM) de cloreto de magnésio $(\mathrm{MgCl} 2)$ com 12 temperaturas de amplificação diferentes que variaram de 52 $64{ }^{\circ} \mathrm{C}$, para escolha da melhor condição de amplificação dos marcadores de microssatélites. Após a reação de amplificação em cadeia da polimerase (PCR), o produto amplificado foi submetido a eletroforese em gel de agarose. Definimos assim as seguintes condições descritas no quadro 5. 
Quadro 5 - Condições ideais de amplificação para os marcadores estudados.

\begin{tabular}{|c|c|c|}
\hline MICROSSAT & CONDIÇÕES DE $\mathbf{T}^{\circ} \mathrm{C}$ P/ PCR & CONDIÇÕES DA REAÇÃO DE PCR [ ]f \\
\hline MTS-1 & $\begin{array}{l}94^{\circ} \mathrm{C}-10^{\prime} \\
94^{\circ} \mathrm{C}-30^{\prime \prime} \\
56^{\circ} \mathrm{C}-30^{\prime \prime}>35 \text { CICLOS } \\
72^{\circ} \mathrm{C}-45^{\prime \prime} \\
72^{\circ} \mathrm{C}-10^{\prime} \\
4^{\circ} \mathrm{C}\end{array}$ & $\begin{array}{l}\text { DNA: 50ng; TAMPÃO } 1 \mathrm{X} \\
\text { dNTps } 0,2 \mu \mathrm{M} ; \mathrm{MgCl} 23,0 \mathrm{mM} \text {; } \\
\text { primers dir. e rev. 0,3nmol/mL; } \\
\text { Vol. Final } 25 \mu \mathrm{L} \text {; } \\
\text { Taq 1U. }\end{array}$ \\
\hline MTS-2 & $\begin{array}{l}94^{\circ} \mathrm{C}-10^{\prime} \\
94^{\circ} \mathrm{C}-30^{\prime \prime} \\
56^{\circ} \mathrm{C}-30^{\prime \prime}>35 \text { CICLOS } \\
72^{\circ} \mathrm{C}-45^{\prime \prime} \\
72^{\circ} \mathrm{C}-10^{\prime} \\
4^{\circ} \mathrm{C}\end{array}$ & $\begin{array}{l}\text { DNA: 50ng; TAMPÃO } 1 \mathrm{X} \\
\text { dNTps } 0,2 \mu \mathrm{M} ; \mathrm{MgCl} 22,0 \mathrm{mM} \\
\text { primers dir. e rev. 0,3nmol/mL; } \\
\text { Vol. Final } 25 \mu \mathrm{L} ; \\
\text { Taq 1U. }\end{array}$ \\
\hline MTS-3 & $\begin{array}{l}94^{\circ} \mathrm{C}-10^{\prime} \\
94^{\circ} \mathrm{C}-30^{\prime \prime} \\
63^{\circ} \mathrm{C}-30^{\prime \prime}>35 \text { CICLOS } \\
72^{\circ} \mathrm{C}-45^{\prime \prime} \\
72^{\circ} \mathrm{C}-10^{\prime} \\
4^{\circ} \mathrm{C}\end{array}$ & $\begin{array}{l}\text { DNA: 50ng; TAMPÃO } 1 \mathrm{X} ; \\
\text { dNTps } 0,2 \mu \mathrm{M} ; \mathrm{MgCl} 22,0 \mathrm{mM} \text {; } \\
\text { primers dir. e rev. 0,3nmol/mL; } \\
\text { Vol. Final } 25 \mu \mathrm{L} ; \\
\text { Taq 1U. }\end{array}$ \\
\hline MTS-4 & $\begin{array}{l}94^{\circ} \mathrm{C}-10^{\prime} \\
94^{\circ} \mathrm{C}-30^{\prime \prime} \\
56^{\circ} \mathrm{C}-30^{\prime \prime}>35 \text { CICLOS } \\
72^{\circ} \mathrm{C}-45^{\prime \prime} \\
72^{\circ} \mathrm{C}-10^{\prime} \\
4^{\circ} \mathrm{C}\end{array}$ & $\begin{array}{l}\text { DNA: 50ng; TAMPÃO } 1 \mathrm{X} ; \\
\text { dNTps } 125 \mu \mathrm{M} ; \mathrm{MgCl} 21,5 \mathrm{mM} \text {; } \\
\text { primers dir. e rev. 0,3nmol/mL; } \\
\text { Vol. Final } 25 \mu \mathrm{L} ; \\
\text { Taq 1U. }\end{array}$ \\
\hline D3S3727 & $\begin{array}{l}96^{\circ} \mathrm{C}-10^{\prime} \\
94^{\circ} \mathrm{C}-40^{\prime \prime} \\
55^{\circ} \mathrm{C}-30^{\prime \prime}>35 \text { CICLOS } \\
72^{\circ} \mathrm{C}-2^{\prime} \\
72^{\circ} \mathrm{C}-10^{\prime} \\
4^{\circ} \mathrm{C}\end{array}$ & $\begin{array}{l}\text { DNA: 50ng; TAMPÃO 1X; } \\
\text { dNTps } 125 \mu \mathrm{M} \text {; } \mathrm{MgCl} 21,5 \mathrm{mM} \text {; } \\
\text { primers dir. e rev. 50pmol; } \\
\text { Vol. Final } 25 \mu \mathrm{L} ; \\
\text { Taq 1U. }\end{array}$ \\
\hline D3S3567 & $\begin{array}{l}96^{\circ} \mathrm{C}-10^{\prime} \\
94^{\circ} \mathrm{C}-40^{\prime \prime} \\
55^{\circ} \mathrm{C}-30^{\prime \prime}>35 \text { CICLOS } \\
72^{\circ} \mathrm{C}-2 \\
72^{\circ} \mathrm{C}-10^{\prime} \\
4^{\circ} \mathrm{C}\end{array}$ & $\begin{array}{l}\text { DNA: 50ng; TAMPÃO 1X; } \\
\text { dNTps } 125 \mu \mathrm{M} ; \mathrm{MgCl} 21,5 \mathrm{mM} \text {; } \\
\text { primers dir. e rev. 50pmol; } \\
\text { Vol. Final } 25 \mu \mathrm{L} ; \\
\text { Taq 1U. }\end{array}$ \\
\hline
\end{tabular}

\subsection{Eletroforese e Análise dos Fragmentos}

Para análise do tamanho dos fragmentos amplificados contendo os microssatélites, os produtos da amplificação foram separados por meio de eletroforese em capilar no equipamento MegaBACE ${ }^{\text {TM }} 1000$ (sistema com 96 capilares, Amersham Biosciences), juntamente com o padrão de peso molecular "MegaBACETM ET 550-R Size Standard" do 
mesmo fabricante (KOUMI et al., 2004; YEUNG et al., 2006). A análise dos marcadores moleculares fluorescentes foi realizada utilizando o programa "Genetic Profiler versão 2.2" que acompanha o equipamento MegaBACE ${ }^{\mathrm{TM}} 1000$ (Amersham Biosciences). A figura 4 representa um gráfico obtido após análise dos eletroferogramas no "Genetic Profiler".

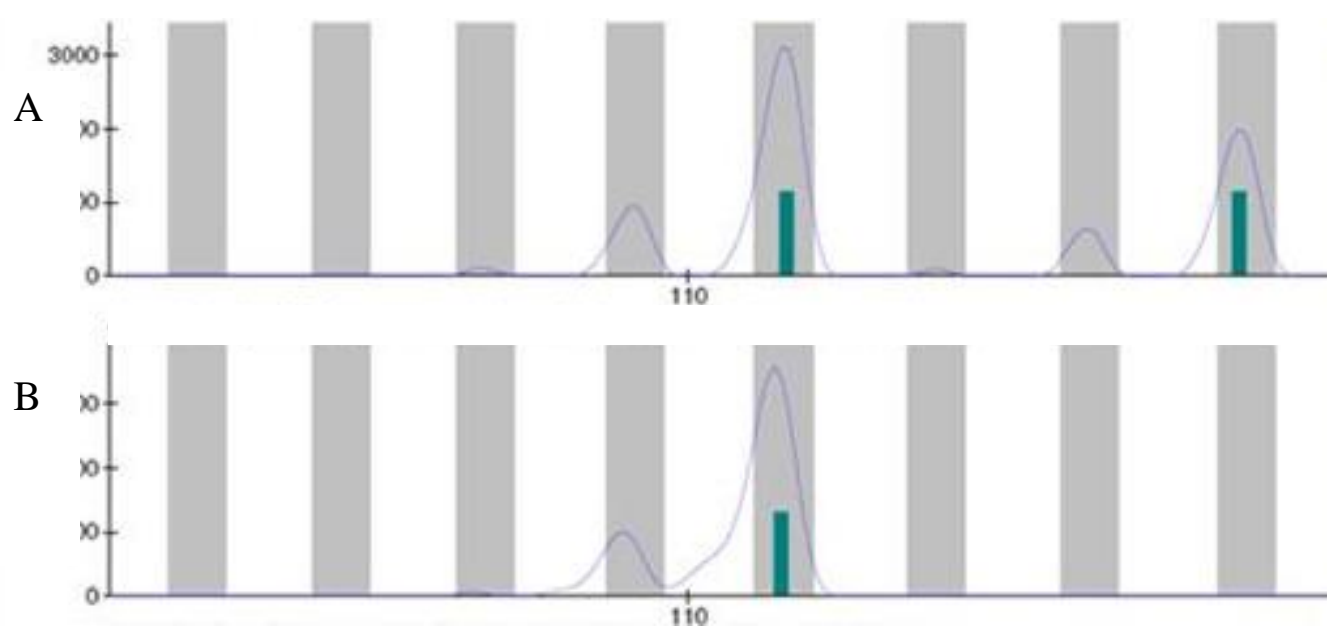

FIG. 4. Gráfico da análise dos marcadores de microssatélites. Os gráficos acima indicam os picos de fluorescência dos fragmentos amplificados com os oligonucleotídeos referentes ao marcador molecular MTS4. (A) indivíduo heterozigoto com fragmentos de $111 \mathrm{pb}$ e $117 \mathrm{pb}$; (B) indivíduo homozigoto com fragmento de $111 \mathrm{pb}$.

\subsection{Cálculos de Lod Scores}

Os resultados da determinação dos genótipos em relação aos microssatélites nas famílias foram analisados com dois programas o Merlin (Abecasis et al., 2002) e o MLINK do pacote de programas FASTLINK 4.2 (COTTINGHAM et al., 1993).

O programa Merlin serve para a obtenção de lod scores de múltiplos pontos, isto é, os lod scores que resultam da análise da segregação de vários marcadores de um mesmo cromossomo simultaneamente em relação à doença. Todos os lod scores obtidos com o programa Merlin foram calculados utilizando-se a freqüência gênica de 0,0001 para o alelo que causa doença nas famílias. Os cálculos realizados pelo programa Merlin não apresentam limitações quanto ao número de microssátelites analisados em cada cromossomo, portanto todos os marcadores de um mesmo cromossomo podem ser analisados simultaneamente. No entanto, o programa Merlin só permite analisar genealogias com até 24 "bits" e a formula para calcular o número de "bits" de uma genealogia é: $2 \mathrm{x}\left(\mathrm{N}^{\circ}\right.$ de indivíduos não fundadores $)-\left(\mathrm{N}^{\circ}\right.$ 
de indivíduos fundadores). Os lod scores máximos para cada família foram calculados através de simulações, admitindo-se que todas as meioses foram informativas.

O programa MLINK do pacote de programas FASTLINK 4.2 é utilizado para a obtenção do lod scores de dois pontos (em um ponto foi considerado o marcador polimórfico e no outro o gene da doença). Todos os lod scores obtidos com o pacote de programas FASTLINK 4.2 foram calculados utilizando-se a frequência gênica de 0,0001 para o alelo que causa doença nas famílias.

Tanto nos cálculos com o Merlin quanto com o MLINK, admitimos também que a taxa de recombinação era semelhante em ambos os sexos, e que a taxa de mutação gênica responsável pela doença era zero, visto que esses parâmetros não alteram os resultados finais. As frequências dos alelos para os marcadores polimórficos foram consideradas iguais a $1 / \mathrm{N}$ para a maioria dos microssatélites analisados, sendo $\mathrm{N}$ o número de alelos daquele marcador encontrados na família em questão.

\subsection{Sequenciamento}

O sequenciamento do DNA foi utilizado para identificar mutações nos genes TGFBRI e TGFBRII. Os exons 1 a 7 do gene TGFBRII foram amplificados utilizando os oligonucleotídeos descritos por Mizuguchi et al. (2004). O gene TGFBRI foi amplificado de acordo com Mátyás et al. (2007).

As reações de PCR para a amplificação dos fragmentos contendo os exons dos genes pesquisados foram quantificadas em espectrofotômetro; em seguida os produtos da PCR foram preparados para as reações de sequenciamento em ambas as direções, nas seguintes condições: 30-60 ng do DNA (amplificado), $1 \mu \mathrm{M}$ de cada "primer", Tampão $10 \mathrm{X}, 5 \mu \mathrm{M}$ de BigDye e água para completar a reação para um volume final de $10 \mu 1$. As condições da PCR para o sequenciamento foram: 35 ciclos de $96{ }^{\circ} \mathrm{C}$ por 10 segundos, $52{ }^{\circ} \mathrm{C}$ por 20 segundos e $60{ }^{\circ} \mathrm{C}$ por 4 minutos. Depois os produtos foram precipitados com etanol.

A precipitação com etanol compreendeu duas centrifugações de 15 minutos cada, a velocidade máxima. Para a primeira etapa de precipitação do DNA, adicionou-se etanol a $100 \%$, e na segunda etapa de lavagem do DNA adicionou-se etanol a $70 \%$. Posteriormente a essa etapa deixou-se o material secar por uma noite, seguindo a ressuspensão do DNA na manhã seguinte. Após a ressuspensão, as amostras de sequenciamento foram analisadas no MegaBACETM 1000 (Amersham Biosciences). 


\subsection{Teste Estatístico}

A análise estatística foi realizada pela Prof(a). Dra. Maria Regina Madruga da Faculdade de Estatística da Universidade Federal do Pará (ICEN/UFPA), utilizando o programa BioEstat versão 5.0. A detecção de segregação em cada família com envolvimento separado em cada sistema foi comparado pelo "teste exato de Fischer", teste não paramétrico utilizado no caso de pequenas amostras. Um valor $p<0,05$ foi considerado significante. 


\section{RESULTADOS}

13.1 Estudo das manifestações clínicas de uma amostra brasileira de pacientes com síndrome de Marfan com o quadro clínico clássico e fenótipos associados

Foram avaliados clinicamente 358 indivíduos afetados e não afetados, que correspondiam a 47 famílias não relacionadas entre si. Em treze das 47 famílias não foram obtidas quantidades suficiente de indivíduos para a realização dos estudos de ligação (anexo I). Muitos indivíduos se negaram a comparecer às consultas e a realizar os exames complementares. Portanto, foram realizados os estudos da segregação dos marcadores moleculares em 34 famílias.

13.2 Análise da segregação de marcadores moleculares intragênicos aos genes $F B N-1$ e TGFBRII nos casos familiais de síndrome de Marfan

Por meio do estudo de marcadores de marcadores moleculares do tipo microssatélites intragênicos do gene $F B N 1$, observamos que em 24 famílias (24/34 ou 70,58\%) existia cosegregação de um haplótipo com o fenótipo da síndrome de Marfan. Esse grupo compreendia as seguintes famílias: 2, 3, 5, 6, 7, 8, 9, 13, 14, 16, 17, 19, 20, 22, 23, 24, 28, 29, 30, 31, 33, 34, 35 e 46 (Tabela 1 e Anexo A). Encontramos um lod score maior que 3.0 (Tabela 4), caracterizando a ligação do gene $F B N 1$ com a síndrome de Marfan em 2 destas famílias (2 e 7), pois apenas elas apresentavam o número necessário de indivíduos informativos para atingir essa significância estatística. Nas outras famílias, os resultados dos lod scores foram abaixo de 3.0, devido a termos conseguido obter um número pequeno de indivíduos para os estudos de ligação. Observamos que o lod score máximo possível de ser obtido nessas famílias com um número pequeno de indivíduos informativos foi menor que 3.0 (Tabela 4).

Para algumas das famílias $(6,9,13,16$ e 28) que apresentaram número pequeno de indivíduos informativos foi realizado o estudo de segregação com os marcadores do gene TGFBRII (Anexo B). Nessas genealogias obtivemos um lod score abaixo de 2.0 demonstrando exclusão de ligação a esse gene (Tabela 5). Não foi possível realizar análise dos marcadores do TGFBRII em todas as famílias com número pequeno de indivíduos informativos, devido à falta de amostras.

Nas 24 famílias que apresentaram co-segregação de haplótipo do gene FBN1 com a doença observamos que 19/24 $(79,16 \%)$ apresentaram indivíduos com luxação do cristalino, 
outras 19/24 (79,16\%) famílias apresentaram indivíduos com dilatação da aorta e todas apresentaram os sinais esqueléticos maiores (Tabela 6).

Em seis famílias (6/34 ou 17,64\%) não existe segregação de um haplótipo formado pelos marcadores intragênicos ao gene FBNl com a doença. Este grupo compreende as seguintes famílias: $1,4,15,37,42$ e 43. Não foi possível realizar os exames clínicos oftalmológicos em todos os indivíduos dessas famílias até o momento, mas dos que foi possível realizar nenhum apresentou o sinal clínico oftalmológico maior para síndrome de Marfan. Em cinco dessas seis famílias os pacientes apresentaram dilatação da aorta (Tabela 1).

Em quatro famílias (4/34 ou 11,76\%) os marcadores do gene FBN1 não foram informativos, não permitindo excluir ou sugerir ligação desse gene com o quadro clínico da família. Este grupo compreende as seguintes famílias: 18, 38, 40 e 45. Nestas famílias o fenótipo é clássico, com comprometimento ocular e cardíaco grave (Tabela 3).

Nas seis famílias $(1,4,15,37,42$ e 43) que não apresentaram segregação de um haplótipo do gene $F B N 1$ com a síndrome foram realizados estudos com marcadores do gene TGFBRII (Anexo B e Tabela 2). Em quatro das seis famílias (4, 15, 37 e 42) não encontramos segregação com o gene TGFBRII. Em uma das seis famílias (43) encontramos co-segregação com o estudo do marcador D3S3727, mas o outro marcador estudado (D3S3567) não se mostrou informativo.

Os indivíduos estudados na família 43 não apresentaram luxação do cristalino e dilatação da aorta, mas apresentaram prolapso de válvula mitral importante e os sinais esqueléticos maiores para Síndrome de Marfan. Em relação à família 1, os dois marcadores estudados (D3S3727 e D3S3567) não foram informativos.

\subsection{Correlação genótipo-fenótipo dos genes $F B N 1$ e $T G F B R I I$ versos a gravidade da doença}

Ao compararmos as famílias que apresentaram segregação do haplótipo dos marcadores do gene $F B N 1$ com a síndrome e as famílias que não apresentaram segregação do haplótipo dos marcadores do gene FBNl com a síndrome, não encontramos diferenças estatísticas significativas quanto aos sinais cardíacos e esqueléticos, mas o envolvimento ocular apresentou diferença estatística significativamente maior (Tabela 6).

Ao compararmos as famílias que apresentaram segregação do haplótipo dos marcadores do gene TGFBRII com a síndrome e as famílias que não apresentaram segregação 
do haplótipo dos marcadores do gene TGFBRII com a síndrome, não encontramos diferenças estatísticas significativas quanto aos sinais clínicos maiores da Síndrome de Marfan.

Entretanto, encontramos diferença estatística significativa para os sinais cardíacos e oculares ao compararmos as famílias cuja síndrome segregou com os marcadores do gene FBN1 em relação às famílias cuja síndrome segregou com os marcadores do gene TGFBRII (Tabela 1).

13.4 Sequenciamento do gene TGFBRII nos casos que co-segregaram com o gene e sequenciamento do gene TGFBRI nos casos que excluíram ligação com o gene TGFBRII

O seqüenciamento dos exons 1 a 7 do gene TGFBRII no probando da família (43) não permitiu identificar mutações. Nos probandos das famílias $(4,15,37$ e 42) onde não se observou a co-segregação da doença com o gene TGFBRII não encontramos mutações nos exons 2, 3, 6 e 7 do gene TGFBRI. Os exons 4, 5, 8 e 9 do gene TGFBRI não foram sequenciados até o momento. 


\begin{tabular}{|c|c|c|c|c|c|}
\hline FAMILIA & $\mathbf{N}^{\circ}$ IND & & & CAR & \\
\hline & & LC & MIO & DILAO & PVM \\
\hline & II-6 & - & - & + & - \\
\hline & III-3 & - & + & + & + \\
\hline & III6 & - & - & + & + \\
\hline 2 & IV-4 & - & + & + & + \\
\hline & IV-5 & $\mathrm{NP}$ & $\mathrm{NP}$ & NP & NP \\
\hline & IV-8 & - & - & - & - \\
\hline & $\mathrm{I}-2$ & + & + & + & + \\
\hline 3 & II-2 & + & + & + & + \\
\hline & $\mathrm{I}-2$ & + & - & + & + \\
\hline & II-1 & + & - & + & + \\
\hline 5 & II-2 & + & - & + & + \\
\hline & II-3 & - & - & - & - \\
\hline & II-4 & $\mathrm{NP}$ & $\mathrm{NP}$ & NP & $\mathrm{NP}$ \\
\hline & $\mathrm{I}-2$ & + & + & + & + \\
\hline & II-6 & - & + & + & + \\
\hline 6 & II-7 & - & + & + & + \\
\hline & II8 & - & + & + & + \\
\hline & II-10 & - & + & + & + \\
\hline & $\mathrm{I}-2$ & $\mathrm{NP}$ & $\mathrm{NP}$ & + & + \\
\hline 7 & II-1 & NP & NP & $\mathrm{NP}$ & NP \\
\hline & III-1 & - & - & + & + \\
\hline & III-1 & + & - & + & + \\
\hline 8 & III-1 & - & - & - & - \\
\hline & III3 & + & - & + & + \\
\hline & IV-5 & + & - & - & + \\
\hline 9 & III-4 & - & - & + & - \\
\hline & IV-1 & - & - & - & - \\
\hline & IV-2 & - & + & + & - \\
\hline & $\mathrm{I}-1$ & - & + & - & + \\
\hline & II-2 & + & - & + & + \\
\hline 13 & III-1 & - & - & + & + \\
\hline & III-2 & - & - & $\mathrm{NP}$ & $\mathrm{NP}$ \\
\hline & III-1 & + & + & - & + \\
\hline 14 & II-2 & - & - & - & + \\
\hline & II-3 & - & - & - & + \\
\hline & II-1 & - & + & NP & NP \\
\hline 16 & II-3 & - & + & NP & $\mathrm{NP}$ \\
\hline & II-5 & - & + & + & - \\
\hline & III-1 & - & + & + & + \\
\hline & II-2 & + & + & + & + \\
\hline & $\begin{array}{ll}\text { II-4 } \\
\end{array}$ & - & + & + & + \\
\hline 17 & III-1 & - & + & + & + \\
\hline & III-2 & - & - & + & + \\
\hline & III-3 & $\mathrm{NP}$ & $\mathrm{NP}$ & + & + \\
\hline & $\begin{array}{ll}\text { II-7 } \\
\end{array}$ & $\mathrm{NP}$ & $\mathrm{NP}$ & - & + \\
\hline & II-11 & + & - & + & + \\
\hline 19 & III-4 & NP & NP & - & + \\
\hline & III-7 & $\mathrm{NP}$ & NP & NP & $\mathrm{NP}$ \\
\hline & III-8 & - & - & - & + \\
\hline & III-9 & - & + & - & + \\
\hline & III-4 & + & - & - & + \\
\hline & III-1 & + & - & - & + \\
\hline & III-1 & - & + & - & + \\
\hline 20 & III-4 & + & - & - & + \\
\hline & III-5 & $\mathrm{NP}$ & $\mathrm{NP}$ & NP & NP \\
\hline & III-6 & NP & NP & NP & NP \\
\hline & III-2 & + & - & - & - \\
\hline 22 & III-4 & + & - & - & + \\
\hline & III-6 & - & + & + & - \\
\hline & III-1 & + & + & + & - \\
\hline 23 & III-2 & + & - & + & + \\
\hline & III-3 & - & + & + & + \\
\hline & III-5 & NP & NP & NP & $\mathrm{NP}$ \\
\hline & II-1 & $\mathrm{NP}$ & $\mathrm{NP}$ & NP & $\mathrm{NP}$ \\
\hline 24 & III-7 & + & + & - & + \\
\hline & $\mathrm{I}-1$ & - & + & + & - \\
\hline 28 & $\begin{array}{ll}\text { III-1 } \\
\end{array}$ & + & + & - & + \\
\hline & III-2 & + & + & + & + \\
\hline & III-2 & + & - & + & - \\
\hline 29 & III-3 & - & + & - & + \\
\hline & III-8 & - & + & + & - \\
\hline & $\mathrm{I}-2$ & + & - & - & - \\
\hline 30 & II-1 & + & - & + & - \\
\hline & III-2 & + & - & - & + \\
\hline & II-8 & + & - & + & - \\
\hline 31 & III-4 & - & - & + & + \\
\hline & III-5 & + & + & + & + \\
\hline & II-3 & + & - & - & + \\
\hline 33 & IV-1 & + & - & + & + \\
\hline & III-4 & - & - & + & + \\
\hline 34 & III-6 & - & + & + & - \\
\hline & III-4 & - & + & + & - \\
\hline & III-4 & + & - & + & - \\
\hline & $\begin{array}{ll}\text { II-8 } \\
\end{array}$ & - & + & NP & NP \\
\hline & II-4 & - & + & NP & NP \\
\hline 35 & $\begin{array}{ll}\text { III-6 } \\
\end{array}$ & - & + & + & - \\
\hline & III-8 & - & + & NP & $\mathrm{NP}$ \\
\hline & $\begin{array}{ll}\text { II-3 } \\
\end{array}$ & - & + & + & - \\
\hline & III-1 & - & + & NP & $\mathrm{NP}$ \\
\hline 46 & II-3 & - & + & NP & NP \\
\hline & II-5 & + & + & & + \\
\hline
\end{tabular}

IND = INDIVÍDUO; PVM = PROLAPSO DE VÁLVA MITRAL; >5 = CINCO SINAIS ESQUELÉTICOS; ED = ECTASIA DURAL; NP = NÃO PESQUISADO; + = PRESENTE; - = AUSENTE; 
Tabela 2 - Famílias em que foi excluída co-segregação com haplótipo dos marcadores do gene FBN1.

\begin{tabular}{|c|c|c|c|c|c|c|c|c|c|}
\hline \multirow[t]{2}{*}{ FAMÍLIA } & \multirow{2}{*}{$\begin{array}{c}\mathbf{N}^{\circ} \\
\text { IND }\end{array}$} & \multicolumn{2}{|c|}{ OCULARES } & \multicolumn{2}{|c|}{ CARDIACOS } & \multicolumn{2}{|c|}{ ESQUELET } & \multirow[t]{2}{*}{ FBN1 } & \multirow[t]{2}{*}{ TGFBRII } \\
\hline & & $\begin{array}{ll}\mathrm{LC} \\
\end{array}$ & $\mathrm{MIO}$ & DILAO & PVM & $>5$ & ED & & \\
\hline \multirow[t]{3}{*}{1} & II-1 & - & + & - & - & + & $\mathrm{NP}$ & \multirow[t]{3}{*}{ N/ SEG } & \multirow[t]{3}{*}{$\mathrm{N} / \mathrm{INF}$} \\
\hline & II-1 & - & - & - & - & + & $\mathrm{NP}$ & & \\
\hline & II-2 & - & + & + & + & + & $\mathrm{NP}$ & & \\
\hline \multirow[t]{3}{*}{4} & $\mathrm{I}-1$ & - & + & + & + & + & $\mathrm{NP}$ & \multirow[b]{3}{*}{ N/ SEG } & \multirow[b]{3}{*}{ N/ SEG } \\
\hline & II-1 & - & + & + & + & + & $\mathrm{NP}$ & & \\
\hline & II-2 & - & + & + & + & + & $\mathrm{NP}$ & & \\
\hline \multirow[t]{3}{*}{15} & II-4 & - & + & + & + & + & $\mathrm{NP}$ & \multirow[t]{3}{*}{ N/ SEG } & \multirow[t]{3}{*}{ N/ SEG } \\
\hline & III-5 & - & - & + & + & + & $\mathrm{NP}$ & & \\
\hline & III-6 & - & + & - & + & + & NP & & \\
\hline \multirow[t]{3}{*}{37} & III-3 & - & - & + & - & + & NP & \multirow{3}{*}{ N/ SEG } & \multirow{3}{*}{ N/ SEG } \\
\hline & IV-1 & $\mathrm{NP}$ & $\mathrm{NP}$ & $\mathrm{NP}$ & $\mathrm{NP}$ & + & NP & & \\
\hline & III-5 & $\mathrm{NP}$ & $\mathrm{NP}$ & $\mathrm{NP}$ & $\mathrm{NP}$ & + & $\mathrm{NP}$ & & \\
\hline \multirow{8}{*}{42} & II-12 & NP & NP & + & - & + & $\mathrm{NP}$ & \multirow{8}{*}{ N/ SEG } & \multirow{8}{*}{ N/ SEG } \\
\hline & II-6 & $\mathrm{NP}$ & NP & + & - & + & NP & & \\
\hline & II-8 & - & + & - & - & $-1+$ & NP & & \\
\hline & II-10 & - & - & - & + & + & NP & & \\
\hline & III-7 & - & - & - & - & + & $\mathrm{NP}$ & & \\
\hline & III-5 & - & + & NP & NP & + & $\mathrm{NP}$ & & \\
\hline & III-16 & - & + & NP & NP & + & NP & & \\
\hline & III-17 & - & + & NP & NP & + & NP & & \\
\hline \multirow[t]{2}{*}{43} & II-5 & - & - & - & + & + & NP & \multirow[t]{2}{*}{ N/ SEG } & \multirow[t]{2}{*}{ SEGRE } \\
\hline & I-3 & - & - & - & + & $-/+$ & NP & & \\
\hline
\end{tabular}

IND = INDIVIIDUO; OCUL = OCULAR; CARD = CARDÍACO; ESQ = ESQUELÉTICO; LC = LUXACC̃̃O DO CRISTALINO; MIO = MIOPIA; DILAO = DILATAÇÃO DA AORTA; PVM = PROLAPSO DE VALVA MITRAL; > $5=$ CINCO SINAIS ESQUELÉTICOS; ED = ECTASIA DURAL; NP = NÃO PESQUISADO; + = PRESENTE; - = AUSENTE; N/ SEG = NÃO SEGREGA HAPLÓTIPO/DOENÇA; SEGRE $=$ SEGEGANDO O HAPLÓTIPO/DOENÇA; N/ INF = NÃO INFORMATIVO.

Tabela 3 - Famílias que apresentam haplótipo não informativo.

\begin{tabular}{|c|c|c|c|c|c|c|c|c|c|}
\hline \multirow[t]{2}{*}{ FAMÍLIA } & \multirow[t]{2}{*}{$N^{0}$ IND } & \multicolumn{2}{|c|}{ OCULARES } & \multicolumn{2}{|c|}{ CARDIACOS } & \multicolumn{2}{|c|}{ ESQUELET } & \multirow[t]{2}{*}{$F B N 1$} & \multirow[t]{2}{*}{ TGFBR2 } \\
\hline & & LC & MIO & DILAO & PVM & $>5$ & ED & & \\
\hline \multirow[t]{7}{*}{18} & II-1 & - & + & + & - & + & NP & \multirow[t]{7}{*}{$\mathrm{N} / \mathrm{INF}$} & \multirow[t]{7}{*}{ N/ SEG } \\
\hline & II-2 & + & - & + & + & + & NP & & \\
\hline & II-4 & + & - & + & + & + & NP & & \\
\hline & III-4 & $\mathrm{NP}$ & NP & NP & NP & $-1+$ & NP & & \\
\hline & III-6 & + & - & + & + & + & NP & & \\
\hline & III-8 & + & - & - & - & + & NP & & \\
\hline & III-9 & $\mathrm{NP}$ & NP & NP & NP & $-1+$ & $\mathrm{NP}$ & & \\
\hline \multirow[t]{2}{*}{38} & II-1 & - & + & + & - & + & $\mathrm{NP}$ & \multirow[t]{2}{*}{$\mathrm{N} / \mathrm{INF}$} & NÃO \\
\hline & $\mathrm{I}-1$ & - & + & + & - & + & NP & & ESTUDADA \\
\hline \multirow[t]{3}{*}{40} & III-1 & + & - & + & - & + & NP & \multirow[t]{3}{*}{$\mathrm{N} / \mathrm{INF}$} & \multirow{3}{*}{$\begin{array}{c}\text { NÃO } \\
\text { ESTUDADA }\end{array}$} \\
\hline & III-2 & + & + & - & - & + & NP & & \\
\hline & II-2 & + & - & - & + & + & $\mathrm{NP}$ & & \\
\hline 45 & IV-2 & + & - & + & - & + & $\mathrm{NP}$ & $\mathrm{N} / \mathrm{INF}$ & N/ SEG \\
\hline
\end{tabular}

IND = INDIVIIDUO; OCUL = OCULAR; CARD = CARDÍACO; ESQ = ESQUELÉTICO; LC = LUXAÇ̃̃O DO CRISTALINO; MIO = MIOPIA; DILAO = DILATAÇÃO DA AORTA; PVM = PROLAPSO DE VAVA MITRAL; >5 = CINCO SINAIS ESQUELÉTICOS; ED = ECTASIA DURAL; NP = NÃO PESQUISADO; + = PRESENTE; - = AUSENTE; N/ SEG = NÃO SEGREGA HAPLÓTIPO/DOENÇA; SEGRE = SEGEGANDO O HAPLÓTIPO/DOENÇA; N/ INF = NÃO INFORMATIVO; 
Tabela 4 - Valores de lod score obtidos com os microssatélites do gene FBN1.

\begin{tabular}{|c|c|c|c|c|c|c|}
\hline FAMILIA & $\begin{array}{c}\theta 0.0 \text { MTS1 } 1 \\
\text { FASTLIK }\end{array}$ & $\begin{array}{c}\theta 0.0 \text { MTS2 } \\
\text { FASTLIK }\end{array}$ & $\begin{array}{c}\theta 0.0 \text { MTS4 } \\
\text { FASTLIK }\end{array}$ & Merlin & $\begin{array}{c}\begin{array}{c}\text { Lod Score máximo } \\
\text { (Merlin) }\end{array} \\
\end{array}$ & RESULTADO \\
\hline 1 & -3.7 & -3.7 & 0.3 & -3.221 & 0.3 & NÃO SEGREGA \\
\hline 2 & 3.61 & 2.29 & 2.29 & 2.104 & 4.2 & SEGREGA \\
\hline 3 & 0.6 & 0.6 & 0.6 & 0.6 & 0.601 & SEGREGA \\
\hline 4 & -3.7 & -3.7 & -3.7 & -3.221 & 0.3 & NÃO SEGREGA \\
\hline 5 & -0.3 & -0.3 & -0.3 & 0.600 & 0.602 & SEGREGA \\
\hline 6 & 1.20 & 1.20 & 1.20 & 1.2 & 1.204 & SEGREGA \\
\hline 7 & 5.12 & 5.12 & 5.12 & $3.911 \mathrm{a}$ & $3.912 \mathrm{a}$ & SEGREGA \\
\hline 8 & 0.9 & 0.9 & 0.9 & 0.778 & 1.204 & SEGREGA \\
\hline 9 & 0.35 & 1.76 & 0.44 & 1.929 & 1.929 & SEGREGA \\
\hline 10 & NÃO EST. & NÃO EST. & NÃO EST. & NÃO EST. & NÃO EST. & NÃO EST. \\
\hline 11 & NÃO EST. & NÃO EST. & NÃO EST. & NÃO EST. & NÃO EST. & NÃO EST. \\
\hline 12 & NÃO EST. & NÃO EST. & NÃO EST. & NÃO EST. & NÃO EST. & NÃO EST. \\
\hline 13 & 0.6 & 0.6 & 0.6 & 0.6 & 0.602 & SEGREGA \\
\hline 14 & 0.32 & 0.32 & 0.32 & 0.598 & 0.598 & SEGREGA \\
\hline 15 & 0.24 & 0.12 & -3.4 & -5.33 & 0.602 & NÃO SEGREGA \\
\hline 16 & 0.12 & 0.15 & 0.12 & 0.147 & 0.147 & SEGREGA \\
\hline 17 & 0.18 & 0.45 & 0.45 & 0.536 & 0.578 & SEGREGA \\
\hline 18 & NÃO INF & NÃO INF & NÃO INF & NÃO INF & NÃO INF & NÃO INF \\
\hline 19 & 1.11 & -5.32 & 0.77 & 0.283 & 2.408 & SEGREGA \\
\hline 20 & 0.88 & 0.17 & 0.11 & 0.461 & 0.593 & SEGREGA \\
\hline 21 & NÃO EST. & NÃO EST. & NÃO EST. & NÃO EST. & NÃO EST. & NÃO EST. \\
\hline 22 & 0.3 & 0.6 & 0.6 & 0.6 & 0.602 & SEGREGA \\
\hline 23 & 1.51 & 1.51 & 1.2 & 1.504 & 1.504 & SEGREGA \\
\hline 24 & 1.17 & 1.17 & 1.17 & 1.2 & 1.203 & SEGREGA \\
\hline 25 & NÃO EST. & NÃO EST. & NÃO EST. & NÃO EST. & NÃO EST. & NÃO EST. \\
\hline 26 & NÃO EST. & NÃO EST. & NÃO EST. & NÃO EST. & NÃO EST. & NÃO EST. \\
\hline 27 & NÂO EST. & NÃO EST. & NÃO EST. & NÃO EST. & NÃO EST. & NÃO EST. \\
\hline 28 & 0.3 & 0.3 & NÃO INF & 0.3 & 0.3 & SEGREGA \\
\hline 29 & 1.51 & 1.51 & 1.51 & 1.5 & 1.503 & SEGREGA \\
\hline 30 & 0.3 & 0.3 & NÃO INF & 0.3 & 0.3 & SEGREGA \\
\hline 31 & 0.66 & $\begin{array}{l}-0.18 \\
\end{array}$ & 0.53 & 1.265 & 0.903 & SEGREGA \\
\hline 32 & NÃO EST. & NÃO EST. & NÃO EST. & NÃO EST. & NÃO EST. & NÃO EST. \\
\hline 33 & 0.60 & 0.3 & -0.29 & 0.6 & 0.602 & SEGREGA \\
\hline 34 & 0.46 & NÃO INF & 1.11 & 0.178 & 0.286 & SEGREGA \\
\hline 35 & 1.38 & -2.73 & 1.3 & -2.381 & -0.537 & SEGREGA \\
\hline 36 & NÃO EST. & NÃO EST. & NÃO EST. & NÃO EST. & NÃO EST. & NÃO EST. \\
\hline 37 & -3.52 & -3.54 & 0.47 & -3.445 & 1.158 & NÃO SEGREGA \\
\hline 38 & NÃO INF & NÃO INF & NÃO INF & NÃO INF & NÃO INF & NÃO INF \\
\hline 39 & NÃO EST. & NÃO EST. & NÃO EST. & NÃO EST. & NÃO EST. & NÂO EST. \\
\hline 40 & NÃO INF & NÃO INF & NÃO INF & NÃO INF & NÃO INF & NÃO INF \\
\hline 41 & NÃO EST & NÃO EST & NÃO EST & NÃO EST & NÃO EST & NÃO EST. \\
\hline 42 & -3.46 & -1.02 & 2.49 & -3.659 & 3.421 & NÃO SEGREGA \\
\hline 43 & -1.4 & -1.4 & -1.4 & -3.095 & 0.601 & NÃO SEGREGA \\
\hline 44 & NÃO EST. & NÃO EST. & NÃO EST. & NÃO EST. & NÃO EST. & NÃO EST. \\
\hline 45 & NÃO INF & NÃO INF & NÃO INF & NÃO INF & NÃO INF & NÃO INF \\
\hline 46 & 0.15 & -3.70 & 0.12 & -2.529 & 0.139 & SEGREGA \\
\hline 47 & $\begin{array}{c}\text { NÃO EST } \\
\text { /AND CLIN }\end{array}$ & $\begin{array}{c}\text { NÃO EST } \\
\text { /AND CLIN }\end{array}$ & $\begin{array}{c}\text { NÃO EST } \\
\text { /AND CLIN }\end{array}$ & $\begin{array}{c}\text { NÃO EST } \\
\text { /AND CLIN }\end{array}$ & NÃO EST /AND CLIN & NÃO EST /AND CLIN \\
\hline
\end{tabular}


Tabela 5 - Valores de lod score obtidos com os microssatélites do gene TGFBRII.

\begin{tabular}{|c|c|c|c|c|}
\hline FAMILIA & $\begin{array}{c}\theta 0.0 \text { D3S3727 } \\
\text { FASTLIK }\end{array}$ & $\begin{array}{c}\text { Merlin } \\
\text { D3S3727 }\end{array}$ & Lodscore máximo (Merlin) & RESULTADO \\
\hline 1 & NÃO INF & NÃO INF & NÃO INF & NÃO INF \\
\hline 2 & NÃO EST. & NẪ EST. & NÃO EST. & NÃO EST. \\
\hline 3 & NÃO EST. & NÃO EST. & NÃO EST. & NÃO EST. \\
\hline 4 & -3.7 & -3.221 & 0.3 & NÃO SEGREGA \\
\hline 5 & NÃO EST. & NÃO EST. & NÃO EST. & NÃO EST. \\
\hline 6 & -2.80 & -5.754 & 1.204 & NÃO SEGREGA \\
\hline 7 & NÃO EST. & NÃO EST. & NÃO EST. & NÃO EST. \\
\hline 8 & NÃO EST. & NÃO EST. & NÃO EST. & NÃO EST. \\
\hline 9 & -3.92 & -9.893 & 1.929 & NÃO SEGREGA \\
\hline 10 & NÃO EST. & NÃO EST. & NÃO EST. & NÃO EST. \\
\hline 11 & NÃO EST. & NÃO EST. & NÃO EST. & NÃO EST. \\
\hline 12 & NÃO EST. & NÃO EST. & NÃO EST. & NÃO EST. \\
\hline 13 & -1.4 & -2.620 & 0.602 & NÃO SEGREGA \\
\hline 14 & NÃO EST. & NÃO EST. & NÃO EST. & NÃO EST. \\
\hline 15 & -0.01 & 0.259 & 0.602 & NÃO SEGREGA \\
\hline 16 & -3.7 & -3.272 & 0.147 & NÃO SEGREGA \\
\hline 17 & NÃO EST. & NÃO EST. & NÃO EST. & NÃO EST. \\
\hline 18 & -2.51 & -8.416 & 1.504 & NÃO SEGREGA \\
\hline 19 & NÃO EST. & NÃO EST. & NÃO EST. & NÃO EST. \\
\hline 20 & NÃO EST. & NÃO EST. & NÃO EST. & NÃO EST. \\
\hline 21 & NÃO EST. & NÃO EST. & NÃO EST. & NÃO EST. \\
\hline 22 & NẪO EST. & NÃO EST. & NÃO EST. & NÃO EST. \\
\hline 23 & NÃO EST. & NÃO EST. & NÃO EST. & NÃO EST. \\
\hline 24 & NÃO EST. & NÃO EST. & NÃO EST. & NÃO EST. \\
\hline 25 & NÃO EST. & NÃO EST. & NÃO EST. & NÃO EST. \\
\hline 26 & NÃO EST. & NÃO EST. & NÃO EST. & NÃO EST. \\
\hline 27 & NÃO EST. & NÃO EST. & NÃO EST. & NÃO EST. \\
\hline 28 & -3.70 & -3.221 & 0.3 & NÃO SEGREGA \\
\hline 29 & NÃO EST. & NÃO EST. & NÃO EST. & NÃO EST. \\
\hline 30 & NÃO EST. & NÃO EST. & NÃO EST. & NÃO EST. \\
\hline 31 & NÃO EST. & NÃO EST. & NÃO EST. & NÃO EST. \\
\hline 32 & NÃO EST. & NÃO EST. & NÃO EST. & NÃO EST. \\
\hline 33 & NÃO EST. & NÃO EST. & NÃO EST. & NÃO EST. \\
\hline 34 & NÃO EST. & NÃO EST. & NÃO EST. & NÃO EST. \\
\hline 35 & NÃO EST. & NÃO EST. & NÃO EST. & NÃO EST. \\
\hline 36 & NÃO EST. & NÃO EST. & NÃO EST. & NÃO EST. \\
\hline 37 & -2.61 & -3.133 & 1.158 & NÃO SEGREGA \\
\hline 38 & NÃO EST. & NÃO EST. & NÃO EST. & NÂO EST. \\
\hline 39 & NÃO EST. & NÃO EST. & NÃO EST. & NÃO EST. \\
\hline 40 & NÃO EST. & NÃO EST. & NÃO EST. & NÃO EST. \\
\hline 41 & NÃO EST. & NÃO EST. & NÃO EST. & NÃO EST. \\
\hline 42 & -4.54 & -9.03 & 3.421 & NÃO SEGREGA \\
\hline$\overline{43}$ & 0.60 & 0.601 & 0.601 & SEGREGA \\
\hline 44 & NÃO EST. & NÃO EST. & NÃO EST. & NÃO EST. \\
\hline 45 & & & & NÃO SEGREGA \\
\hline 46 & NÃO EST. & NÃO EST. & NÃO EST. & NÃO EST. \\
\hline 47 & AND CLIN & AND CLIN & AND CLIN & AND CLIN \\
\hline
\end{tabular}


Tabela 6 - Famílias que apresentaram no mínimo 1 sinal maior e demonstraram segregação ou não do haplótipo com a doença.

\begin{tabular}{|c|c|c|c|c|c|c|c|}
\hline $\begin{array}{c}\text { SINAIS } \\
\text { MAIORES / } \\
\text { SISTEMA }\end{array}$ & $\begin{array}{l}\text { FAM } \\
\text { Q/ CO- } \\
\text { SEGR. } \\
\text { FBN1 } \\
\text { C/ } \\
\text { SMF }\end{array}$ & $\begin{array}{c}\text { FAM } \\
\text { Q/ } \\
\text { NÃ̃ } \\
\text { SEGR. } \\
\text { FBN1 } \\
\text { C/ SMF }\end{array}$ & $\begin{array}{l}\text { COMPARAÇÃO } \\
\text { ENTRE FAM. } \\
\text { Q/ CO-SEGR C/ } \\
\text { AS Q/ NÃO CO- } \\
\text { SEGR. FBN1 C/ } \\
\text { A SMF }\end{array}$ & $\begin{array}{l}\text { FAM. Q/ } \\
\text { CO- } \\
\text { SEGR. } \\
\text { TGFBRII } \\
\text { C/ A } \\
\text { SMF }\end{array}$ & $\begin{array}{c}\text { FAM Q/ } \\
\text { NÃO CO- } \\
\text { SEGR. } \\
\text { TGFBRII } \\
\text { C/ SMF }\end{array}$ & $\begin{array}{c}\text { COMPARAÇÃO } \\
\text { ENTRE FAM Q } \\
\text { CO- SEGR. C/ } \\
\text { AS Q/ NÃO CO- } \\
\text { SEGR. TGFBRII } \\
\text { C/ A SMF }\end{array}$ & $\begin{array}{c}\text { COMPARAÇÃO } \\
\text { ENTRE } \\
\text { FAMÍLIAS Q/ } \\
\text { CO-SEGR. } \\
\text { FBNI E } \\
\text { TGFBRII C/ A } \\
\text { SMF }\end{array}$ \\
\hline$\overline{\text { CARDIACO }}$ & $\begin{array}{l}19 / 24 \\
(79 \%)\end{array}$ & $\begin{array}{c}5 / 6 \\
(83 \%)\end{array}$ & (NS) $p=1$ & $\begin{array}{c}1 / 6 \\
(16,6 \%)\end{array}$ & $3 / 6(50 \%)$ & $(\mathrm{NS}) \mathrm{p}=0,5455$ & $p=0,0008$ \\
\hline OCULAR & $\begin{array}{l}19 / 24 \\
(79 \%) \\
\end{array}$ & $\begin{array}{c}0 / 6 \\
(0 \%) \\
\end{array}$ & $P=0,0008$ & $0 / 6(0 \%)$ & $0 / 6(0 \%)$ & $(\mathrm{NS}) \mathrm{p}=1$ & $p=0,0008$ \\
\hline ESQUELET & $\begin{array}{c}25 / 25 \\
(100 \%)\end{array}$ & $\begin{array}{c}8 / 8 \\
(100 \%)\end{array}$ & $(\mathrm{NS}) p=1$ & $\begin{array}{c}6 / 6 \\
(100 \%)\end{array}$ & $\begin{array}{c}6 / 6 \\
(100 \%)\end{array}$ & $(\mathrm{NS}) \mathrm{p}=1$ & $(\mathrm{NS}) p=1$ \\
\hline
\end{tabular}

FAM Q/ CO-SEGR. FBN1 C/ SMF = FAMILIAS QUE CO-SEGREGARAM HAPLÓTIPO DO GENE FBN1 COM A SÍNDROME DE MARFAN.FAM Q/ NÃO SEGR. FBNI C/ SMF = FAMILIAS QUE NÃO CO-SEGREGARAM HAPLÓTIPO DO GENE FBNI COM A SÍNDROME DE MARFAN;

COMPARAÇÃO ENTRE FAM. Q/ CO-SEGR C/ AS Q/ NÃO CO-SEGR. FBN1 C/ A SMF = COMPARAÇÃO ENTRE AS FAMILIAS QUE CO-SEGREGARAM HAPLÓTIPO DO GENE FBN1 COM AS COM AS FAMILIAS QUE NÃO CO-SEGREGARAM HAPLÓTIPO DO GENE $F B N 1$ COM A SÍNDROME DE MARFAN;

FAM. Q/ CO-SEGR. TGFBRII C/ A SMF = FAMILIAS QUE CO-SEGREGARAM HAPLÓTIPO DO GENE TGFBRII COM A SÍNDROME DE MARFAN;

FAM Q/ NÃO CO-SEGR. TGFBRII C/ SMF = FAMILIAS QUE NÃO CO-SEGREGARAM HAPLÓTIPO DO GENE TGFBRII COM A SÍNDROME DE MARFAN:

COMPARAÇÃO ENTRE FAM Q CO- SEGR. C/ AS Q/ NÃO CO-SEGR. TGFBRII C/ A SMF = COMPARAÇÃO ENTRE AS FAMILIAS QUE CO-SEGREGARAM HAPLÓTIPO DO GENE TGFBRII COM AS COM AS FAMILIAS QUE NÃ̃ COSEGREGARAM HAPLÓTIPO DO GENE TGFBRII COM A SÍNDROME DE MARFAN;

COMPARAÇÃO ENTRE FAMÍLIAS Q/ CO-SEGR. FBNI E TGFBRII C/ A SMF = COMPARAÇÃO ENTRE AS FAMILIAS QUE CO-SEGREGARAM HAPLÓTIPO DO GENE $F B N 1$ COM A SÍNDROME DE MARFAN E AS FAMILIAS QUE CO-SEGREGARAM HAPLÓTIPO DO GENE TGFBRII COM A SÍNDROME DE MARFAN; 


\section{DISCUSSÃO}

A alta taxa de mutações, a ausência de marcadores específicos de doenças e a alta frequência de síndromes com fenótipos semelhantes diminuem a eficiência no diagnóstico clínico de várias síndromes genéticas, entre elas, a síndrome de Marfan. Entretanto, com a descoberta das mutações causadoras da síndrome de Marfan no gene FBN1, por meio do diagnóstico molecular, aumentaram-se as chances de identificação da doença em indivíduos atípicos ou oligossintomáticos (DIETZ et al., 1991).

Existem ainda dificuldades para o rastreamento das mutações no gene FBN1 e também há um aumento no custo do diagnóstico genético, fatores estes devido ao grande número de mutações encontradas ao longo do gene FBN1 sem uma correlação genótipo/fenótipo (exceto para algumas regiões) ao tamanho do gene (65 exons) e à heterogeneidade de locos (DIETZ e PYERTZ, 1995; COLLOD et al., 1998; PEREIRA et al., 1999; MIZUGUCHI et al., 2004; SUMMERS et al., 2006).

Outro fator complicador do diagnóstico molecular da síndrome de Marfan foi a descrição de mutações em outros genes causando fenótipos sobrepostos à síndrome de Marfan e sugerindo a existência de heterogeneidade genética (BOILEAU et al., 1991; MIZUGUCHI et al., 2004; MATYAS et al., 2006a; SINGH et al., 2006; SAKAI et al., 2006).

O objetivo deste trabalho foi analisar a heterogeneidade genética da síndrome de Marfan por meio de estudo de segregação, demonstrando a eficácia do método no rastreamento de uma doença com heterogeneidade alélica em um grande gene (FBN1) e heterogeneidade de locus (FBN1, TGFBRI e TGFBRII).

\subsection{Estudo das manifestações clínicas de uma amostra brasileira de pacientes com síndrome de Marfan com o quadro clínico clássico e fenótipos associados}

Os estudos que utilizaram marcadores do tipo microssatélites encontrados nos genes FBN1 e TGFBRII para a realização da análise de ligação em famílias com síndrome de Marfan são resultantes de trabalhos com um número pequeno de famílias (VALIEV et al., 2006; MIZUGUCHI et al., 2004; LEE et al., 2005; MOTTES et al., 2000; JUDJE et al., 2001). Apesar deste fato não ser relevante para o estudo de ligação, ele auxilia nos resultados estatísticos. Em nosso trabalho, conseguimos realizar análise de segregação em 34 famílias com síndrome de Marfan, as quais foram avaliadas clinicamente segundo os critérios de Ghent. As características clínicas foram estudadas de acordo com as limitações da Instituição 
e dos pacientes, com o objetivo de se observar quantos preenchiam os critérios diagnósticos, a variabilidade fenotípica intra e inter-familial, assim como estabelecer um padrão fenotípico, de maneira que diante de um determinado paciente fosse possível direcionar a pesquisa molecular, supondo que haveria maior chance de encontrar a mutação em um determinado gene (FBN1, TGFBR1 ou TGFBR2).

O fenótipo clínico nos indivíduos estudados variou intra e inter familiarmente, como esperado. De uma maneira geral observou-se o fenótipo esquelético clássico, com exceção do indivíduo II-1 da família 28, que apresenta baixa estatura e recebe tratamento para crescer com hormônio de crescimento, apesar do comprometimento cardíaco e oftalmológico típicos. Provavelmente trata-se de outra doença concomitante. Em todos os indivíduos afetados observou-se no mínimo uma das características esqueléticas maiores informados pela nosologia de Ghent. Das 34 famílias estudadas no trabalho, observamos que em 67,64\%, no mínimo um indivíduo apresentou luxação do cristalino e em 82,35\%, no mínimo um indivíduo apresentou dilatação da aorta.

\subsection{Análise da segregação de marcadores moleculares intragênicos aos genes $F B N-1$ e TGFBRII nos casos familiais de síndrome de Marfan}

A análise de segregação realizada com marcadores moleculares intragênicos ou próximos aos genes alvos é uma técnica eficaz e de menor custo, utilizada na análise de casos familiares (MOTTES et al., 2000). Os marcadores MTS-1, MTS-2, MTS-3 e MTS-4 presentes no gene $F B N 1$ já foram utilizados por vários autores e demonstram ser muito úteis na interpretação do diagnóstico genético, como também no diagnóstico pré-implantação da síndrome de Marfan (SARFARAZI et al., 1992; MOTTES et al., 2000; HUTCHINSON et al., 2003; LEE et al., 2005; SPITS et al., 2006). Na maior parte dos trabalhos realizados com esses marcadores, o marcador MTS-3 mostrou-se pouco informativo, fato também observado em nossa amostragem. Alguns autores inclusive optaram por não utilizá-lo como Valiev et al., 2006, os quais demonstram a possibilidade e aplicação da análise de segregação de haplótipo com o uso dos marcadores intragênicos (MTS-1, MTS-2 e MTS-4) no diagnóstico de famílias afetadas com síndrome de Marfan.

A eficácia do uso da análise de segregação de haplótipo nas famílias com indivíduos oligossintomáticos, ou até mesmo com indivíduos diagnosticados clinicamente com síndrome de Marfan, é bem demonstrada no trabalho de Judje et al., 2001. Em uma das genealogias (3A) estudadas no trabalho são descritos três indivíduos oligossintomáticos que não 
apresentavam o haplótipo obtido nos seus familiares com síndrome de Marfan clássica, sendo depois demonstrado que os mesmos não portavam a mutação encontrada nos outros membros afetados da família, como previsto na análise de segregação. Em outra genealogia (4A), estudada pelos mesmos autores, foi demonstrado que um indivíduo não obteve o haplótipo igual ao dos membros afetados da sua família, sendo também visto posteriormente que o mesmo não portava a mutação encontrada nos indivíduos afetados. Esse indivíduo apresentava luxação do cristalino, dilatação da raiz da aorta e dilatação da artéria pulmonar proximal e, além disso, parentes em primeiro grau com diagnóstico inequívoco da síndrome de Marfan, isto é, completava os critérios diagnósticos da nosologia de Ghent. Em nosso trabalho também encontramos que os pacientes IV-1 e IV-3 da genealogia 2, os quais demonstraram no exame físico uma escoliose importante e envergadura maior do que a altura, o I-2 da genealogia 14, que demonstrava envolvimento esquelético e cardíaco em exames anteriores e os indivíduos III-6 e IV-1 da genealogia 32, onde o primeiro foi descrito pelos familiares com características clínicas da doença e o outro apresentou envolvimento esquelético e cardíacos da doença. Portanto, em todos esses pacientes que foram tidos como oligossintomáticos devido à presença de sinais clínicos da doença, foi possível concluir por meio da análise de segregação que os mesmos não portavam o haplótipo característico dos membros afetados.

Nos trabalhos realizados com síndrome de Marfan utilizando o teste de análise de segregação não se observa a interpretação dos dados por meio do lod score, fato este bastante intrigante, visto que uma das funções deste método é estimar a frequência de recombinação em uma genealogia. Observamos em nossos resultados co-segregação de um haplótipo com a doença em 70,58\% das famílias estudadas com os marcadores do gene FBN1. Em duas genealogias grandes estudadas, obtivemos um lod score > 3.0, com os marcadores MTS-1, MTS-2 e MTS-4, indicando ligação do haplótipo com a doença. Na maioria das famílias estudadas, a genealogia é pequena demais para se obter um lod score igual a 3.0; demonstramos esse fato ao realizar o lod score máximo. Portanto obtivemos lod score $>1.0$ e/ou igual ao lod score máximo simulado para aquela genealogia em 7 famílias que cosegregaram um haplótipo com a doença. Nas 15 famílias restantes obtivemos um lod score máximo < 1, nesses casos não podemos afirmar que há ligação, pois o tamanho da genealogia não permite atingir diferença significativa para esta afirmação. Mas o lod score resultante dessas 15 famílias foi igual ao lod score máximo das mesmas.

Os marcadores do gene TGFBRII utilizados por Mizuguchi et al. (2004) foram informativos no estudo de análise de segregação dos haplótipos realizado pelos autores em 
uma família francesa com indivíduos afetados pela síndrome de Marfam. Em nosso trabalho, apenas o marcador D3S3727 do gene TGFBRII apresentou-se informativo. O marcador D3S3567 apresentou-se não informativo na maior parte das famílias analisadas com o mesmo. Além disso, demonstramos exclusão de ligação em 66,66\% das famílias analisadas com o marcador D3S3727 e co-segregação do gene TGFBRII com a doença em uma família.

\subsection{Correlação genótipo-fenótipo dos genes $F B N 1$ e TGFBRII versos a gravidade da doença}

Vários autores tentam correlacionar os tipos de mutações encontradas ao longo do gene FBN1 com as características clínicas presentes na síndrome de Marfan. As mutações encontradas nos exons 24-40 são associadas com um fenótipo mais grave da doença (TIECKE et al., 2001; FAIVRE et al., 2007). Mutações nos primeiros 15 exons do gene FBN1 e as que causam substituições de cisteínas estão associadas com luxação do cristalino. Entretanto, outros estudos demonstram que mutações que causam substituições de cisteínas estão associadas com o envolvimento cardiovascular (COMEGLIO et al., 2002, 2007). Mutações encontradas na extremidade 5' estão associadas com um fenótipo menos grave da doença e as encontradas na extremidade 3' estão associadas com pouca predominância do envolvimento aórtico (ROBINSON et al., 2002; PALZ et al., 2000).

Correlações genótipo-fenótipo para o gene TGFBRII em indivíduos com síndrome de Marfan são menos descritas. Stheneur et al. (2008) demonstram que o envolvimento cardíaco é mais frequente nos indivíduos com mutações no gene TGFBRII quando comparados com os indivíduos com ausência de mutações no gene TGFBRII. Além disso, ao compararem o envolvimento cardíaco e ocular nos indivíduos com mutações nos genes TGFBRII e FBN1, os autores demonstraram que existe uma maior frequência de indivíduos com problemas cardíacos e uma menor frequência de pacientes com luxação do cristalino. Em nosso trabalho encontramos que os sinais cardíacos e oculares são frequentemente iguais ao compararmos as famílias cuja síndrome segregou com os marcadores do gene FBN1 em relação às famílias cuja síndrome segregou com os marcadores do gene TGFBRII. Além disso, não encontramos diferenças estatísticas significativas quanto aos sinais cardíacos e esqueléticos, mas o envolvimento ocular apresentou diferença estatística significativamente maior ao compararmos as famílias que apresentaram segregação do haplótipo dos marcadores do gene FBN1 com a síndrome e as famílias que não apresentaram segregação do haplótipo dos marcadores do gene FBN1 com a doença. 


\subsection{Sequenciamento do gene TGFBRII nos casos que co-segregarão com o gene e sequenciamento do gene TGFBRI nos casos que excluíram ligação com o gene TGFBRII}

A heterogeneidade genética na síndrome de Marfan clássica já está comprovada desde 2004 com o trabalho de Mizuguchi et al.. Foram encontradas mutações espalhadas ao longo do gene TGFBRII nos exons 3, 4, 5, 6 e 7, como também nos exons 4 e 6 do gene TGFBR1 (MIZUGUCHI et al., 2004; MÁTYÁS et al., 2006; DISABELLA et al., 2006; STHENEUR et al., 2008). Em nosso trabalho não encontramos mutações para o gene TGFBRII no sequenciamento realizado no probando da família que apresentou co-segregação do gene TGFBRII com a doença. Para o gene TGFBRI, foram sequenciados até o momento os exons 2, 3, 6 e 7, e não encontramos nenhuma mutação nesses exons no probando em questão.

Grandes deleções dentro dos introns ou próximas ao gene $F B N 1$ foram conservadas com a evolução, e contêm provavelmente os elementos importantes para o controle da expressão gênica. Assim, o potencial para que a recombinação intragênica ou perigênica obscureça a interpretação dos resultados em uma análise de ligação deve ser levado em consideração (BIERY et al., 1999; YIN et al., 1995; RANTAMAKI et al., 1994; CORSON et al.,1993). Portanto, nas famílias 4, 15, 37 e 42 em que foi realizado o sequenciamento, apesar de ainda não termos completado o seqüenciamento do gene TGFBRI, é possível que exista uma grande deleção no gene FBN1 ou até mesmo no gene TGFBRII, que nos levou a um engano na interpretação dos resultados da análise de ligação.

Uma técnica recentemente introduzida, que é apropriada para a identificação de grandes deleções e menos laboriosa do que métodos usados tradicionalmente para detecção de rearranjos tais como o "Southern blot" e técnicas de citogenéticas, é a amplificação de múltiplas sondas dependentes de ligação (MLPA) (SCHOUTHEN et al., 2002), que pode nos auxiliar na confirmação dessa hipótese. 


\section{CONCLUSÕES}

15.1 Estudo das manifestações clínicas de uma amostra brasileira de pacientes com síndrome de Marfan com o quadro clínico clássico e fenótipos associados

Com relação ao quadro clínico observado nas famílias estudadas em nosso trabalho, podemos concluir que as características esqueléticas aparecem em um número maior de indivíduos afetados. Posteriormente a essas vêm os problemas de dilatação da aorta e a luxação do cristalino, respectivamente.

Observamos também comprometimento cardíaco típico e grave nos indivíduos de mais idade, mostrando que este deve ser monitorado nas crianças, já que o desenvolvimento da dilatação da aorta é progressivo.

15.2 Análise da segregação de marcadores moleculares intragênicos aos genes $F B N-1$ e TGFBRII nos casos familiais de síndrome de Marfan

Podemos concluir que os marcadores do gene FBN1, com exceção do marcador MTS3, se mostram bastante informativos. Dessa forma, podemos estabelecer a co-segregação do haplótipo na maior parte das famílias. Demonstramos assim, por meio da análise de segregação, que as famílias com síndrome de Marfan encontram-se em maior número segregadas aos marcadores do gene FBNI do que aos marcadores do gene TGFBRII, como esperado.

15.3 Correlação genótipo-fenótipo dos genes FBN1 e TGFBRII versus a gravidade da doença

Até o momento, sabemos que os fenótipos cardíaco e esquelético não variam substancialmente entre os grupos das famílias com co-segregação e sem segregação para os marcadores do gene FBN1 com a síndrome, mas varia em relação ao envolvimento ocular no mesmo grupo.

Com relação às famílias que apresentaram co-segregação de marcadores do gene TGFBRII com a doença, concluímos que os fenótipos esquelético, cardíaco e ocular não apresentam diferença estatística significante. 
Mas ao compararmos as famílias que co-segregam haplótipo dos genes FBN1 e TGFBRII com a doença encontramos diferença estatística significativa para os sinais cardíacos e oculares maiores. Assim sendo, sugerimos que em um paciente sem luxação do cristalino e sem dilatação da aorta é mais indicado realizar primeiramente uma análise molecular do gene TGFBRII.

\subsection{Sequenciamento do gene TGFBRII nos casos que co-segregaram com o gene e sequenciamento do gene TGFBRI nos casos que excluíram ligação com o gene TGFBRII}

Por meio do seqüenciamento, podemos concluir que a família 43, a qual apresentou co-segregação do gene TGFBRII com a doença, não apresentou mutações no gene.

Em relação ao gene TGFBRI, as famílias 4, 5, 37 e 42 não apresentaram mutações nos exons 2, 3, 6 e 7. Entretanto, pode haver uma grande deleção em pelo menos alguma delas que esteja atrapalhando a interpretação dos resultados de análise de ligação.

\subsection{Conclusão geral}

Concluímos que a análise de ligação evidenciou a heterogeneidade de lócus e demonstrou-se útil como teste diagnóstico e na assistência das famílias oligossintomáticas com manifestações atípicas ou ambíguas da síndrome de Marfan. Em suma, a técnica de análise de ligação poderá servir no auxílio do diagnóstico clínico de famílias com síndrome de Marfan e consequentemente proporcionar um aconselhamento genético mais adequado. Indicamos que seja realizado nos pacientes atípicos da síndrome de Marfan que não apresentam luxação do cristalino e dilatação da aorta primeiramente uma análise molecular do TGFBRII. 


\section{REFERÊNCIAS BIBLIOGRÁFICAS*}

ABECASIS, G. R.; CHERNY, S. S.; COOKSON, W. O.; CARDON L. R. Merlin-rapid analysis of dense genetic maps using sparse gene flow trees. Nat. Genet., v. 30, p. 97-101, 2002.

ADES, L. C.; HOLMAN, K. J.; BRETT, M. S.; EDWARDS, M. J. Ectopia lentis phenotypes and the FBN1 gene. Am. J. Med. Genet., v. 126A, p. 284, 2004.

AHN, N. U.; NALLAMSHETY, L.; AHN, U. M.; BUCHOWSKI, J. M.; ROSE, P. S.; GARRETT, E. S.; KEBAISH, K. M. SPONSELLER P. D. Dural ectasia and conventional radiography in Marfan lumbosacral spine. Skeletal Radiol., v. 30, p. 338-345, 2001.

APERT, E. Les formes frustes du syndrome dolichoste'nomélique de Marfan. Nourrisson, v. 26, p.1-12, 1938.

BAER, R. W.; TAUSSIG. H. B.; OPPENHEIMER, E. H. Congenital aneurismal dilatation of the aorta associated with arachnodactyly. Bull. Johns Hopkins Hosp., v. 72, p. 309-31, 1943.

BEIGHTON, P.; DE PAEPE, A.; DANKS, D.; FINIDORI, G.; GEDDEDAHI, T.; GOODMAN, R.; HALL, J. G.; HOLLISTER, D. W.; HORTON, W.; MCKUSICK, V. A.; OPITZ, J. M.; POPE, F. M.; PYERITZ, R. E.; RIMOIN, D. L.; SILLENCE, D.; SPRANGER, J. W.; THOMPSON, E.; TSIPOURAS, P.; VILJOEN, D.; WINSHIP, I.; e YOUNG, I. International nosology of heritable disorders of connective tissue, Berlin, 1986. Am. J. Med. Genet., v. 29, p. 581, 1988.

BEIGHTON, P.; MCKUSICK'S. Heritable Disorders Connective Tissue. $5^{\text {th }}$. Ed. St. Louis: Mosby, 1993.

BIERY, N. J.; ELDADAH, Z. A.; MOORE, C. S.; STETTEN, G.; SPENCER, F.; DIETZ, H. C. Revised genomic organization of FBN1 and significance for regulated gene expression. Genomics, v. 56, p 70-77, 1999.

BOILEAU, C.; ALEXANDRE, J. A.; HARITI, G.; BABRON, M. C.; COULON, M.; SALVAT, C.; JONDEAU, G.; BOURDARIAS, J. P.; BONAITI-PELLIE, C.; JUNIEN, C. Evidence for genetic heterogeneity in Marfan syndrome. Cytogenet. Cell Genet., v. 58, 1991.

BONYADI, M.; RUSHOLME, S. A.; COUSINS, F. M.; SU H. C.; BIRON, C. A.; FARRALL, M.; AKHURST, R. J. Mapping of a major genetic modifier of embryonic lethality in TGF beta 1 knockout mice. Nat. Genet., v. 15, n. 2, p. 207-11, 1997.

CHEN, S.; FAGAN, L. F.; NOURI, S.; DONAHOE, J. L. Ventricular dysrhythmias in children with Marfan's syndrome. Am. J. Dis. Child., v. 139, n. 3, p. 273-6, 1985.

\footnotetext{
*De acordo com:

ASSOCIAÇÃO BRASILEIRA DE NORMAS TÉCNICAS. NBR 6023: Informação e documentação: referências:

elaboração. Rio de Janeiro, 2002.
} 
COLLOD, G.; BABRON, M. C.; JONDEAU, G.; COULON, M.; WEISSENBACH, J.; DUBOURG, O.; BOURDARIAS, J.-P.; BONAITI-PELLIE, C.; JUNIEN, C.; BOILEAU, C. A second locus for Marfan syndrome maps to chromosome 3p24.2-p25. Nat. Genet., v. 8, 264-268, 1994.

COLLOD-BÉROUD, G.; BÉROUD, C.; ADÈS, L.; BLACK, C.; BOXER, M.; BROCK, D. J. H.; HOLMAN, K. J.; DE PAEPE, A.; FRANCKE, U.; GRAU, U.; HAYWARD, C.; KLEIN, H.G.; LIU, W.; NUYTINCK, L.; PELTONEN, L.; PEREZ, A. B. A.; RANTAMÄKI, T.; JUNIEN, C.; BOILEAU, C. Marfan database (third edition): New mutations and new routines for the software. Nucleic. Acids. Res., v. 26, p. 229, 1998.

COMEGLIO, P.; EVANS, A. L.; BRICE, G.; COOLING, R. J.; CHILD, A. H. Identification of FBN1 gene mutations in patients with ectopia lentis and marfanoid habitus. Br. J. Ophthalmol., v. 86, p. $1359-1362,2002$.

COMEGLIO, P.; JOHNSON. P. P.; ARNO, G.; BRICE, G.; EVANS, A.; ARAGONMARTIN, J.; DA SILVA, F. P.; KIOTSEKOGLOU, A.; CHILD, A. The importance of mutation detection in Marfan syndrome and Marfan-related disorders: Report of 193 FBN1 mutations. Hum. Mutat., 28:928, 2007.

CORDENONSI, M.; DUPONT, S.; MARETTO, S.; INSINGA, A.; IMBRIANO, C.; PICCOLO, S. Links between tumor suppressors: p53 is required for TGF-beta gene responses by cooperating with Smads. Cell, v. 113, n. 3, p. 301-14, 2003.

COTTINGHAM, R. W. JR.; IDURY R. M, SCHAFFER A. A. Faster sequential genetic linkage computations. Am. J. Hum. Genet., v. 53, p. 252-63, 1993.

CLEARY, E. G., e M. A. GIBSON. Elastin-associated microfibrils and microfibrillar proteins. Int. Rev. Connect. Tissue Res., v. 10, p. 97-209, 1983.

DEAN. J. C. Marfan syndrome: clinical diagnosis and management. J. Hum. Genet., v. 15, n. 7, p. 724-733, 2007.

DEMETRACOPOULOS, C. A.; SPONSELlER, P. D. Spinal deformities in Marfan syndrome. Orthop. Clin. North. Am., v. 38, n. 4, p. 563-572 VII, 2007.

DE PAEPE, A.; DEVEREAUX, R. B.; DIETZ, H. C.; HENNEKAM, R. C. M.; PYERITZ, R. E. Revised criteria for the Marfan syndrome. Am. J. Med. Genet., v. 62, p. 417, 1996.

DEAN, J. C. Eur Marfan syndrome: clinical diagnosis and management. J. Hum. Genet., v. 15, n. 7, p. 724-733, 2007.

DIJKE, P.; ARTHUR, H. M. Extracellular control of TGF signaling in vascular development and disease. Nat. Rev. Mol. Cell Biol., p. 1-13, 2007

DIETZ, H. C.; CUTTING, G. R.; PYERITZ, R. E. Defects in the fibrillin gene cause the Marfan syndrome; linkage evidence and identification of a missense mutation. Nature, $\mathrm{v}$. 352, p. 37-39, 1991. 
DIETZ, H. C e PYERITZ R. E. Mutations in the gene for fibrillin-1 (FBN-1) in the Marfan syndrome and related disorders. Hum. Mol. Genet., v. 4, p. 1799, 1995.

DISABELLA, E.; GRASSO, M.; MARZILIANO, N.; ANSALDI. S.; LUCCHELLI, C.; PORCU, E.; TAGLIANI, M.; PILOTTO, A.; DIEGOLI, M.; LANZARINI, L.; MALATTIA, C.; PELLICCIA, A.; FICCADENTI, A.; GABRIELLI, O.; ARBUSTINI, E. Two novel and one known mutation of the TGFBR2 gene in Marfan syndrome not associated with FBN1 gene defects. Eur. J. Hum. Genet., v. 14, n. 1, p. 34-38, 2006.

DWYER, E. M, JR.; TRONCALE, F. Spontaneous pneumothorax and pulmonary disease in the marfan syndrome. report of two cases and review of the literature. Ann. Intern. Med., v. 62, p. 1285-92, 1965.

EL HABBAL, M. H. Cardiovascular manifestations of Marfan's syndrome in the young. Am. Heart J., v. 123, n. 3, p. 752-757, 1992.

ETTER, L. E.; GLOVER, L. P. Arachnodac tyly complicated by dislocated lens and death from rupture of dissecting aneurysm of aorta. JAMA, v. 123, p. 88-89, 1943.

FAIVRE, L.; COLLOD-BEROUD, G.; LOEYS B. L.; CHILD, A.; BINQUET, C.; GAUTIER E.; CALLEWAERT, B.; ARBUSTINI E.; MAYER, K.; ARSLAN-KIRCHNER, M.; KIOTSEKOGLOU, A.; COMEGLIO, P.; MARZILIANO, N.; DIETZ, H. C.; HALLIDAY, D.; BEROUD, C.; BONITHON-KOPP, C.; CLAUSTRES, M.; MUTI, C.; PLAUCHU, H.; ROBINSON, P. N.; ADÈS, L. C.; BIGGIN, A.; BENETTS, B.; BRETT, M.; HOLMAN, K. J.; DE BACKER, J.; COUCKE, P.; FRANCKE, U.; DE PAEPE, A.; JONDEAU, G.; BOILEAU, C. Effect of mutation type and location on clinical outcome in 1,013 probands with Marfan syndrome or related phenotypes and FBN1 mutations: an international study. Am. J. Hum. Genet., v. 81, n. 3, p. 454-66, 2007.

FAIVRE, L.; COLLOD-BEROUD, G.; CHILD, A.; CALLEWAERT, B.; LOEYS, B. L.; BINQUET, C.; GAUTIER, E.; ARBUSTINI, E.; MAYER, K.; ARSLAN-KIRCHNER, M.; STHENEUR, A.; KIOTSEKOGLOU, C.; COMEGLIO, P.; MARZILIANO, D.; HALLIDAY, N.; BEROUD, C.; BONITHON-KOPP, C.; CLAUSTRES, M.; PLAUCHU, H.; ROBINSON, P. N.; ADE`S, L.; DE BACKER, J.; COUCKE, P.; FRANCKE, U.; DE PAEPE A.; BOILEAU, C.; JONDEAU. G. Contribution of molecular analyses in diagnosing. Marfan syndrome and type I fibrillinopathies: an international study of 1009 probands. J. Med. Genet., v. 45, p. 384-390, 2008.

FRANZEN, P.; TEN DIJKE, P.; ICHIJO, H.; YAMASHITA, H.; SCHULZ, P.; HELDIN, C.H.; MIYAZONO, K. Cloning of a TGF-beta type I receptor that forms a heteromeric complex with the TGF-beta type II receptor. Cell, v. 75, p. 681-692, 1993.

FREDERICKSON, R. G.; LOW, F. N. The fine structures of perinotochoradal microfibrils in control and enzyme-treated chick embryos. Am. J. Anat., v. 130, p. 347-376, 1971.

GEVA, T.; HEGESH, J.; FRAND, M. The clinical course and echocardiographic features of Marfan's syndrome in childhood. Am. J. Dis. Child., v. 141, n. 11, p. 1179-1182, 1987. 
GEVA, T.; SANDERS, S. P.; DIOGENES, M. S.; ROCKENMACHER, S.; VAN PRAAGH, R. Two-dimensional and Doppler echocardiographic and pathologic characteristics of the infantile Marfan syndrome. Am. J. Cardiol., v. 65, n. 18, p. 1230-1237, 1990.

HABERMANN, C. R.; WEISS, F.; SCHODER, V.; CRAMER, M. C.; KEMPER, J.; WITTKUGEL, O.; ADAM G. MR evaluation of dural ectasy in Marfan syndrome: reassessment of the established criteria in children, adolescents, and young adults. Radiology, v. 234, p. 535-541, 2005.

HALL J. R.; PYERITZ, R. E.; DUDGEON, D. L.; HALLER, J. A. JR. Pneumothorax in the Marfan syndrome: prevalence and therapy. Ann. Thorac. Surg., v. 37, n. 6, p. 500-504, 1984.

HAY, E. D. Fine structure of embryonic matrices and their relation to the cell surface in ruthenium red-fixed tissues. Growth, v. 42, p. 399-423, 1978.

HAYWARD, C.; PORTEOUS, M. E.; BROCK, D. J. Identification of a novel nonsense mutation in the fibrillin gene (FBN1) using nonisotopic techniques. Hum. Mutat., v. 3, n. 2, p. 159-162, 1994.

HECHT, F.; BEALS, R. K. "New" syndrome of congenital contractural arachnodactyly originally described by Marfan in 1896. Pediatrics, v. 49, n. 4, p. 574-579, 1972.

HOLBROOK, K. A., AND P. H. BYERS. Structural abnormalities in dermal collagen and elastic matrix from the skin of patients with inherited connective tissue disorders. J. Invest. Dermatol., v. 79, p. 7s-16s, 1982.

HOLLISTER, D. W.; GODFREY, M.; SAKAI, L. Y.; PYERITZ, R. E. Immunohistologic abnormalities of the microfibrillar-fiber system in the Marfan syndrome. N. Engl. J. Med., v. 323, p. 152-159, 1990.

HUTCHINSON, S.; FURGER, A.; HALLIDAY, D.; JUDGE, D. P.; JEFFERSON, A.; DIETZ, H. C.; FIRTH, H.; HANDFORD, P. A. Allelic variation in normal human FBN1 expression in a family with Marfan syndrome: a potential modifier of phenotype? Hum. Mol. Genet., v. 12, n. 18, p. 2269-2276, 2003.

JOHNSON, D. W.; QUMSIYEH, M.; BENKHALIFA, M.; MARCHUK, D. A. Assignment of human transforming growth factor-beta type I and type III receptor genes (TGFBR1 and TGFBR3) to 9q33-q34 and 1p32-p33, respectively. Genomics, v. 28, p. 356-357, 1995.

JONES, K. B.; MYERS, L.; JUDGE, D. P.; KIRBY, P. A.; DIETZ, H. C.; SPONSELLER, P. D. Toward an understanding of dural ectasia: a light microscopy study in a Murine model of Marfan syndrome. Spine, v. 30, p. 291-293, 2005.

JUDGE, D. P.; BIERY, N. J.; DIETZ, H. C. Characterization of Microsatellite Markers Flanking FBN1: Utility in the Diagnostic Evaluation for Marfan Syndrome. Am. J. Med. Genet., v. 99, p39 $\pm 47,2001$.

JUDGE, D. P.; DIETZ, H. C. Marfan’s syndrome. Lancet, v. 366, p. 1965-76, 2005. 
KAINULAIEN, K.; SAVOLAINEN, A.; PALOTIE, E. A.; KAITILA, I.; ROSENBLOOM, J.; PELTONEN, L. Marfan syndrome: exclusion of genetic linkage to five genes coding for connective tissue components on the long arm of chromosome 2. Hum. Genet., v. 84, p. 233, 1990.

KANZAKI, T.; OLOFSSON, A.; MORÉN, A.; WERNSTEDT, C.; HELLMAN, U.; MIYAZONO, K.; CLAESSON-WELSH, L.; HELDIN, C. H. TGF-beta 1 binding protein: a component of the large latent complex of TGF-beta 1 with multiple repeat sequences. Cell, v. 61, n. 6, p. 1051-1061, 1990.

KNIRSCH, W.; KURTZ, C.; HAFFNER, N.; LANGER, M.; KECECIOGLU, D. Normal values of the sagittal diameter of the lumbar spine (vertebral body and dural sac) in children measured by MRI. Pediatr. Radiol., v. 35, p. 419-424, 2005.

LEE B, GODFREY, M.; VITALE, E.; HORI, H.; MATTEI, M. G.; SARFARAZI, M.; TSIPOURAS, P.; RAMIREZ, F.; HOLLISTER, D. W. Linkage of Marfan syndrome and a phenotypically related disorder to two different fibrillin genes. Nature, v. 352, p. 330, 1991.

LEE, N. C.; HWANG, B.; CHEN, C. H.; NIU, D. M. Intrafamilial phenotype variation in Marfan syndrome ascertained by intragenic linkage analysis. J. Formos. Med. Assoc., v. 104, p. 964-967, 2005.

LLEDÓ, B. TEN, J.; GALÁN, F. M.; BERNABEU, R. Preimplantation genetic diagnosis of Marfan syndrome using multiple displacement amplification._Fertil. Steril,, v. 86, n. 4, p. 949-55, 2006.

LOEYS, B.; DE BACKER, J.; VAN ACKER, P.; WETTINCK, K.; PALS, G.; NUYTINCK L.; COUCKE, P.; DE PAEPE, A. Comprrehensive mlecular screening of the FBN1 gene favors locus homogeneity of classical Marfan syndrome. Hum. Mut., v. 24, p. 140, 2004.

LOEYS, B. L.; CHEN, J.; NEPTUNE, E. R.; JUDGE, D. P.; PODOWSKI, M.; HOLRN, T.; MEYERS, J.; LEITCH, C. C.; KATSANIS, N.; SHARIFI, N.; XU, F. L.; NYERS, L. A.; SPEVAK, P. J.; CAMERON, D. E.; DE BACKER, J.; HELLEMANS, J.; CHEN, Y.; DAVIS, E. C.; WEBB, C. L.; KRESS, W.; COUCKE, P.; RIFKIN, D. B.; DE PAEPE, A. M.; DIETZ, H. C. A syndrome of altered cardiovascular, craniofacial, netrocognitive and skeletal development caused by mutations in TGFBR1 or TGFBR2. Nat. Genet., v. 37, p. 275-281, 2005 .

LOEYS, B. L., SCHWARZE U, H. T.; CALLEWAERT, B. L.; THOMAS, G. H.; PANNU, H.; DE BACKER, J. F.; OSWALD, G. L.; SYMOENS, S.; MANOUVRIER S. Aneurysm syndromes caused by mutations in the TGF- $\beta$ receptor. N. Engl. J. Med., v. 355, p. 788-798, 2006.

LOPEZ, V. M. O.; PEREZ, A. B. A.; MOISÉS, V. A; GOMES, L; PEDREIRA, P. S. D.; SILVA, C. M.; CAMPOS, F. O.; CARVALHO, A. C. Avaliação clinico-cardiológica ecocardiográfica, seqüencial, em crianças portadoras de síndrome de Marfan. Arq. Bras. Cardiol., v. 85, p. 314-318, 2005.

LOW, F. N. The extracellular portion oftbe human blood-air barrier and its relation to tissue space. Anat. Rec., v. 139, p. 105-123, 1961. 
LOW, F. N. Microfibrils: fine filamentous components of the tissue space. Anat. Rec., v. 142, p. 131-137, 1962.

MALESZEWSKI, J. J.; MILlER, D. V.; LU, J.; DIETZ, H. C.; HALUSHKA, M. K. Histopathologic findings in ascending aortas from individuals with Loeys-Dietz syndrome (LDS). Am. J. Surg. Pathol., v. 33, n. 2, p. 194-201, 2009.

MARFAN, A. B. Un cas de déformation congénitale des quatre membres plus prononcée aux extremites caractérisée par l'allongement des os avec un certain degré d'amincissesment.

Bull. Mem. Soc. Med. Hop., Paris, v. 13, p. 220-226, 1896.

MASLEN, C. L.; CORSON, G. M.; MADDOX, B. K.; GLANVILLE, R. W.; SAKAI, L. Y. Partial sequence of a candidate gene for the Marfan syndrome. Nature, v. 352, n. 6333, p. :334-347, 1991.

MATHEW, S.; MURTY, V. V.; CHEIFETZ, S.; GEORGE, D.; MASSAGUÉ, J.; CHAGANTI, R. S. Transforming growth factor receptor gene TGFBR2 maps to human chromosome band 3p22._Genomics, v. 20, n. 1, p. 114-115, 1994.

MÁTYÁS, G; ARNOLD, E; CARREL, T; BAUMGARTNER, D; BOILEAU, C; BERGER, W; STEINMANN, B Identification and In Silico analysis of novel TGFBR1 e TGFBR2 mutations in Marfan syndrome-related disorders. Hum. Mut., v. 27, p. 760-69, 2006.

MÁTYÁS, G.; ALONSO, S.; PATRIGNANI, A.; MARTI, M.; ARNOLD, E.; MAGYAR, I.; HENGGELER, C.; CARREL, T. Steinmann B.; Berger W. Large genomic Wbrillin-1 (FBN1) gene deletions provide evidence for true haploinsuYciency in Marfan syndrome. Hum. Genet., v. 122, p. 23-32, 2007.

MAUMENEE, I. H. The eye in the Marfan syndrome. Trans. Am. Ophthalmol. Soc., v. 79, p. 684-733, 1981.

MCGOOKEY, D. J.; SMITH, A. C. M.; WALDSTEIN, G.; BYERS, P. H. Mosaicisim for a deletion in one of the type III collagen alleles indicates that the deletion occurred after identification of cells for recruitment to different cell lineages early in human development Am. J. Hum. Genet., v. 45, p. 809, 1989.

MCKUSICK, V. A. The cardiovascular aspects of Marfan's syndrome: a heritable disorder of connective tissue. Circulation, v. 11, n. 3, p. 321-42, 1955.

MCKUSICK, V. A. Heritable disorders of connective tissue. The Marfan syndrome. J. Chronic. Dis., v. 2, n. 6, p. 609-644, 1956.

MCKUSICK, V. A. The defect in Marfan syndrome. Nature, v. 352, p. 279-281, 1991.

MILLER, S. A.; DYKES, D. D.; POLESKY, H. F. A simple salting out procedure for extracting DNA from human nucleated cells. Nucleics Acids Research, v. 16, n. 3, p. 1215, 1988. 
MILEWICZ, D. M.; PYENTZ, E. R.; CRAWFORD, E. S.; BYERS, H. P. Marfan syndrome: Defective Synthesis, Secretion, and Extracellular Matrix Formation of Fibrillin by Cultured Dermal Fibroblasts. J. Clin. Invest., v. 89, p. 79-86, 1992.

MILEWICZ, D. M.; DUVIC, M. Severe neonatal Marfan syndrome resulting from a de novo 3-bp insertion into the fibrillin gene on chromosome 15. Am. J. Hum. Genet., v. 54, p. 44753. 1994.

MILEWICZ, D. M.; GROSSFIELD, J.; CAO, S. N. A mutation in FBN1 disrupts profibrillin processing and results in isolated skeletal features of the Marfan syndrome. J. Clin. Invest., v. 95, p. 2373-78, 1995.

MIZUGUCHI, T.; COLLOD-BEROUD, G.; AKIYAMA, T.; ABIFADEL, M.; HARADA, N.; MORISAKI, T.; ALLARD, D.; VARRET, M.; CLAUSTRES, M.; MORISAKI, H.; IHARA, M.; KINOSHITA, A.; YOSHIURA, K.; JUNIEN, C.; KAJII, T.; JONDEAU, G.; OHTA, T.; KISHINO, T.; FURUKAWA, Y.; NAKAMURA, Y.; NIIKAWA, N.; BOILEAU, C.; MATSUMOTO N. Heterozigous TGFBR2 mutations in Marfan syndrome. Nat. Genet., v. 36, p. 855, 2004.

MOTTES, M.; MIRANDOLA, S.; RIGATELLI, F.; ZOLEZZI, F.; LISI, V.; GORDON, D.; PIGNATTI, P. F. Allelic frequencies of FBN1 Gene polymorphisms and genetic analysis of Italian families with Marfan syndrome. Hum. Hered., v. 50, p. 175-179, 2000.

NIJBROEK, G.; SOOD, S.; MCLNTOSH, I.; FRANCOMANO, C. A; BULL, E.; PEREIRA, L.; RAMIREZ, F.; PYERITZ, R. E.; DIETZ, H. C. Fifteen novel FBN1 mutations causing Marfan syndrome detected by heteroduplex analysis of genomic amplicons. Am. J. Hum. Genet., v. 1995, p. 57:8-21, 1995

MURDOCH, J. L.; WALTER, B. A.; HALPEN, B. L. Lite expectancy and cuses of death in the Marfan syndrome. N. Engl. J. Med., v. 286, p. 804-808, 1972.

OOSTERHOF, T.; GROENINK, M.; HULSMANS, F. J.; MULDER, B. J. M.; VAN DER, W. E.; SMIT, R.; HENNEKAM, R. C. M. Quantitative assessment of dural ectasia as a marker of Marfan syndrome. Radiology, v. 220, p. 514-518, 2001.

OWENS, G. K.; BACHHUBER, B. G.; SAREMBOCK, I. J.; GIMPLE, L. W. alphaThrombin induces transforming growth factor-beta1 mRNA and protein in cultured vascular smooth muscle cells via a proteolytically activated receptor. J. Vasc. Res., v. 34, n. 1, p. 41-8, 1997.

PAGON, R. A. Gene Reviews. Seattle (WA): University of Washington, 2008.

PALZ, M.; TIECKE, F.; BOOMS, P.; GOLDNER, B.; ROSENBERG, T.; FUCHS, J. Clustering of mutations associated with mild Marfan-like phenotypes 1 the 3 region of FBN1 suggests a potential genotype - phenotype correlation. Am. J. Med. Genet., v. 91, p. 212$221,2000$.

PEREIRA, L.; D'ALESSIO, M.; RAMIREZ, F.; LYNCH, J. R.; SYKES, B.; PANGILINAN, T.; BONADIO, J. Genomic organization of the sequence coding for fibrillin, the defective gene product in Marfan syndrome. Hum. Molec. Genet., v. 2, p. 961-968, 1993. 
PEREIRA, L.; LEVRAN, O.; RAMIREZ, F.; LYNCH, J. F.; SIKES, B.; PYERITZ, R. E.; DIETZ, H. C. A molecular approach to the stratification of cardiovascular risk in families with Marfan syndrome. New Engl. J. Med., v. 331, p. 148-153, 1994.

PEREIRA, L.; LEE, S. Y.; GAYRAUD, B.; ANDRIKOPOULOS, K.; SHAPIRO, S. D.; BUNTON, T.; BIERY, N. J.; DIETZ, H. C.; SAKAI, L. Y.; RAMIREZ, F. Pathogenetic sequence for aneurysm revealed in mice underexpressing fibrillin-1. Proc. Natl. Acad. Sci. U.S. A., v. 96, n. 7, p. 3819-23, 1999.

PHORNPHUTKUL, C.; ROSENTHAL, A.; NADAS, A. S. Cardiac manifestations of Marfan syndrome in infancy and childhood. Circulation, v. 47, n. 3, p. 587-96, 1973.

PYERITZ, R. E.; MCKUSICK V. A. The Marfan syndrome: diagnosis and management. N. Engl. J. Med., v. 300, n, 14, p. 772-777, 1979.

PYERITZ, R. E. The marfan syndrome. Am. Fam. Physician., v. 34, p. 83, 1986a.

PYERITZ, R.; FISHMAN, E. K.; BERNHARDT, B. A.; SIEGELMAN, S. S. Dural ectasia: a common pleiotropic feature of the Marfan's syndrome. Am. J. Hum. Genet., v. 39S, p. A75, $1986 \mathrm{~b}$.

PYERITZ, R. E. Marfan syndrome. In: EMERY,A.E.H. \& RIMOIN,D.L. Principles and Practice of Medical Genetics. 2nd ed. New York: Churchill Livingstone, 1990. p. 10471063.

PYERITZ, R. e FRANCKE, U. The Second International Symposium on the Marfan Syndrome. Am. J. Med. Genet., v. 47, n. 1, p. 127-135, 1993.

RANTAMAKI, T.; LONNQVIST, L.; KARTTUNEN L. DNA diagnostics of the Marfan syndrome: applifiable polymorphic markers. Eur. J. Hum. Genet., v. 2, p. 66-75, 1994.

RAMIREZ, F.; PEREIRA, L. Mutations of extracellular matrix components in vascular disease. Ann. Thorac. Surg., v. 67, n. 6, p. 1857-8, 1999.

ROBINSON, P. N.; BOOMS, P.; KATZKE, S.; LADEWIG, M.; NEUMANN, L.; PALZ, M.; PREGLA, R.; TIECKE, F.; ROSENBERG, T. Mutations of FBN1 and genotype-phenotype correlations in Marfan syndrome and related fibrillinopathies. Hum Mutat., v. 20, n. 3, p. 153-61, 2002.

ROBINSON, P. N.; ARTEAGA-SOLIS, E.; BALDOCK, C.; COLLOD-BEROUD, G.; BOOMS, P.; DE PAEPE, A.; DIETZ, H. C.; GUO, G.; HANDFORD, P. A.; JUDGE, D. P.; KIELTY, C. M.; LOEYS, B.; MILEWICZ, D. M.; NEY, A.; RAMIREZ, F.; REINHARDT, D. P.; TIEDEMANN, K.; WHITEMAN, P.; GODFREY, M. The molecular genetics of Marfan syndrome and related disorders. J. Med. Genet., v. 43, p. 769-787, 2006.

ROSE, P. S.; LEVY, H. P.; AHN, N. U.; SPONSELLER, P. D.; MAGYARI, T.; DAVIS, J.; FRANCOMANO, C. A. A comparison of the Berlin and Ghent nosologies and the influence of dural ectasia in the diagnosis of Marfan syndrome. Genet. Med., v. 2, n. 5, p. 278-82, 2000. 
ROSENBLOOM, J., ABRAMS, W.; MECHAM, R. Extracellular matrix 4: The elastic fiber. FASEB J., v. 7, p. 1208- 1218, 1993.

ROSS, R.; FIALKOW, P. J.; ALTMAN, L. K. The morphogenesis of elastic fibers. Adv. Exp. Biol. Med., v. 79, p. 7-17, 1977

SAKAI, L. Y.; KEENE, D. R. Engvall E. Fibrillin, a new 350-kD glycoprotein, is a component of extracellular microfibrils. J. Cell. Biol., v. 103, p. 2499, 1986.

SAKAI, L. Y. V. R.; IKEGAWA, S.; ITO, E.; NUMABE, H.; WATANABE, Y.; MIKAMI, H.; KONDOH, T.; KITOH, H.; SUGIYAMA, R.; OKAMOTO, N.; OGATA, T.; FODDE, R.; MIZUNO, S.; TAKAMURA, R.; EGASHIRA, M.; SASAKI, N.; WATANABE, S.; NISHIMAKI, S.; TAKADA, F.; OKADA, Y.; AOKA, Y.; YASUDA, K.; IWASA, M.; KOGAKI, S.; HARADA, S.; MIZUGUCHI, T.; MATSUMOTO, N. Cohompreensive genetic analysis of relevant four genes in 49 patients with Marfan syndrome or Marfan-related phenotypes. Am. J. Med. Genet., v. 140 A, p. 1719-25, 2006.

SARFARAZI, M.; TSIPOURAS, P.; DEL MASTRO, R.; KILPATRICK, M.; FARNDON, P.; BOXER, M.; BRIDGES, A.; BOILEAU, C.; JUNIEN, C.; HAYWARD, C. A linkage map of 10 loci flanking the Marfan syndrome locus on 15q: results of an International Consortium study._J. Med. Genet., v. 29, n. 2, p. 75-80, 1992.

SAYERS, C. P.; GOLTZ, R. W.; MOTTAZ, J. Pulmonary elastic tissue in generalized elastolysis (cutis laxa) and Marfan's syndrome. A light and electron microscopic study. J. Invest. Dermatol., v. 65, p. 451-457, 1975.

SCHRIJVER, I.; LUI, W.; ODOM, R.; BRENN, T.; OEFNER, P.; FURTHMAYR, H.; FRACKE, U. Premature termination mutations in FBN1 distinct effects on differential allelic expresion and on protein and clinical phenotypes. Am. J. Hum. Genet., v. 71 p.223-237, 2002.

SISK, H. E.; ZAHKA, K. G.; PYERITZ, R. E. The Marfan syndrome in early childhood: analysis of 15 patients diagnosed at less than 4 years of age. Am. J. Cardiol., v. 52, p. 35358, 1983.

SINGH, K. K.; ELLIGSEN, D.; LIERSCH, R.; SHUBERT, S.; PABST, B.; KIRCHNER, M. A.; SCHMIDTKE, J. Mult-exon out frame deletion of the FBN1 gene leading to a severe juvenile onset cardiovascular phenotype in Marfan syndrome. Hum. Mut., v. 27, p. 770-777, $2006 a$.

SINGH, K. K.; ROMMEL, K.; MISHRA, A.; KARCK, M.; HAVERICH, A.; SCHMIDTKE, J.; ARSLAN-KIRCHNER, M. TGFBR1 and TGFBR2 mutations I patients with features of Marfan syndrome and Loeys-Dietz syndrome. Hum. Mut., v. 27, p. 770-77, 2006a.

SINGH, K. K.; SHUKLA, P. C.; SCHMIDTKE, J. Conservation of 5'-upstream region of the FBN1 gene in primates._Eur. J. Hum. Genet., v. 16, n. 7, p. 869-72, 2008. 
SPITS, C.; DE RYCKE, M.; VERPOEST, W.; LISSENS, W.; VAN STEIRTEGHEM, A.; LIEBAERS, I.; SERMON, K. Preimplantation genetic diagnosis for Marfan syndrome. Fertil. Steril., v. 86, n. 2, p. 310-20, 2006.

SUMMERS, K. M.; WEST, J. A.; PETERSON, M. M.; STARK, D.; MCGILL, J. J.; WEST, M. J. Challenges in the diagnosis of Marfan syndrome. MJA, v. 184, n. 12, p. 627-631, 2006.

STHENEUR, C.; COLLOD-BÉROUD, G.; FAIVRE, L.; GOUYA, L.; SULTAN, G.; LE PARC, J. M.; MOURA, B.; ATTIAS, D.; MUTI, C.; SZNAJDER, M.; CLAUSTRES, M.; JUNIEN C.; BAUMANN, C.; CORMIER-DAIRE, V.; RIO, M.; LYONNET, S.; PLAUCHU, H.; LACOMBE, D.; CHEVALLIER, B.; JONDEAU, G.; BOILEAU, C. Identification of 23 TGFBR2 and 6 TGFBR1 gene mutations and genotype-phenotype investigations in 457 patients with Marfan syndrome type I and II, Loeys-Dietz syndrome and related disorders. Hum. Mutat., v. 1031, n. 29, p. E284-E295, 2008.

STRACHAN, T.; READ, A. P. Human Molecular Genetics 2. New York: Garland Science, 1999.

TAKENOSHITA, S.; HAGIWARA, K.; NAGASHIMA, M.; GEMMA, A.; BENNETT, W. P.; HARRIS C. C. The genomic structure of the gene encoding the human transforming growth factor beta type II receptor (TGF-beta RII). Genomics, v. 36, n. 2, p. 341-4, 1996.

TEN DIJKE, P.; ARTHUR, H. M. Extracellular control of TGFbeta signalling in vascular development and disease. Nat. Rev. Mol. Cell. Biol., v. 8, n. 11, p. 857-69, 2007.

TSIPOURAS, P.; SARFARAZI, M.; DEVI, A.; WEIFFENBACH, B.; BOXER, M. Marfan syndrome is closely linked to a marker on chromosome 15q1.5-q2.1. Proc. Natl. Acad. Sci. U.S. A., v. 88, n. 10, p. 4486-8, 1991.

TSIPOURAS, P.; DEL MASTRO, R.; SARFARAZI, M. Genetic linkage of the Marfan syndrome, ectopia lentis, and congenital contractual arachnodactyly to the fibrillin genes on chromosomes 15 and 5. N. Engl. J. Med., v. 326 p. 905-9, 1992.

TURNER, C. L. S.; EMERY, H.; COLLINS, A. L.; HOWARTH, R. J.; YEARWOOD, C. M.; CROSS, E.; DUNCAN, P. J.; BUNYAN, D. J.; HARVEY, J. F.; FOULDS, N. C. Detection of 53 FBN1 Mutations (41 Novel and 12 Recurrent) and Genotype-Phenotype Correlations in 113 Unrelated Probands Referred With Marfan Syndrome, or a Related Fibrillinopathy. Am. J. Med. Genet. A., v. 149A, p.161-170, 2009.

TYNAN, K.; COMEAU, K.; PERSON, M.; WILGENBUS, P.; LETT, D.; GASNER, C.; BERG, M. A.; MILLER, D. C.; FRANCKE U. Mutation screening of complete fibrillin-1 coding sequence: report of five new mutations, including two in 8-cysteine domains. Hum. Mol. Genet., v. 2, p.1813-1821, 1993

UITO, J. Biochemistry of the Elastic Fibers in Normal Connective Tissues and its Alterations in Diseases. J. Invest. Dermatol., v. 72, p. 1-10, 1979.

VARADI, D. P. Studies on the chemistry and fine structure of elastic fibers from normal adult skin. J. Invest. Dermatol., v. 66, p. 59-79, 1976. 
VELLUCCI, V. F.; REISS, M. Cloning and genomic organization of the human transforming growth factor-beta type I receptor gene. Genomics, v. 46, n. 2, p. 278-83, 1997.

VALIEV, R. R.; KHUSAINOVA, R. I.; KUTUEV, I. A.; KHUSNUTDINOVA E. K. Analysis of the Fibrillin-1 Gene (FBN1) in Patients with Marfan Syndrome. Mol. Biol., v. 40, n. 6, p. 922-930, 2006.

WANG, M.; KISHNAMI, P. E.; DECKER-PHILLIPS, M. Double mutant fibrillin-1 (FBN1) allele in a patient with neonatal Marfan syndrome. J. Med. Genet., v. 33, p. 760-63, 1996.

WEVE, H. Uber Arachnodaktylie. (Dystrophia mesodermalis congenita, Typus Marfan). Arch. Augenheilkd., v. 104, p.1-46, 1931. 
ANEXO A

HEREDOGRAMAS DAS FAMILIAS ESTUDADAS COM MARCADORES DO GENE FBN1 (MTS-1, MTS-2, MTS-3 e MTS-4).

FAMÍLIA 01 NÃO SEGREGA
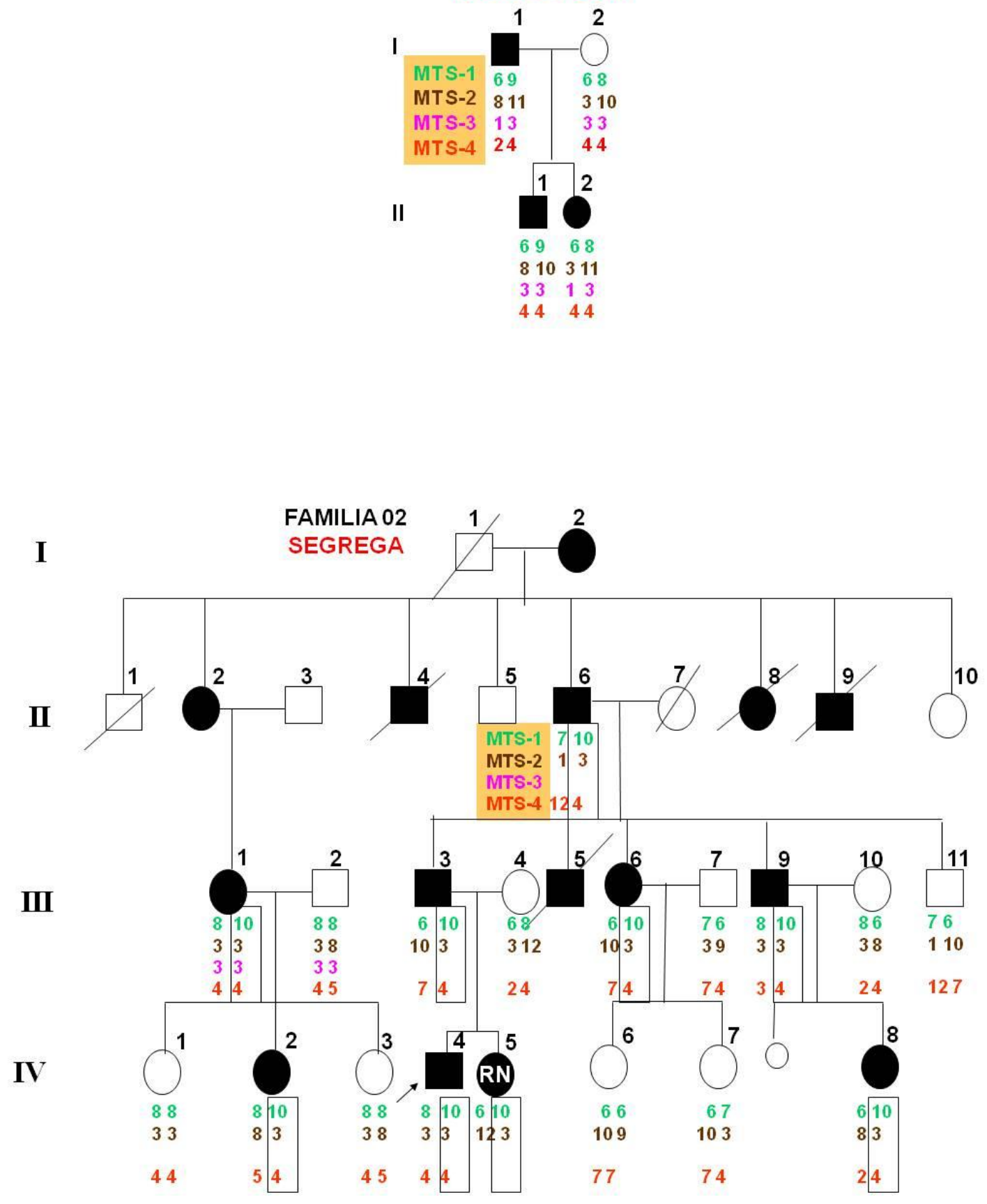


\section{FAMILIA 03}

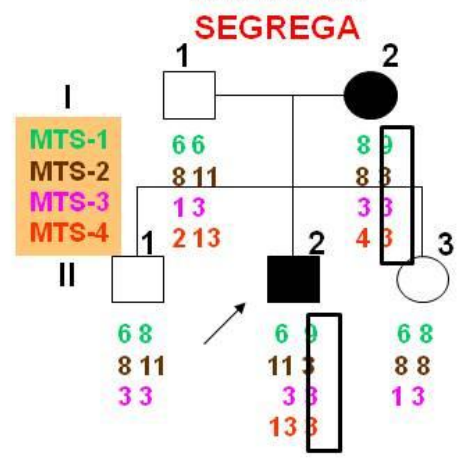

FAMILIA 04

NÄO SEGREGA

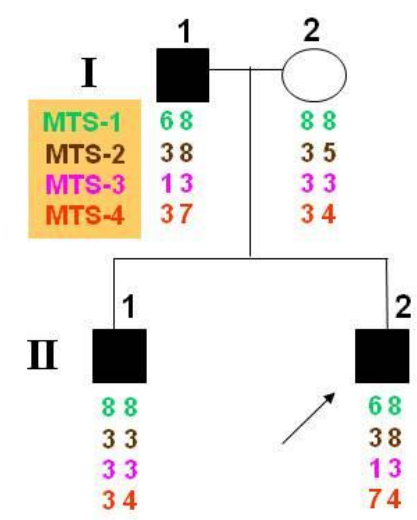



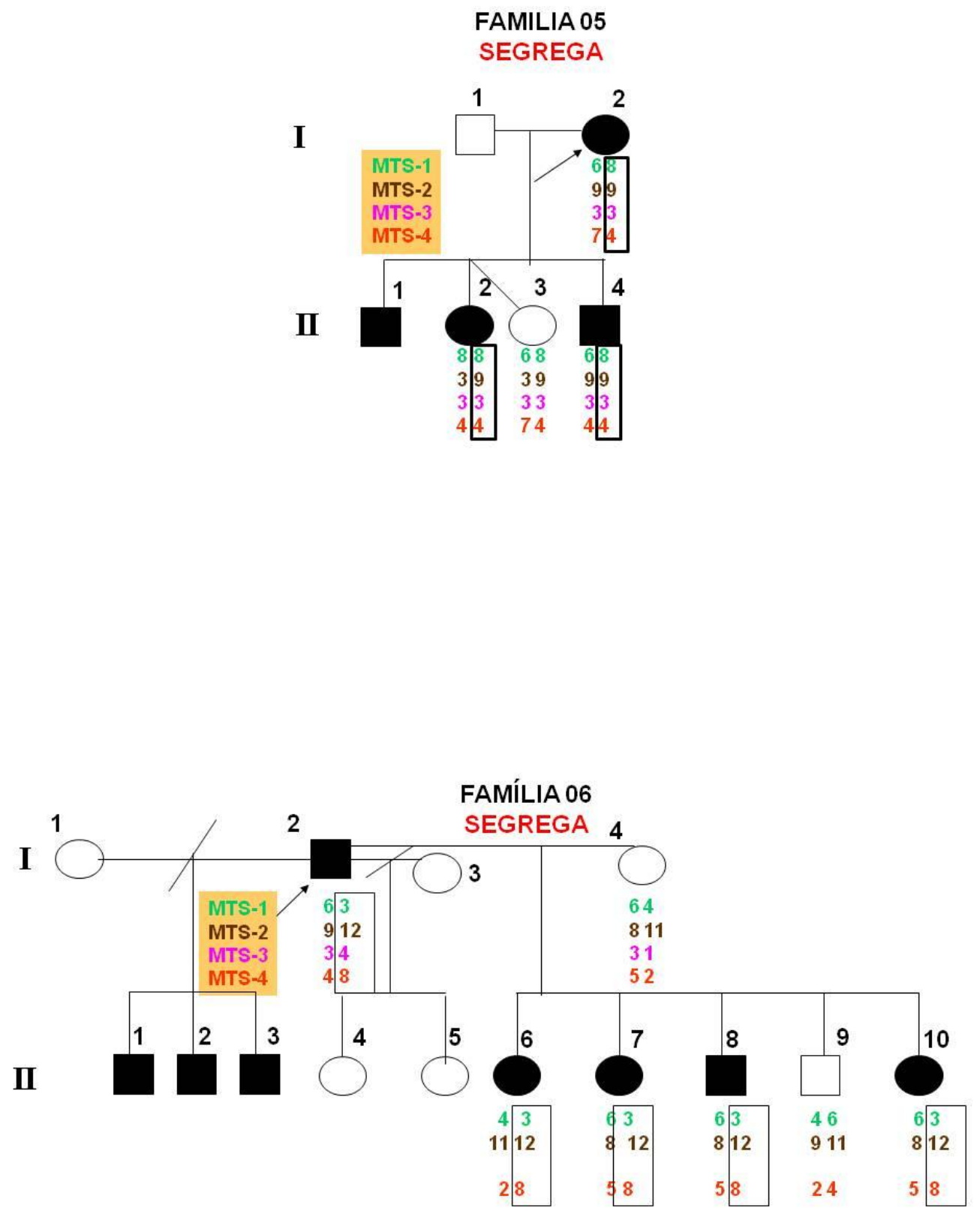

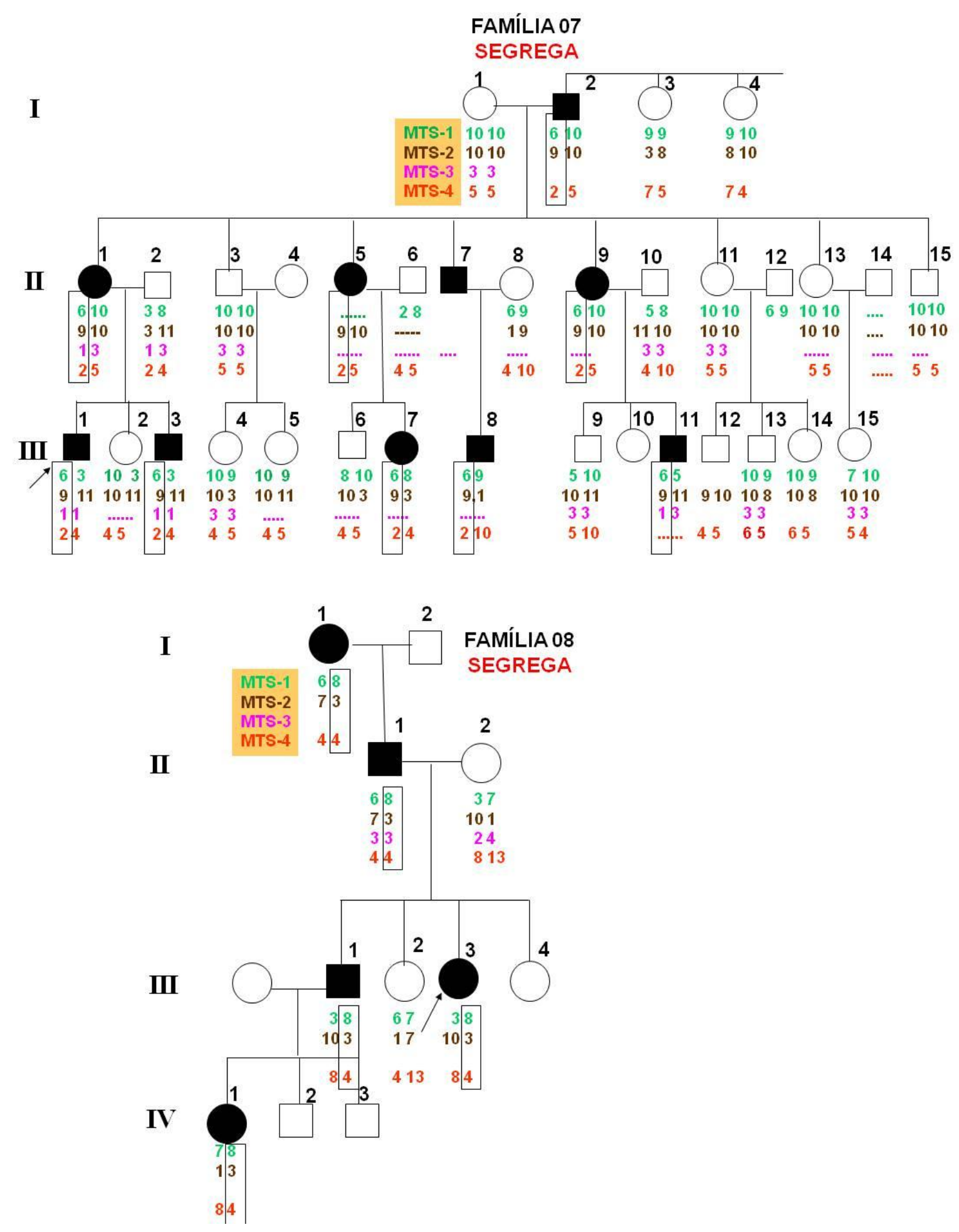


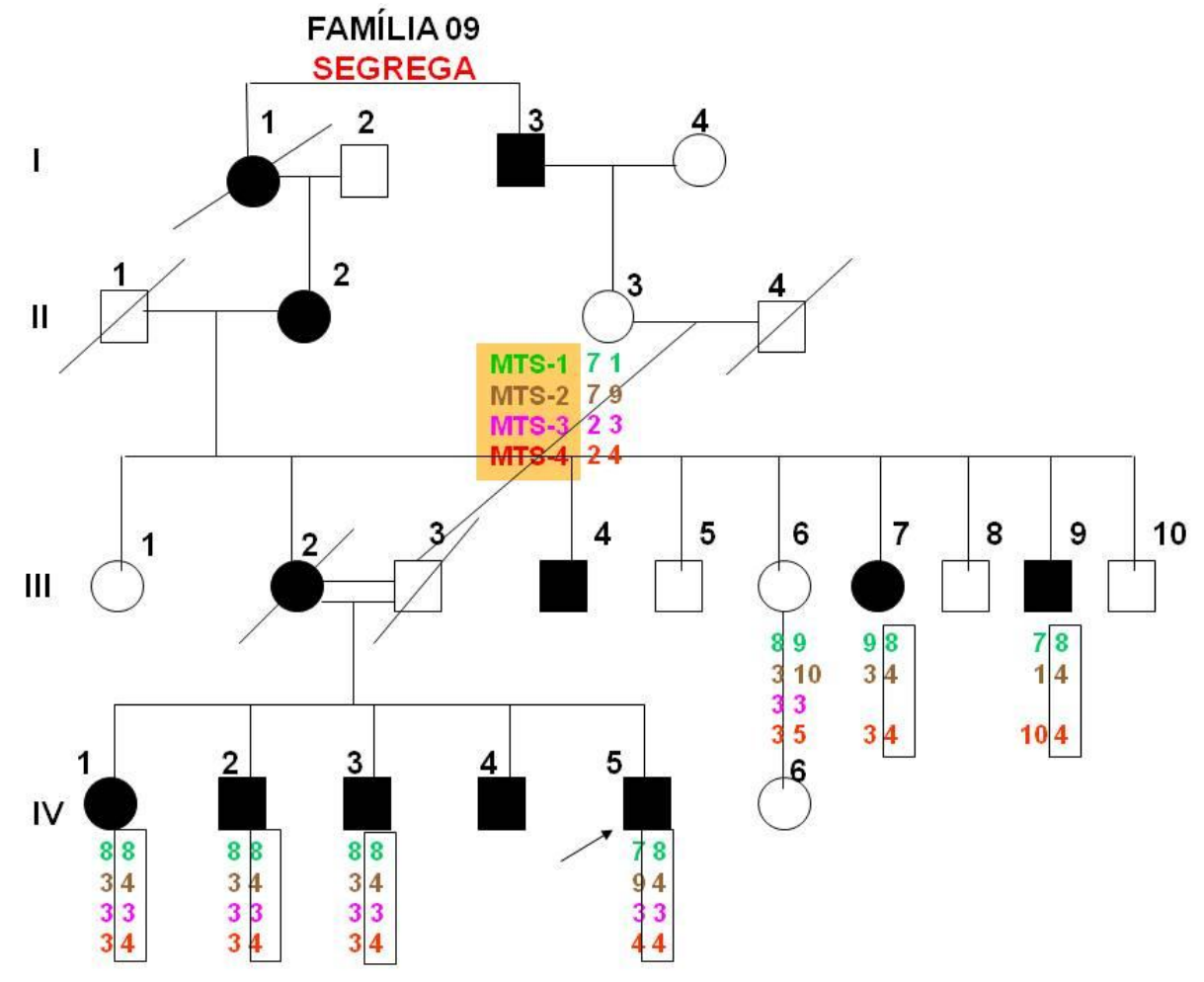

FAMÍLIA 10

INCONCLUSIVO

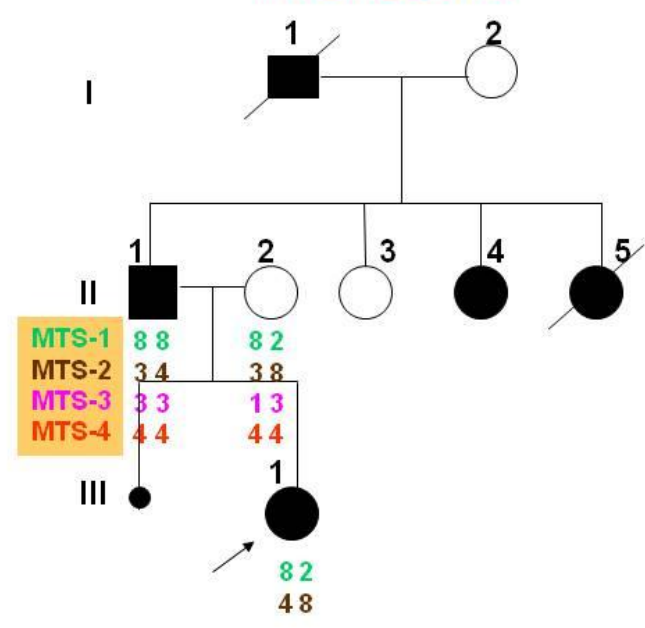

44 

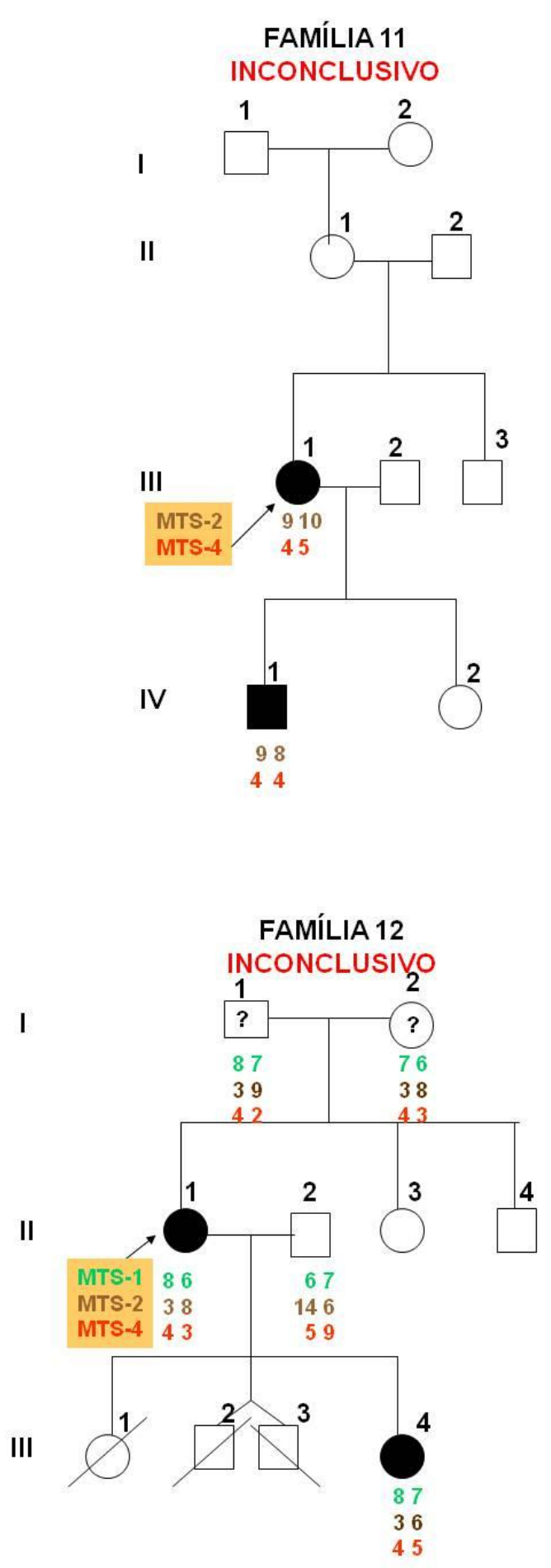


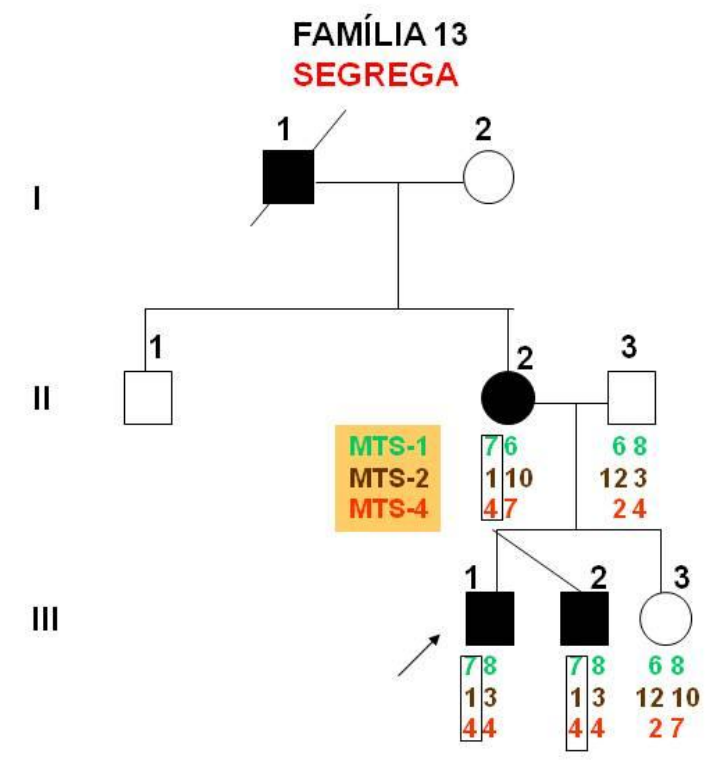

FAMÍLIA 14

SEGREGA

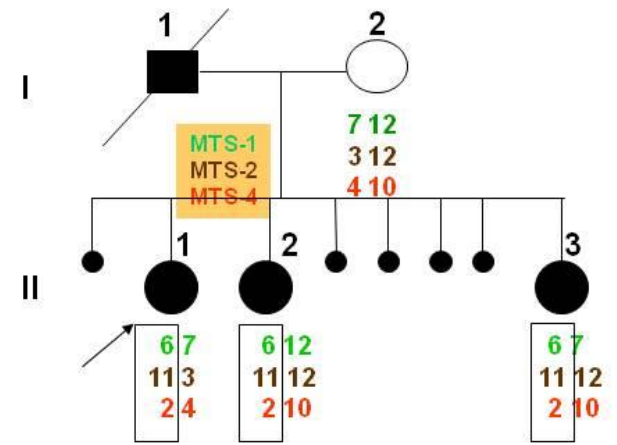




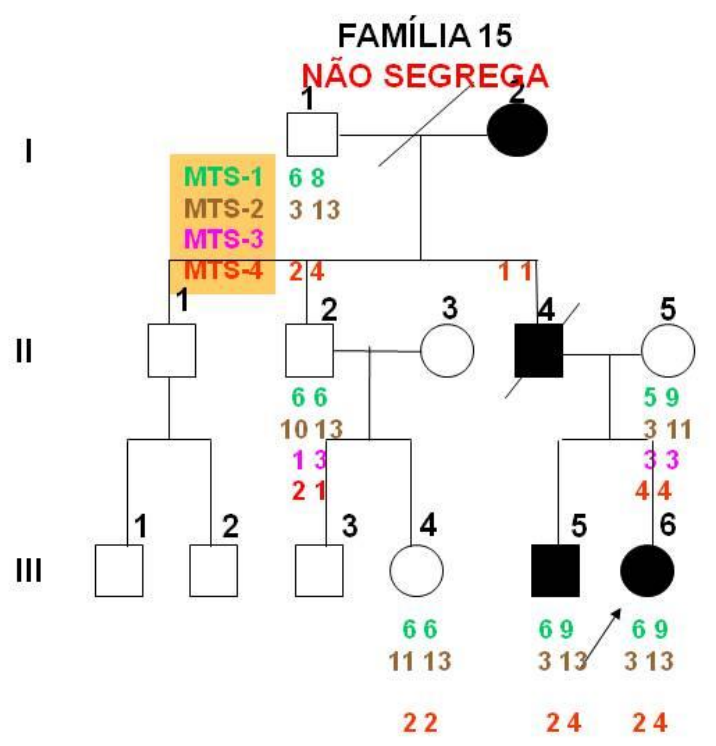

FAMÍLIA 16

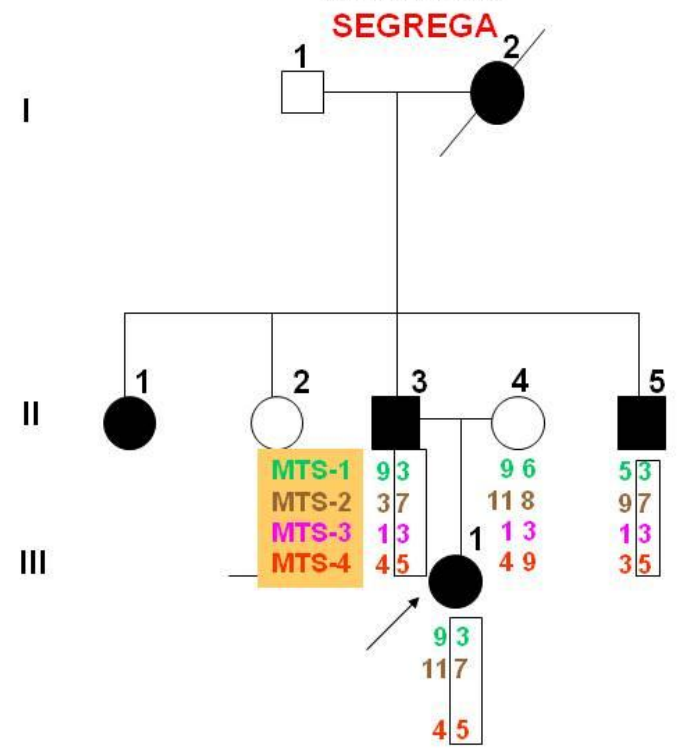




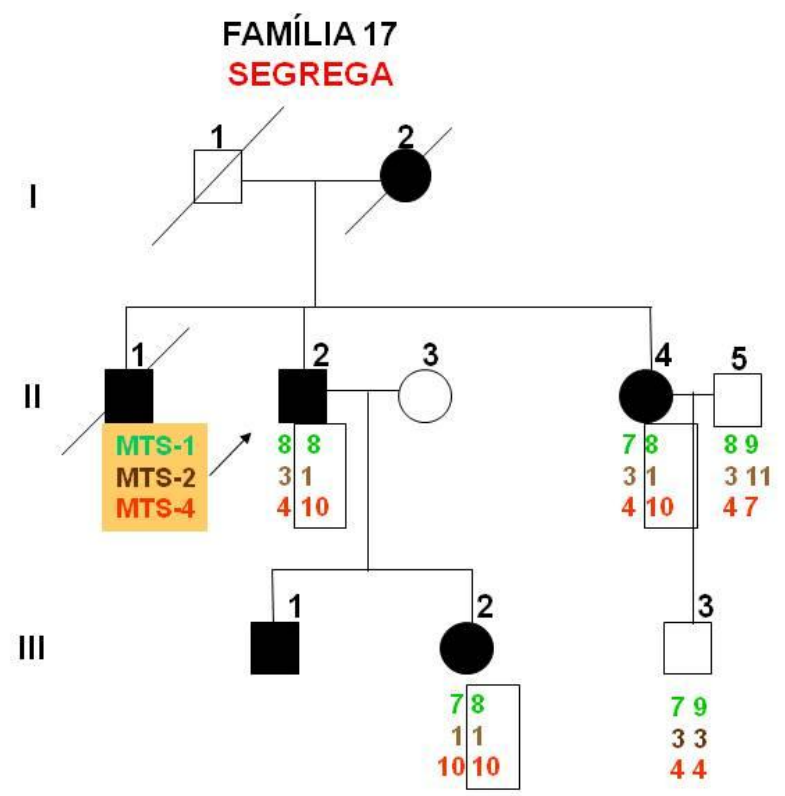

I

FAMÍLIA 18 NÃO INFORMATIVO

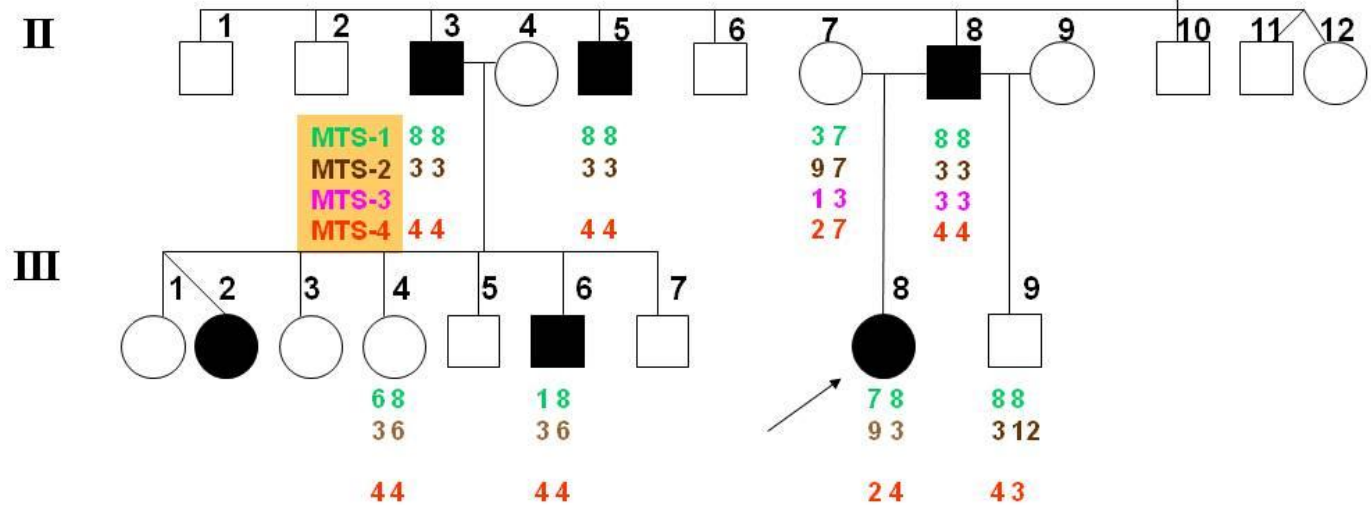




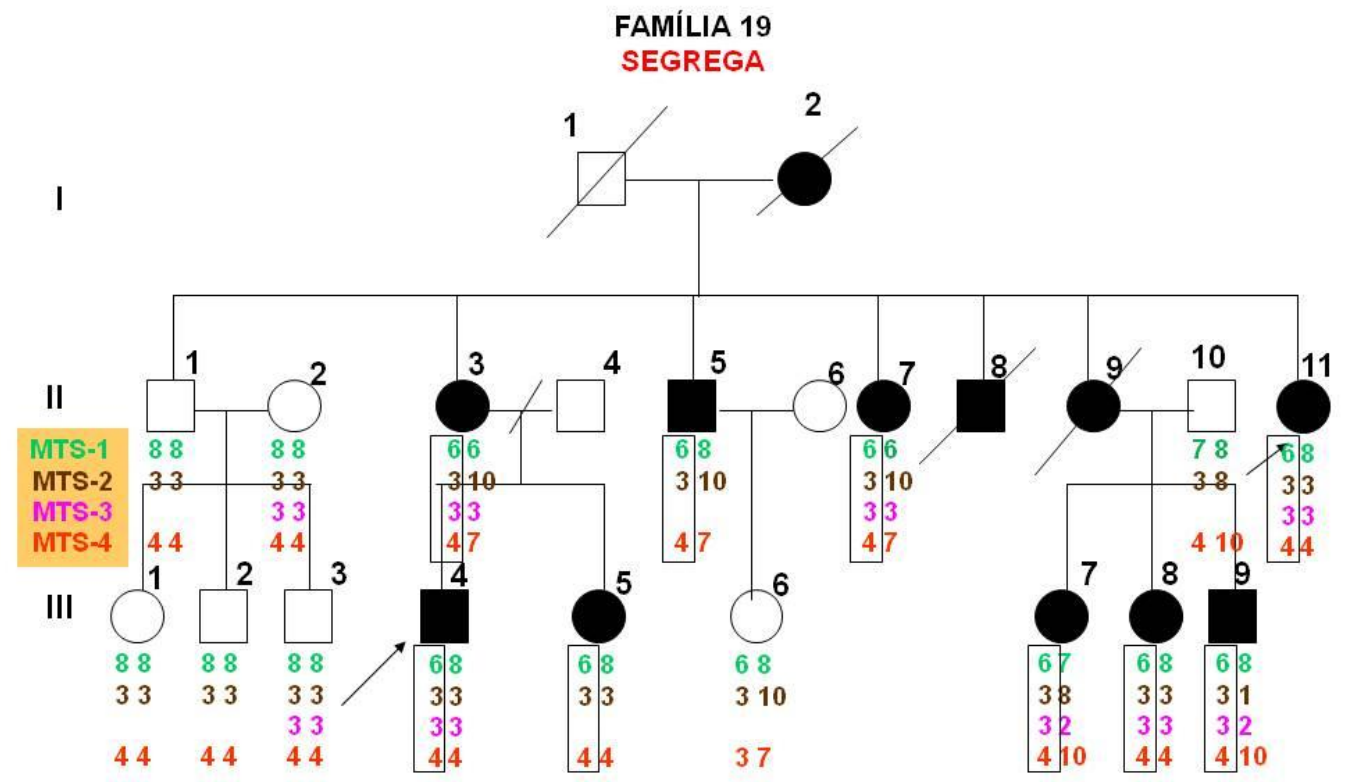

FAMÍLIA 20

SEGREGA

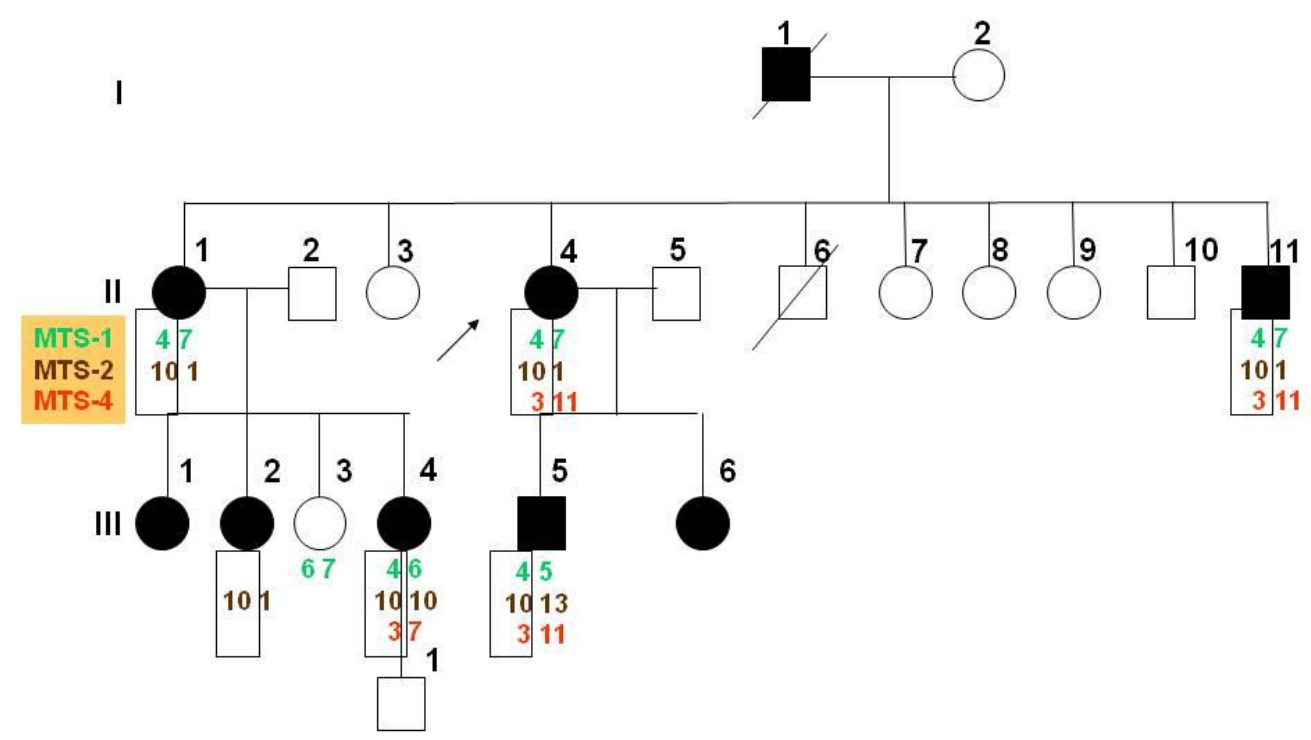


FAMÍLIA 21

INCONCLUSIVO

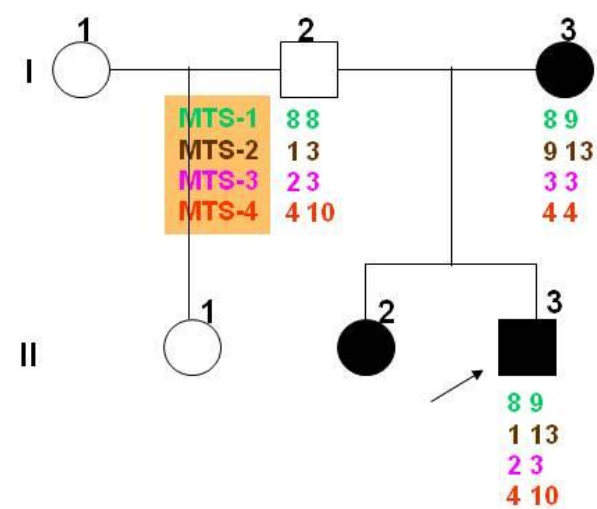

FAMÍLIA 22

SEGREGA

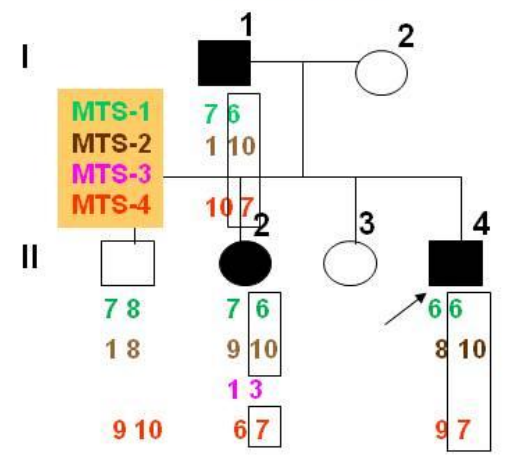


FAMÍLIA 23

SEGREGA
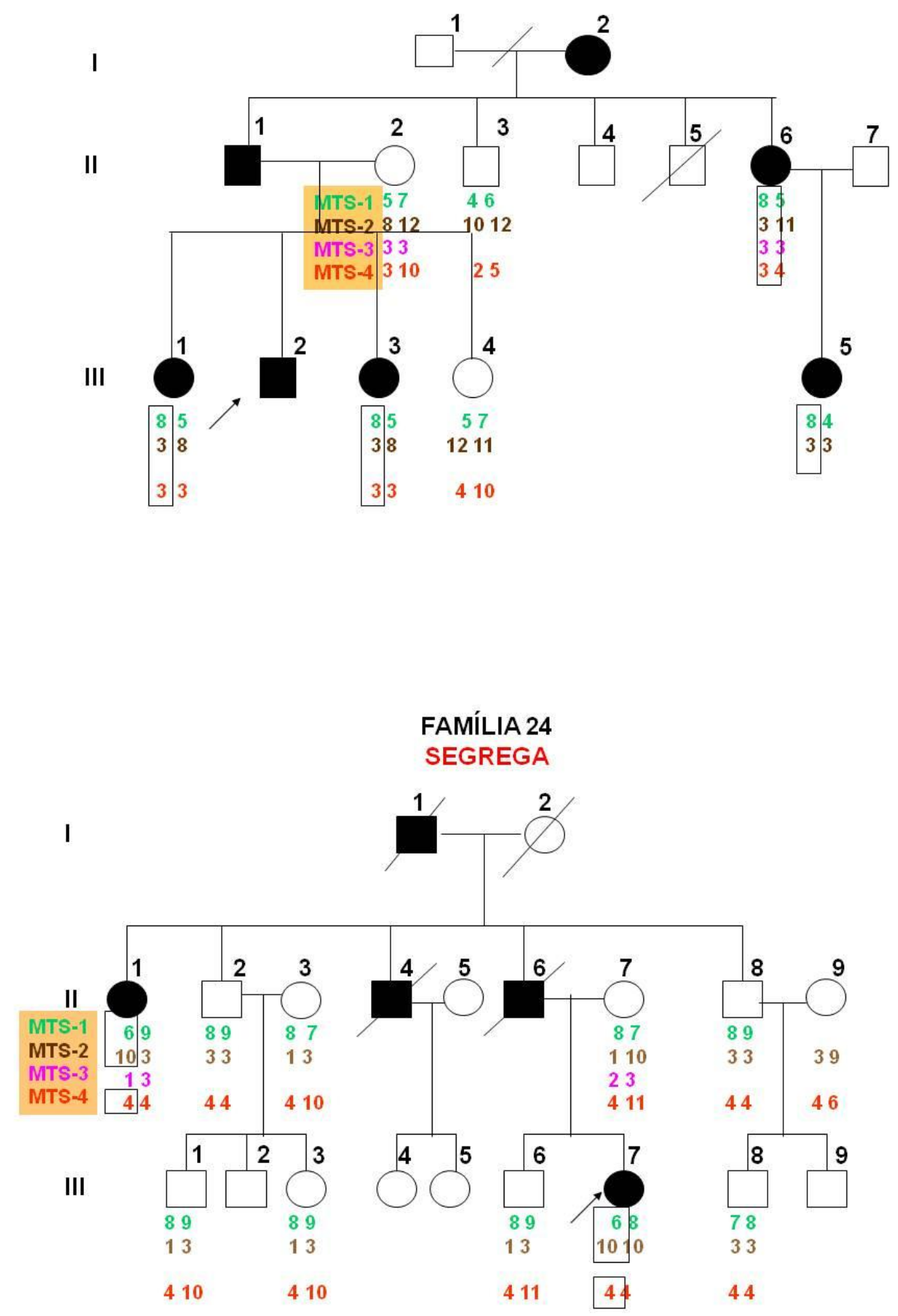

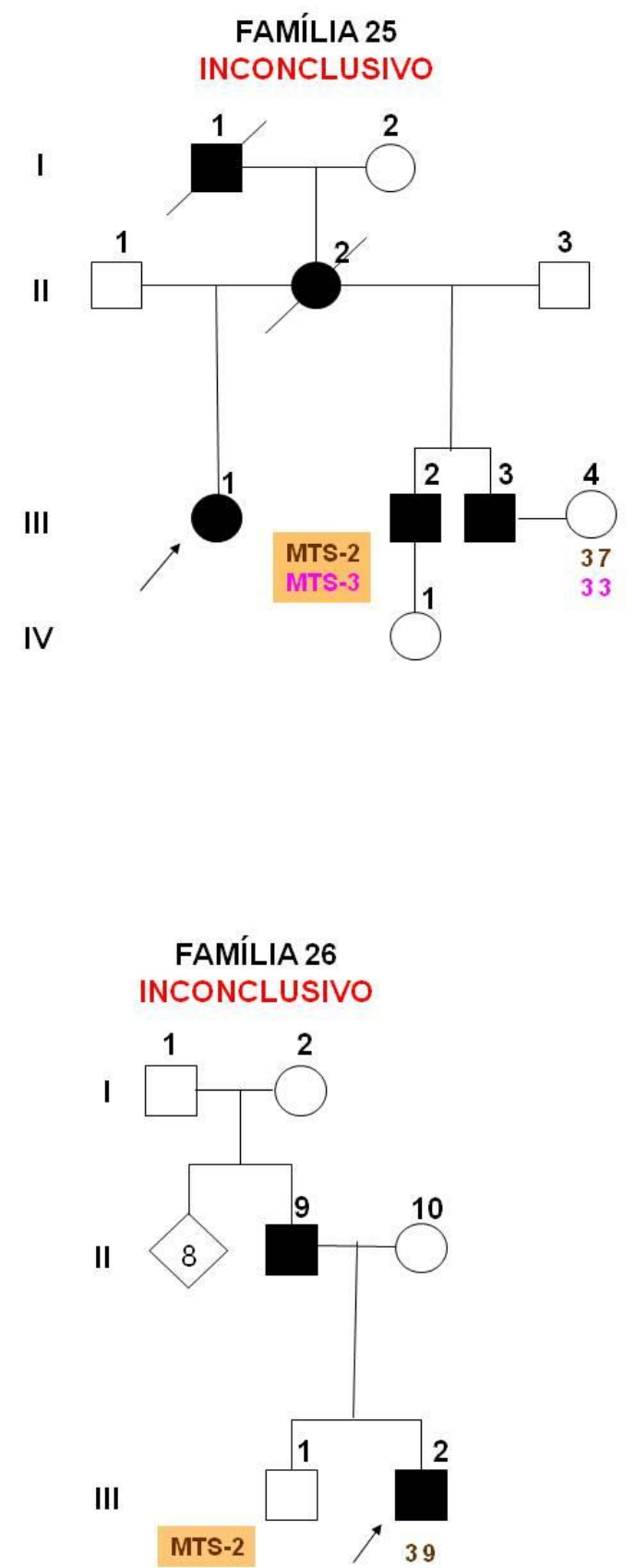
FAMÍLIA 27

INCONCLUSIVO

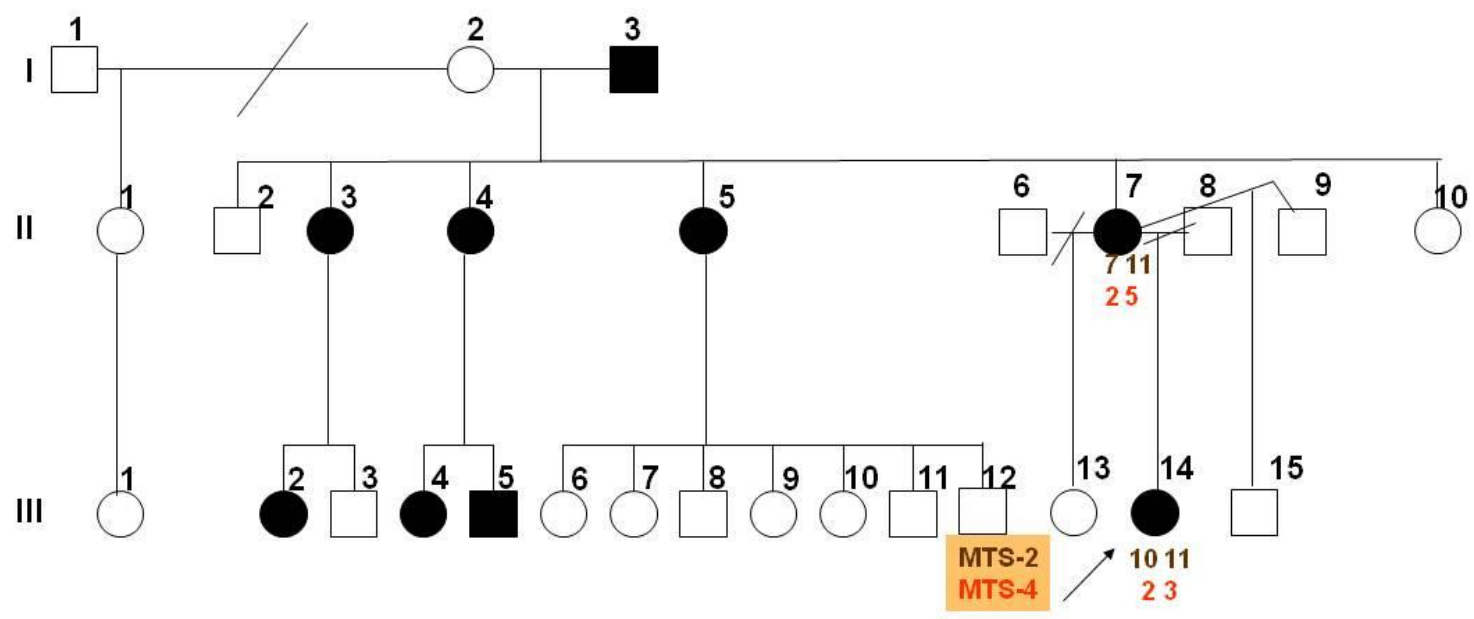

FAMÍLIA 28

SEGREGA

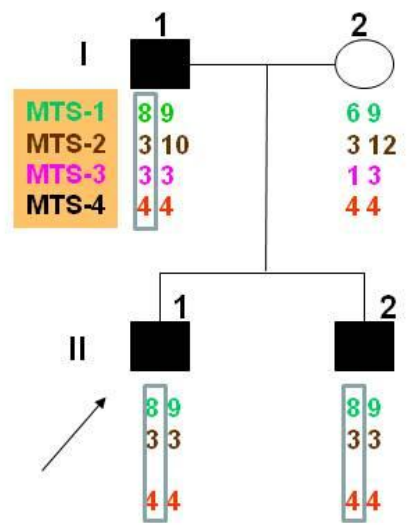




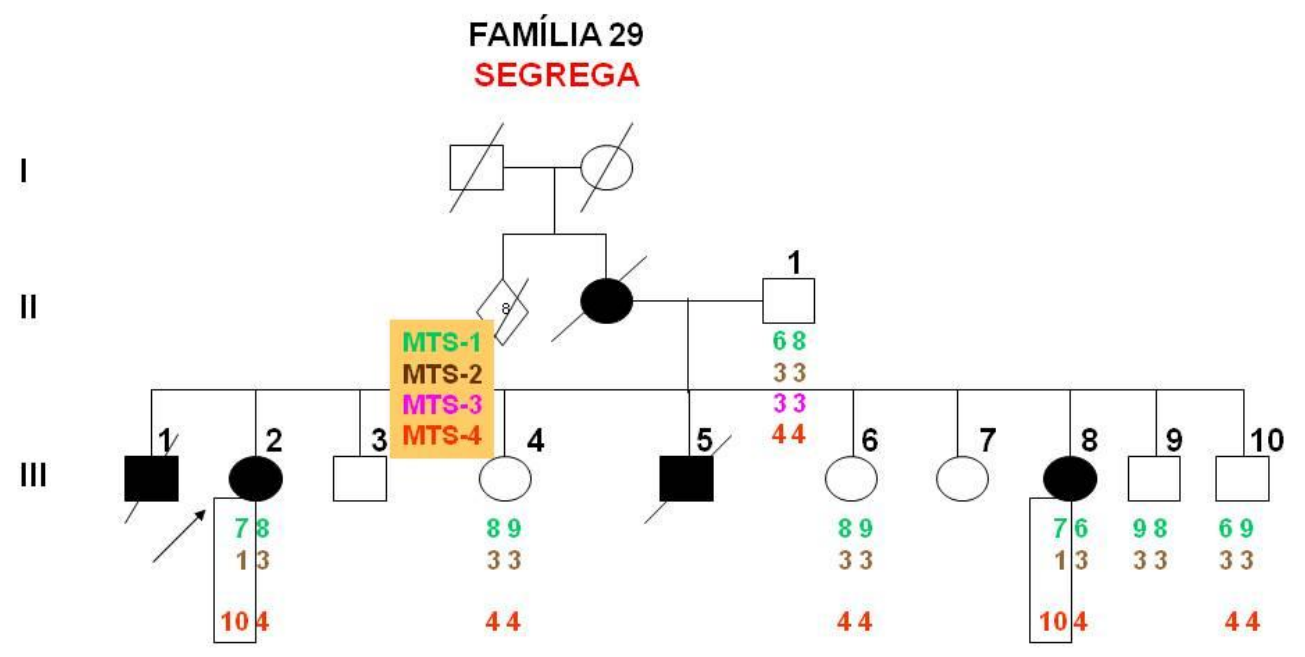

FAMÍLIA 30

SEGREGA

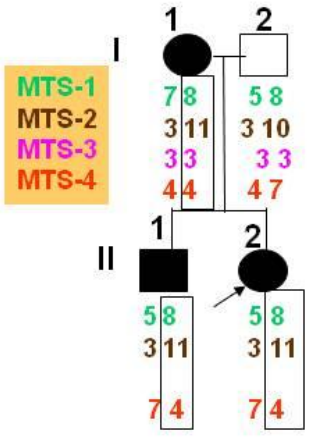



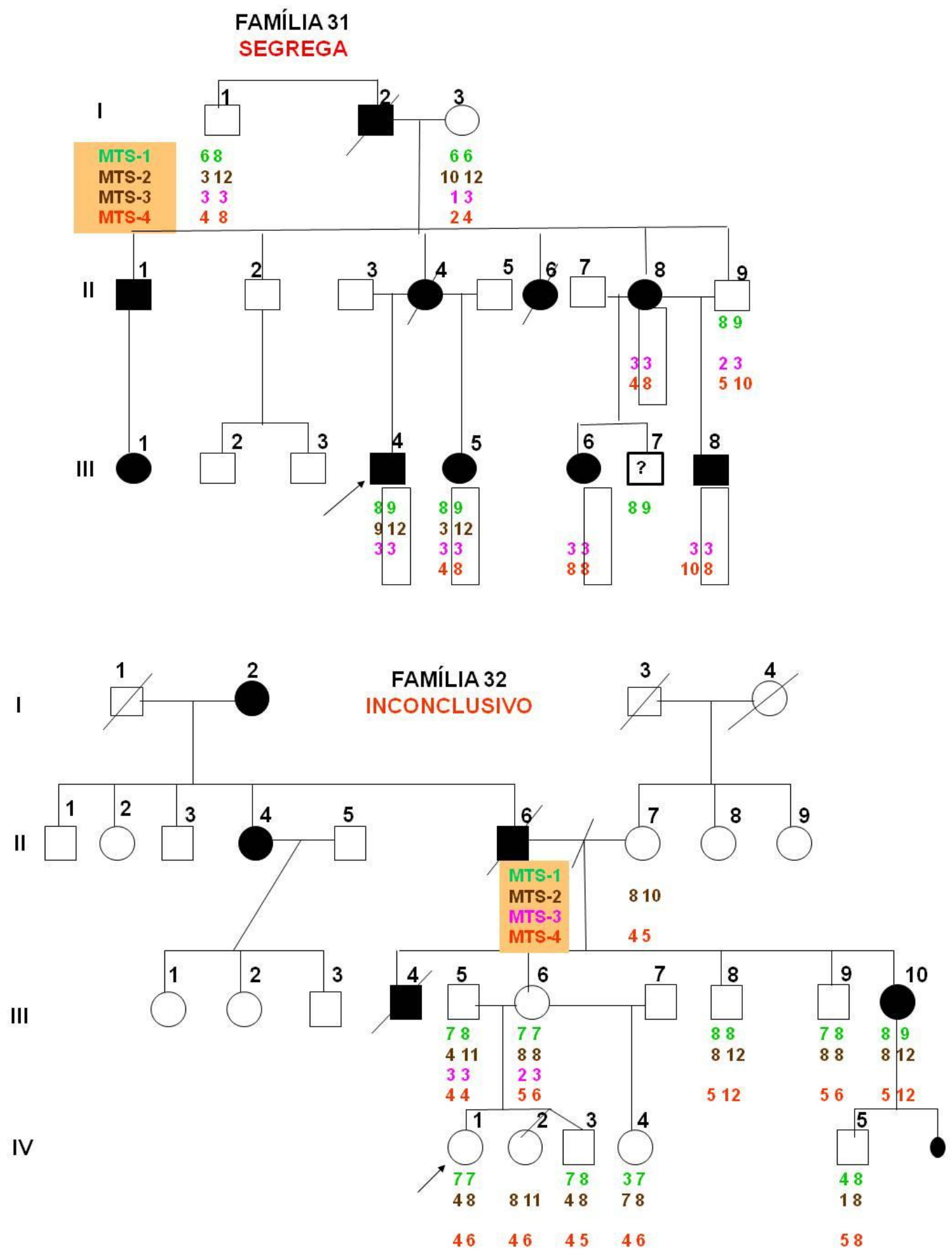
FAMÍLIA 33

SEGREGA

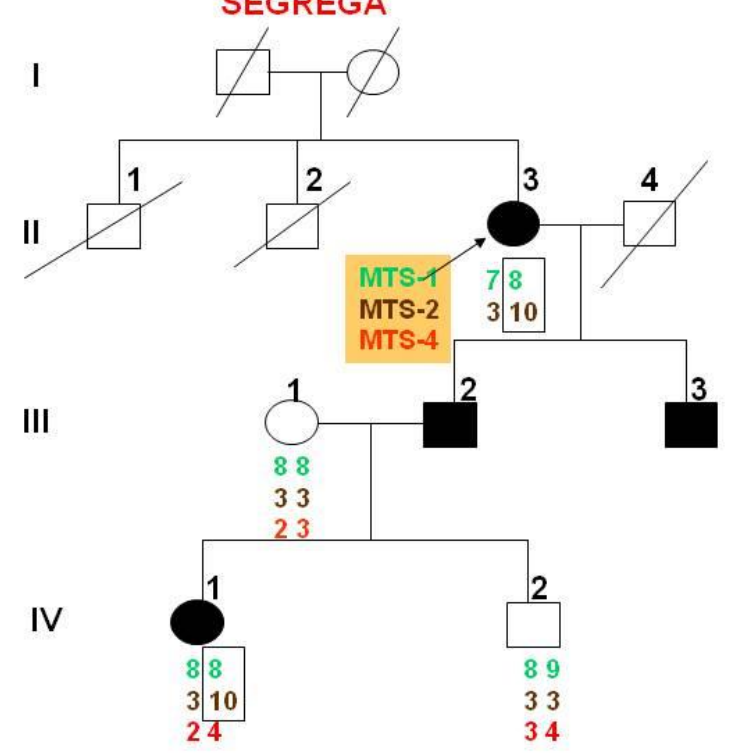

FAMÍLIA 34

SEGREGA

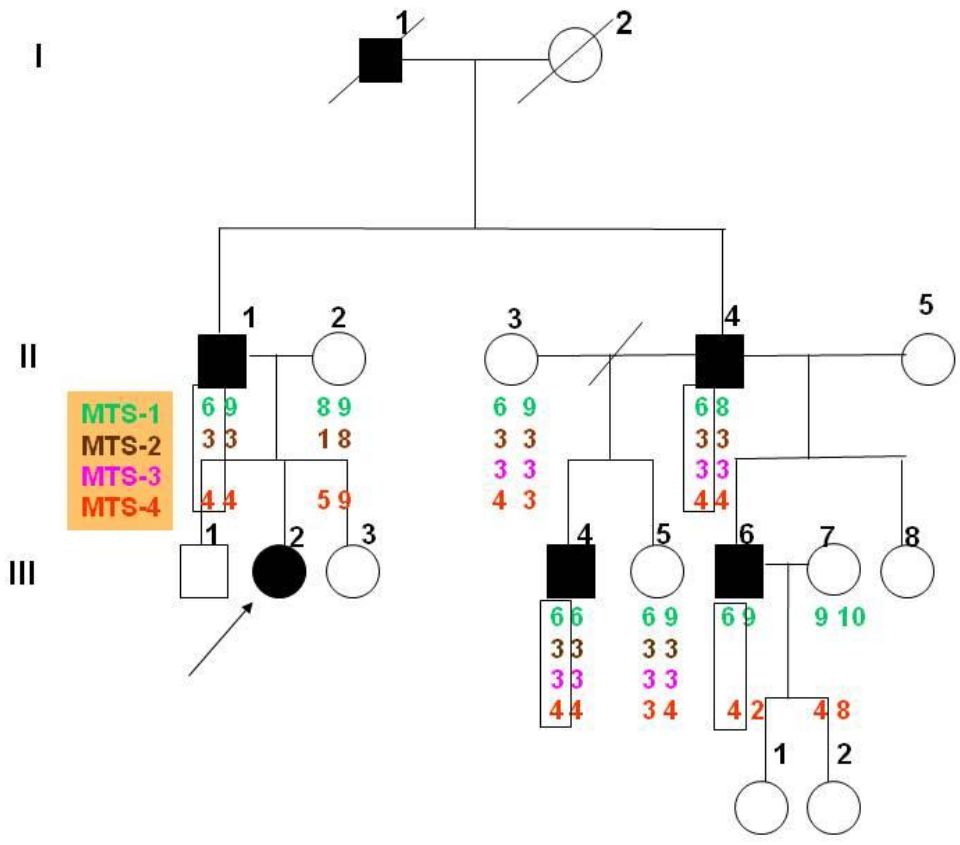




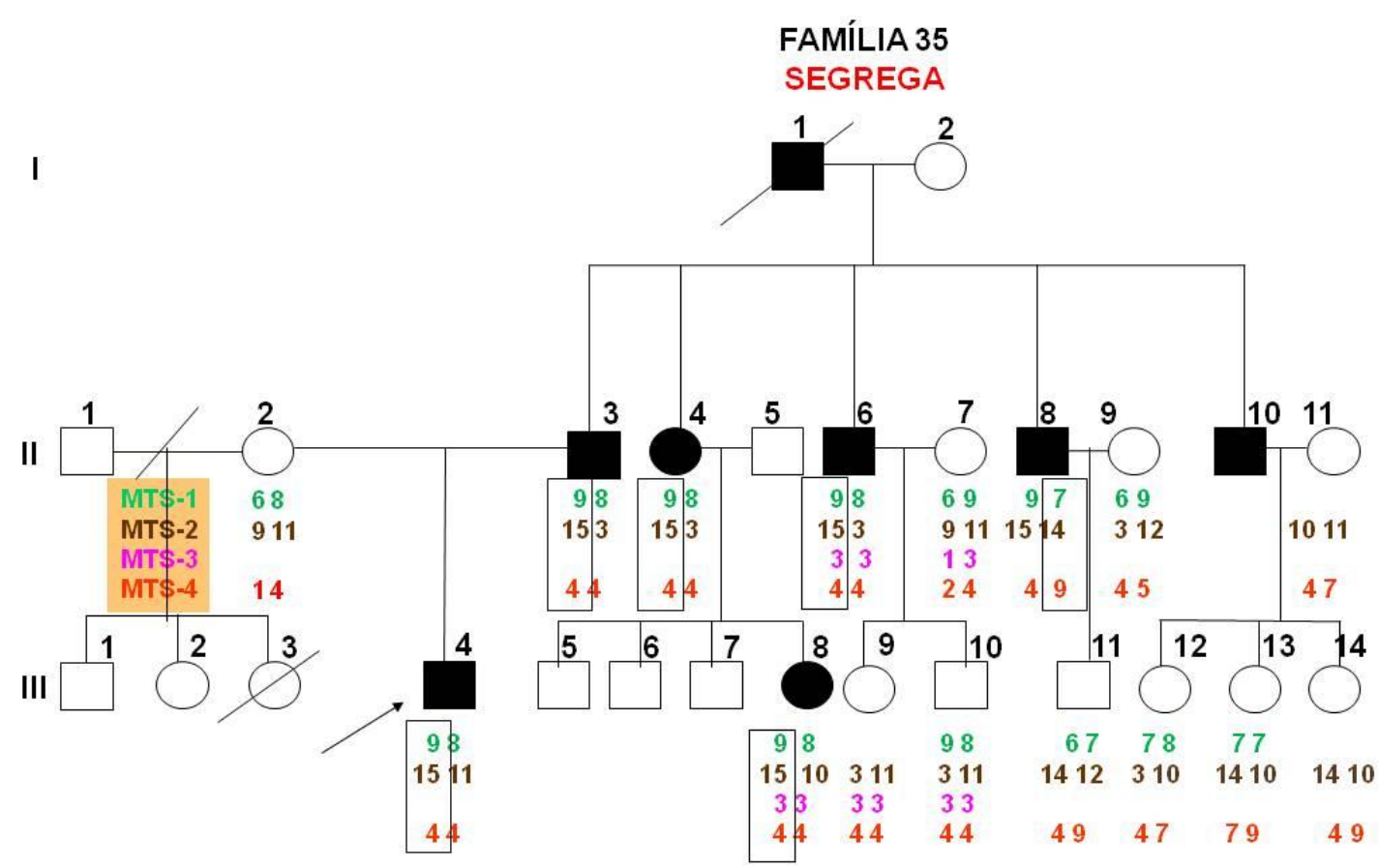

FAMÍLIA 36

INCONCLUSIVO

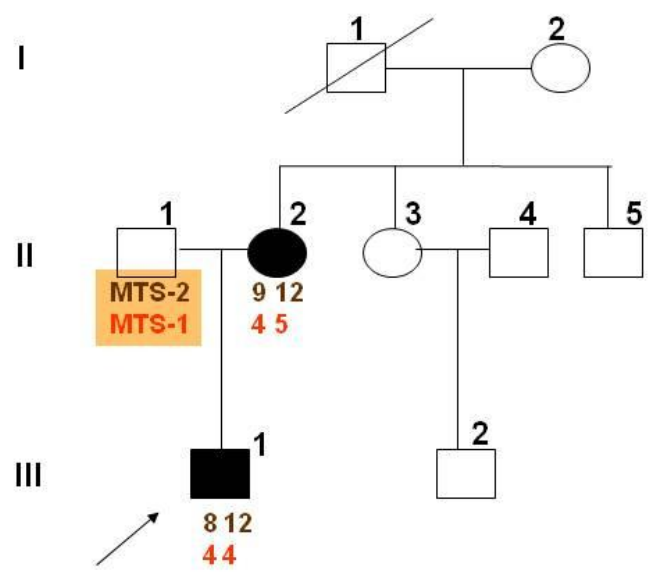




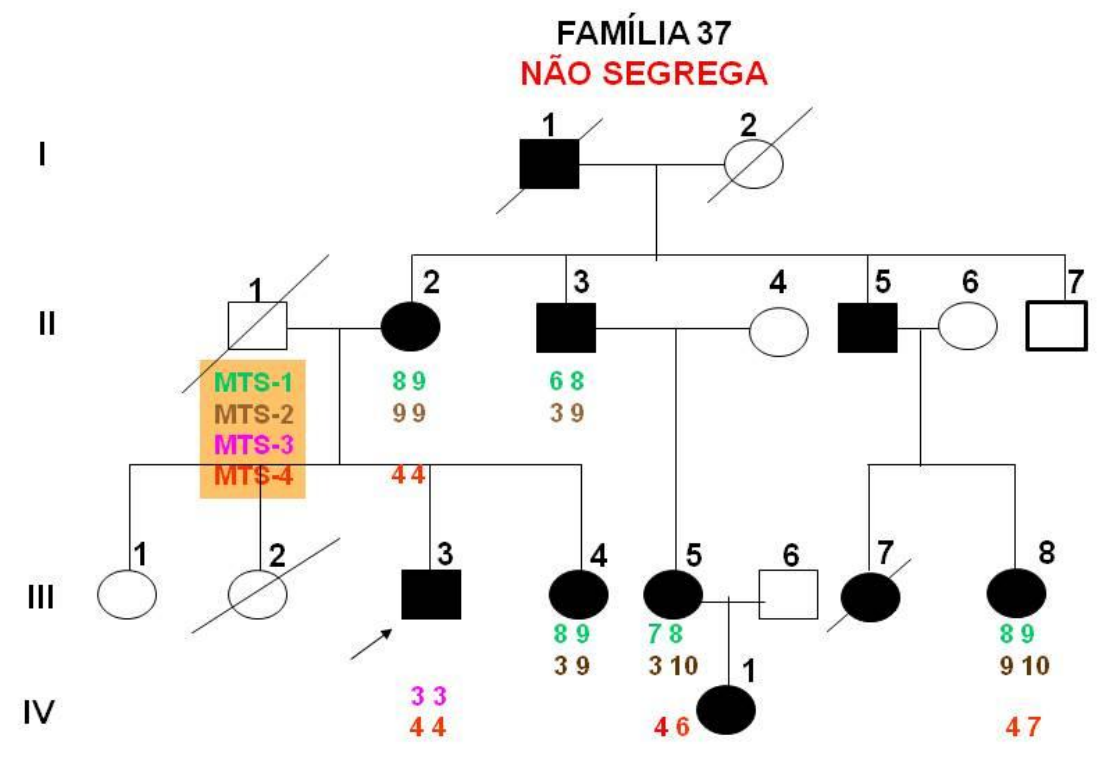

47

FAMÍLIA 38

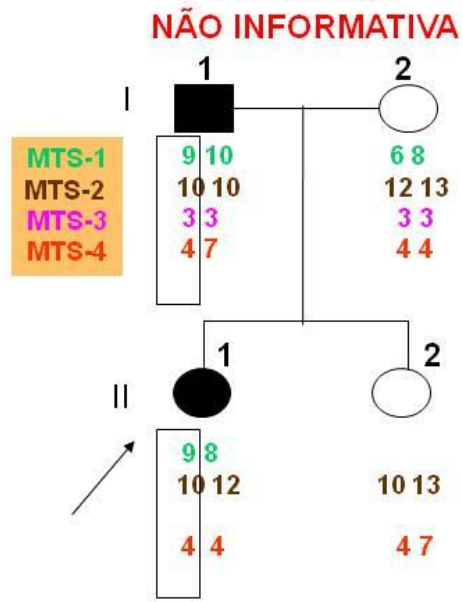



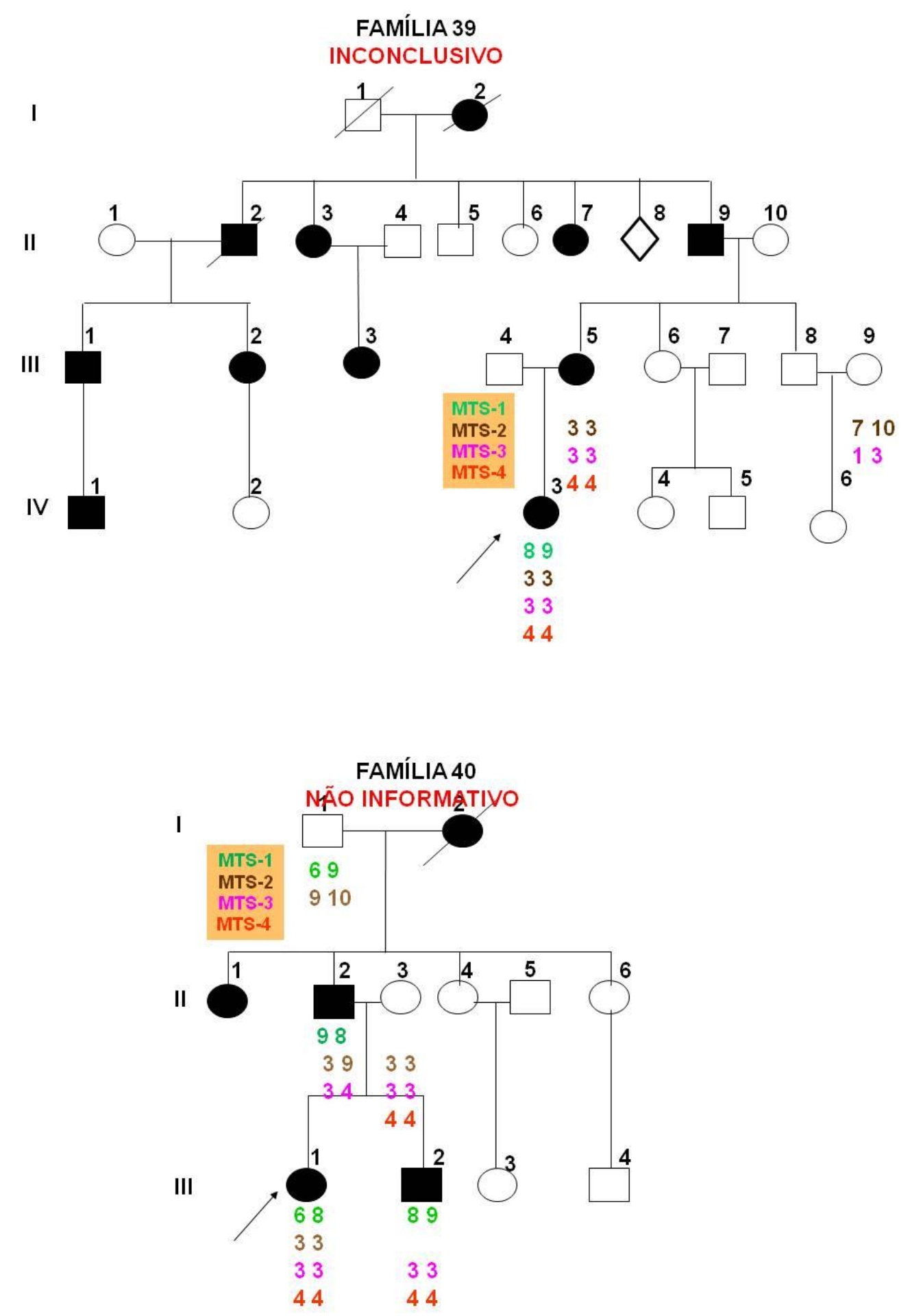


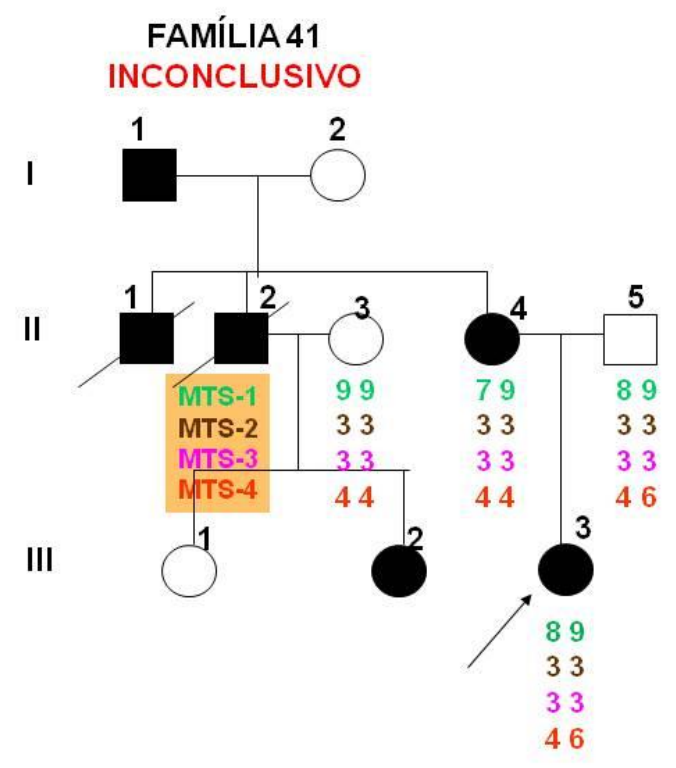

FAMILIA 42

NÄO SEGREGA

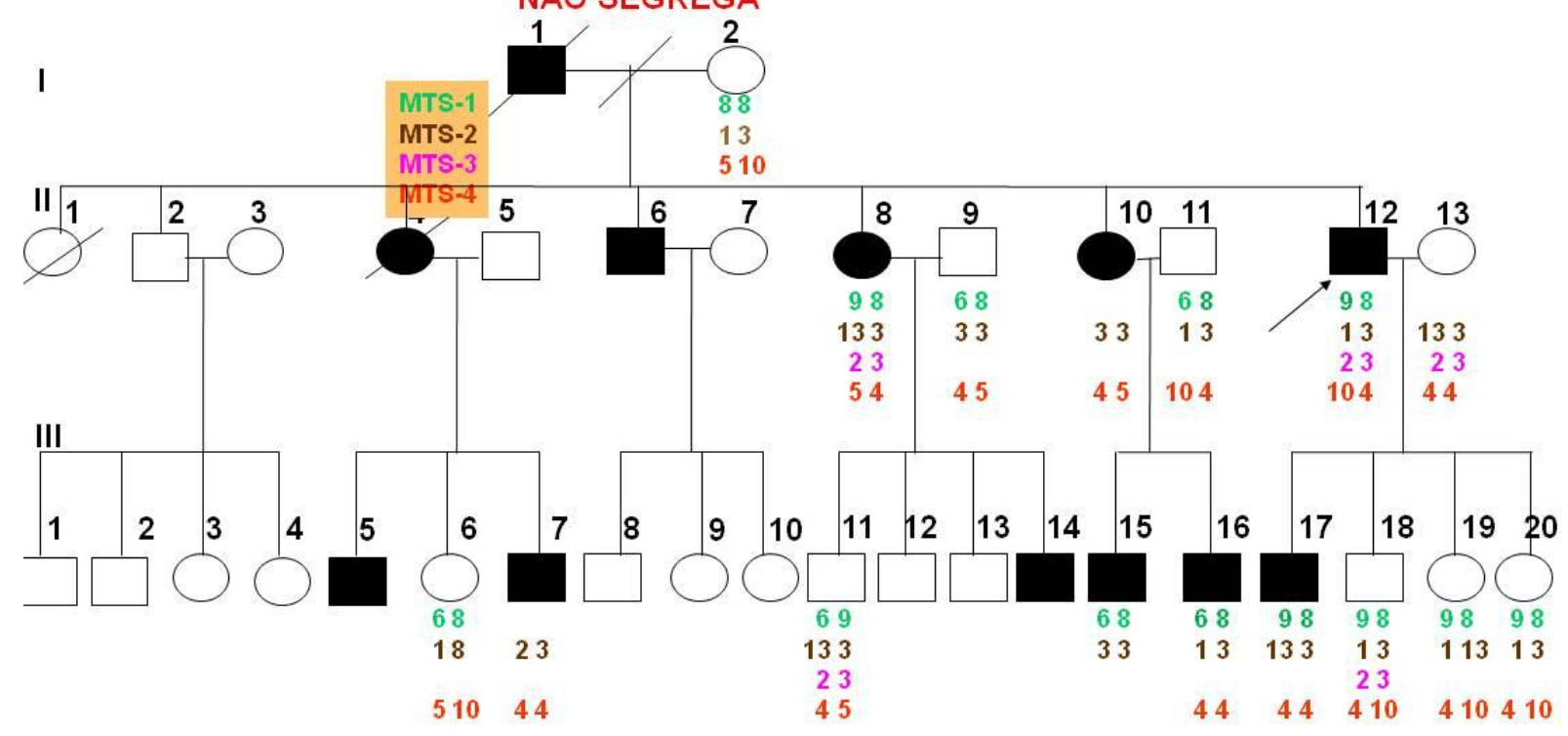


FAMÍLIA 43

NÄO SEGREGA

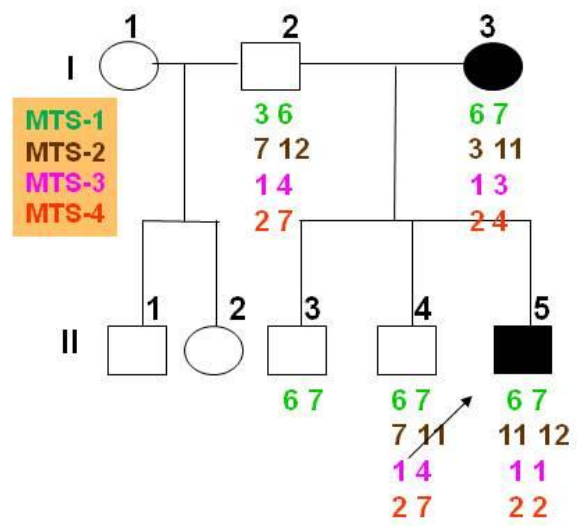

FAMÍLIA 44

INCONCLUSIVO

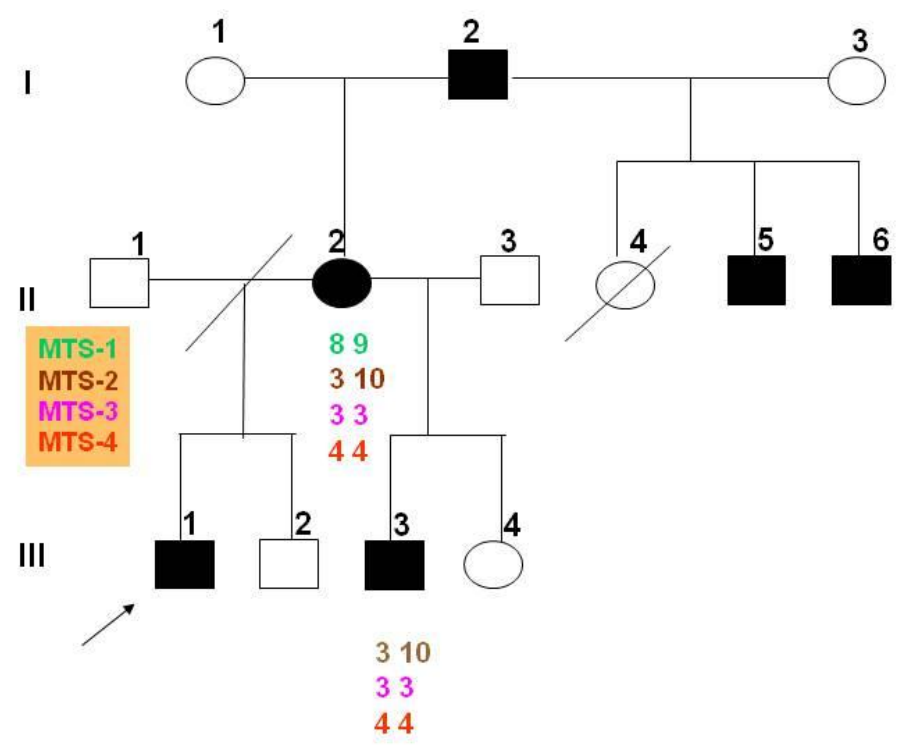



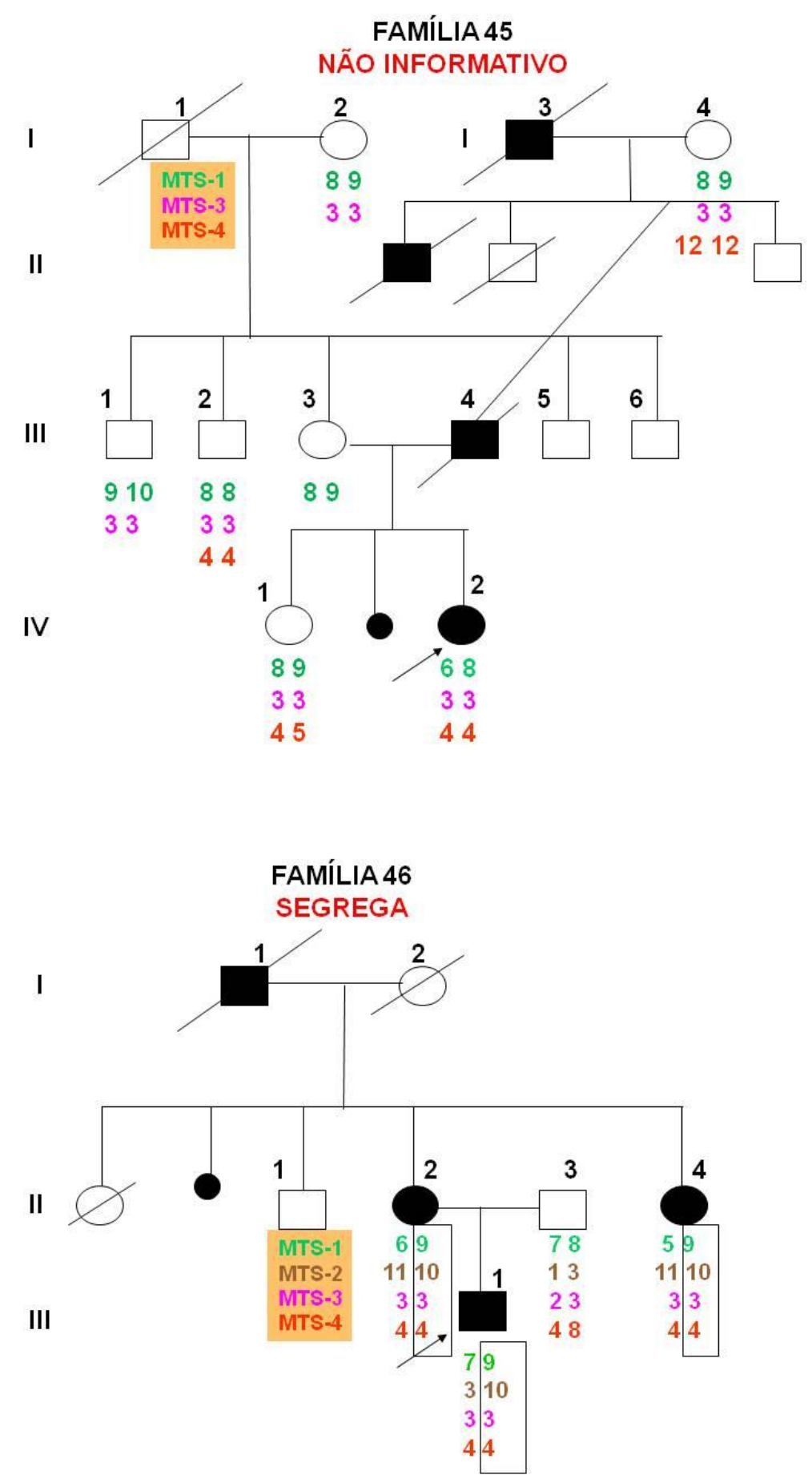


\section{FAMÍLIA 47}

NÄO INFORMATIVO

ANDAMENTO CLÍNICO

I

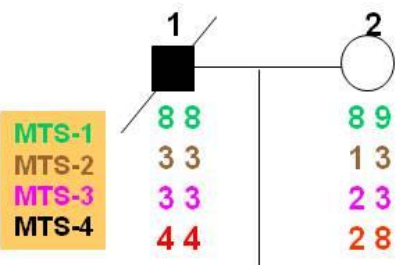

II

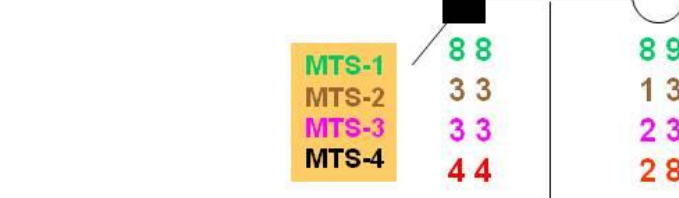

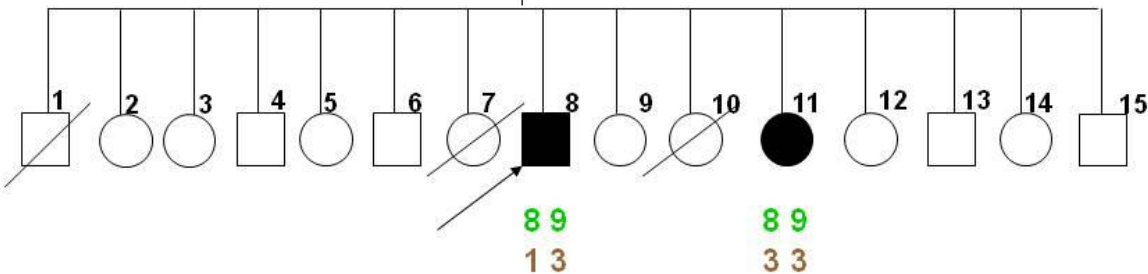

48

24 


\section{ANEXO B}

HEREDOGRAMAS DAS FAMILIAS ESTUDADAS COM MARCADORES DO GENE TGFBRII (D3S3727 e D3S3567).
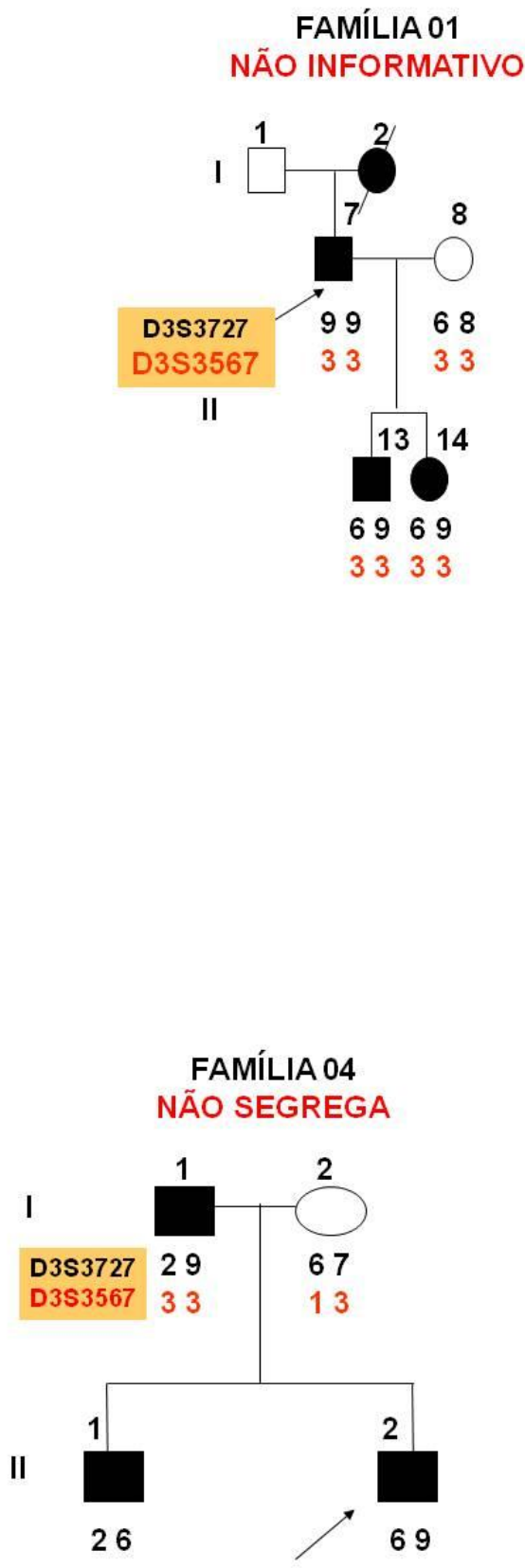
FAMÍLIA 06

NÃO SEGREGA

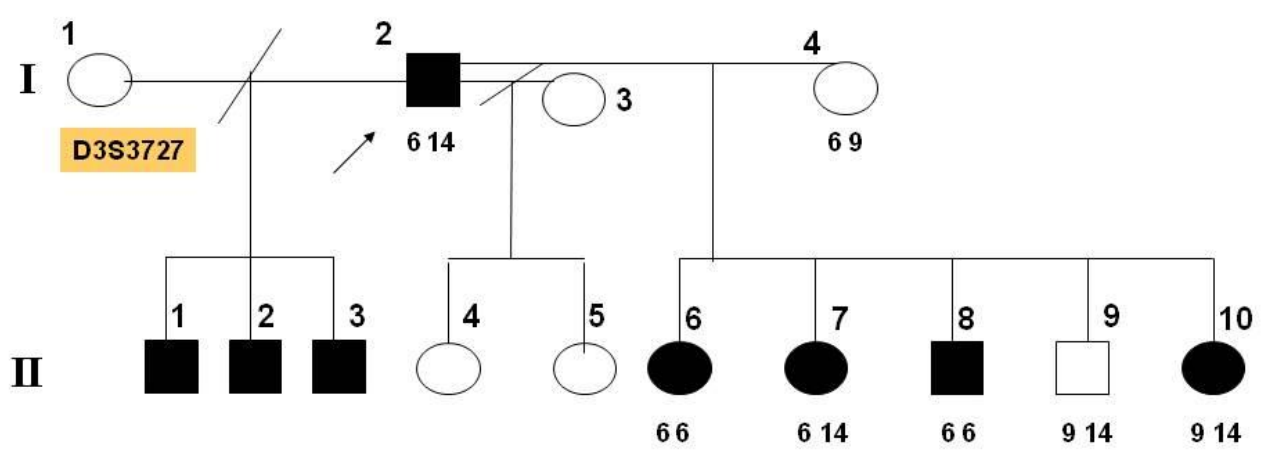

FAMÍLIA 09

NÃO SEGREGA

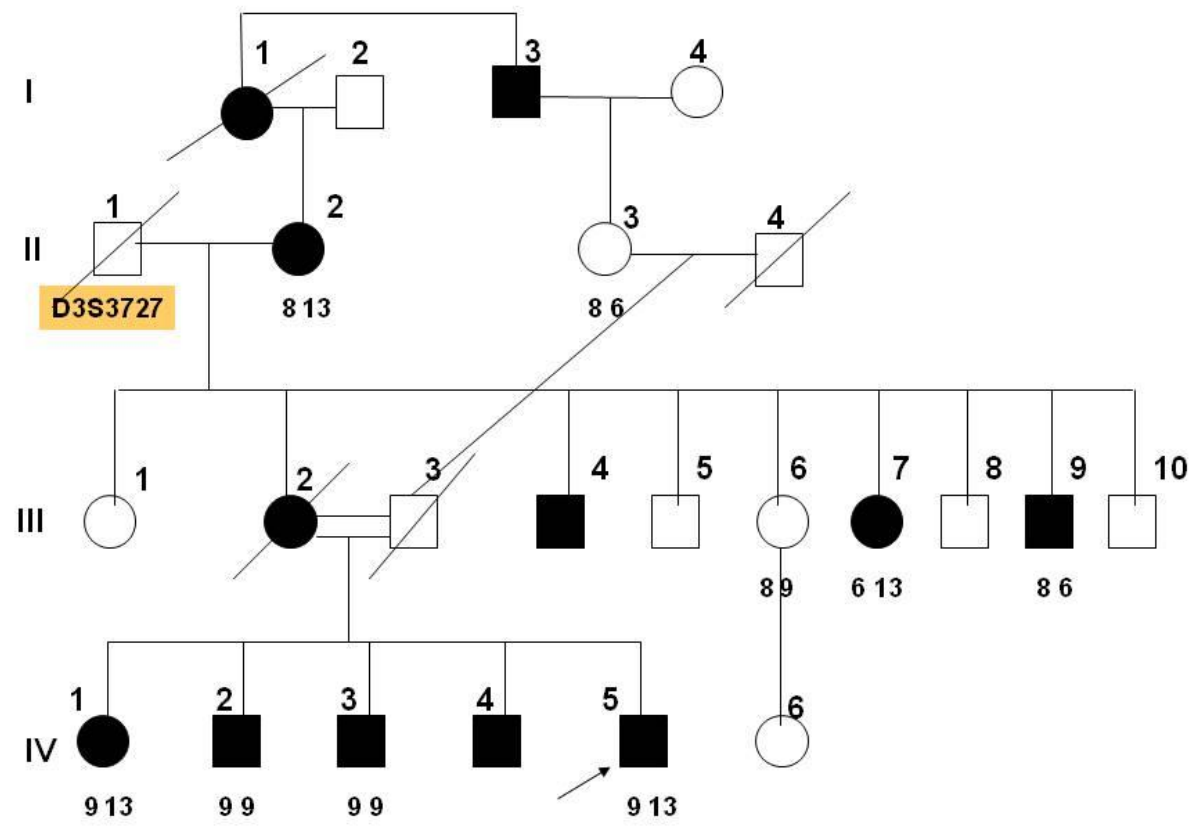



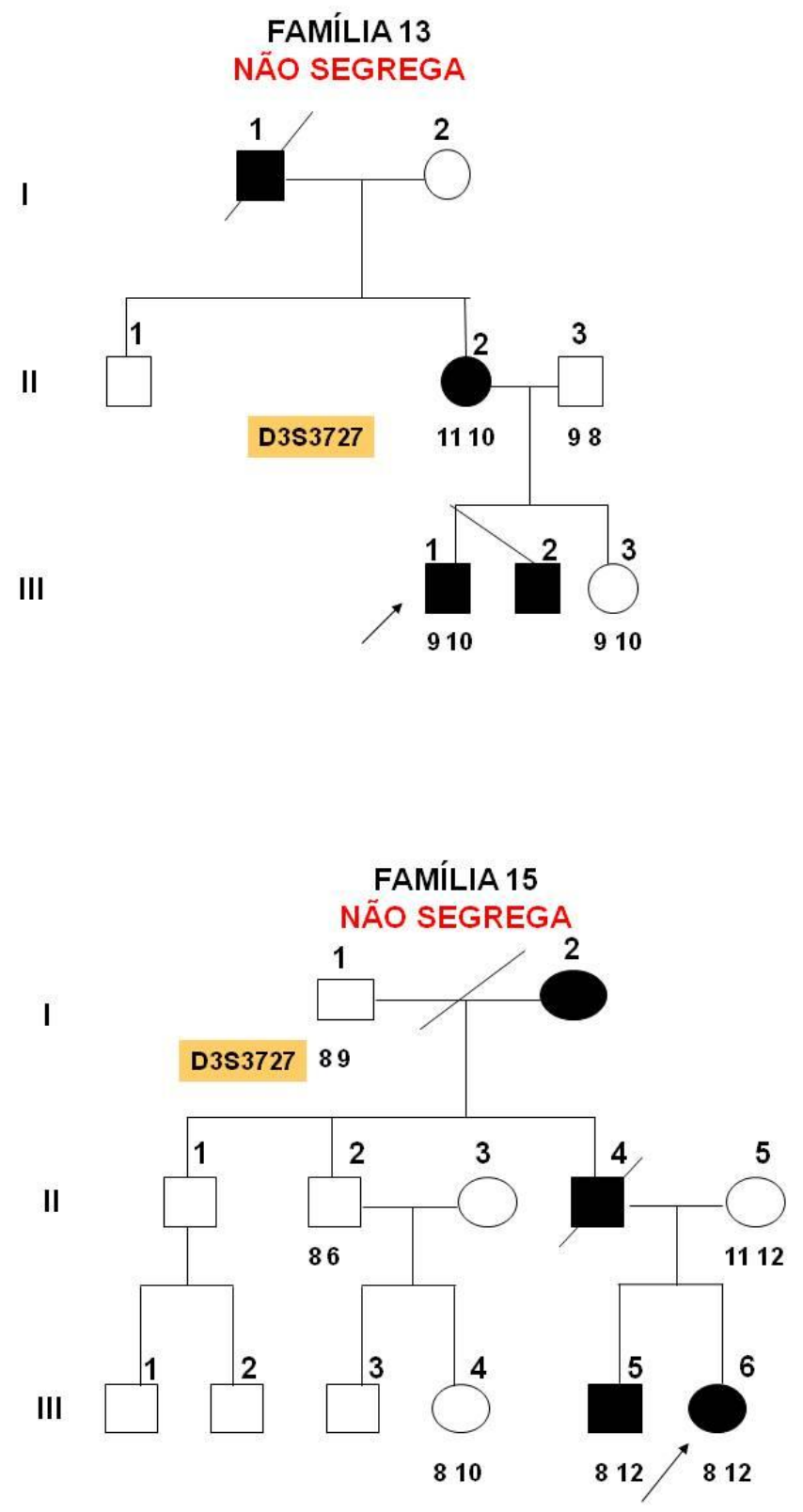


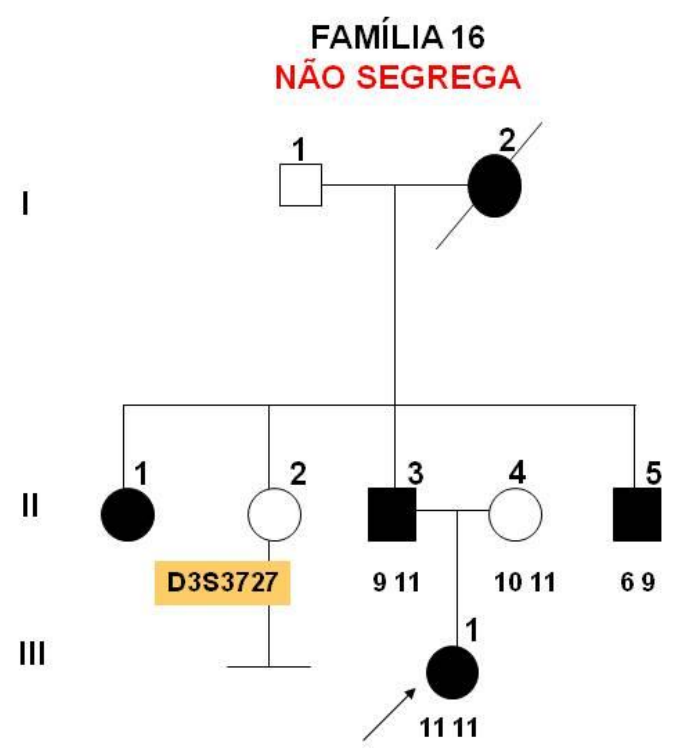

FAMÍLIA 17 NÃO SEGREGA

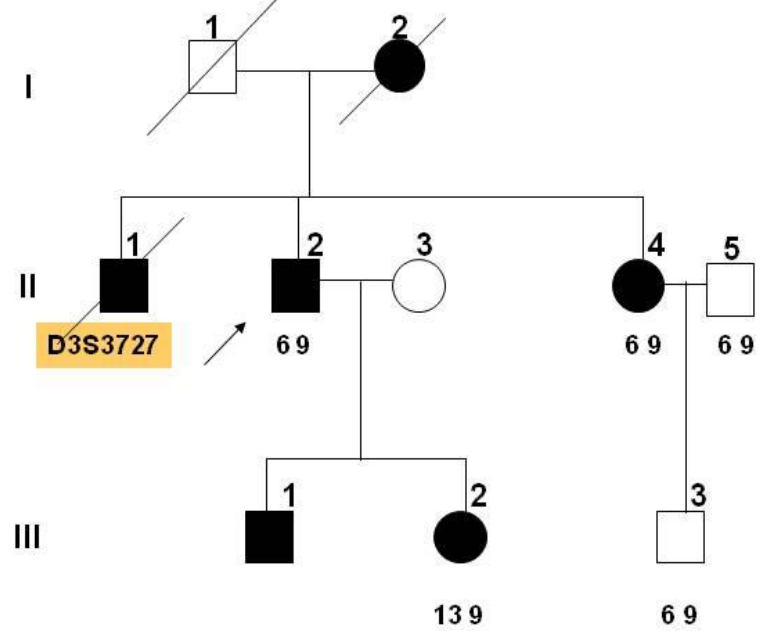


FAMÍLIA 18

NÃO SEGREGA

I

1

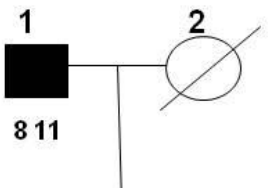

II
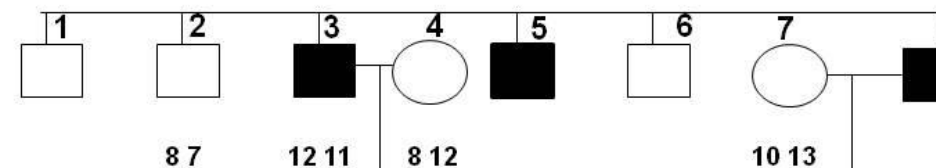

3S 3567

1211

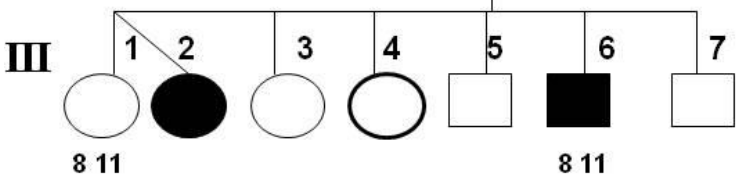

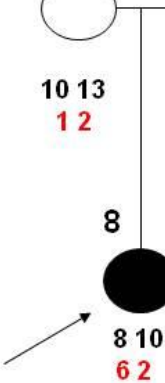

FAMÍLIA 28

NÃO SEGREGA

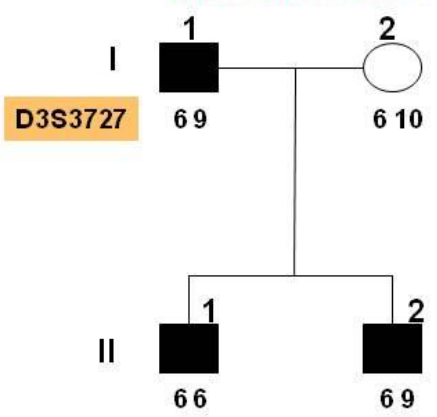




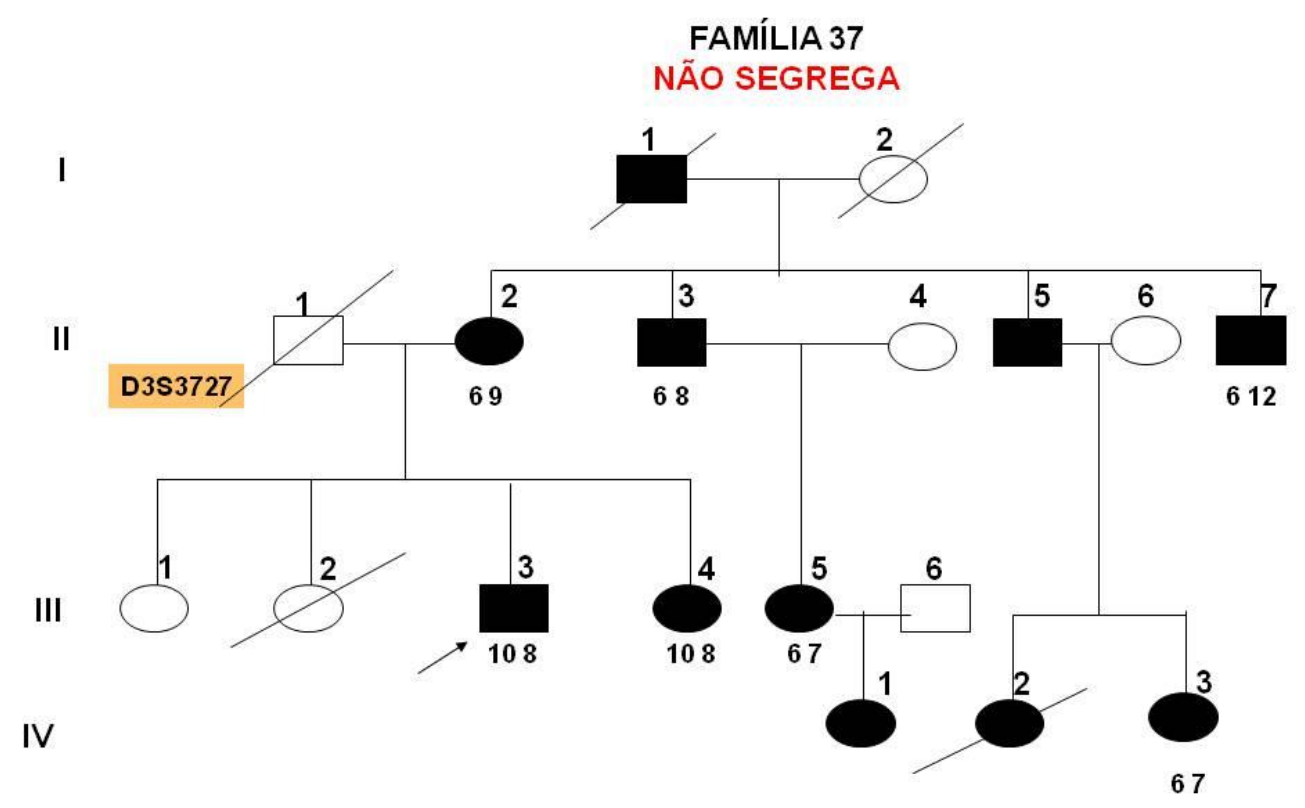

FAMÍLIA 40

INCOCLUSIVO

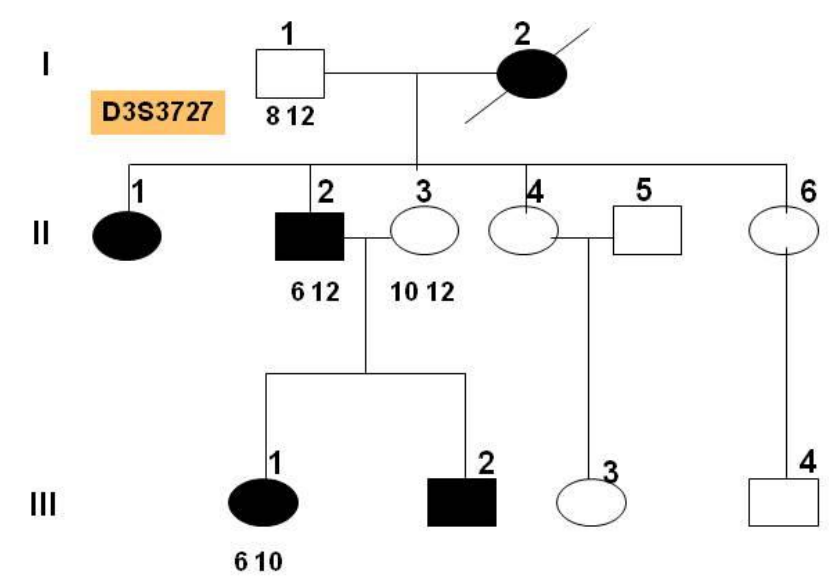




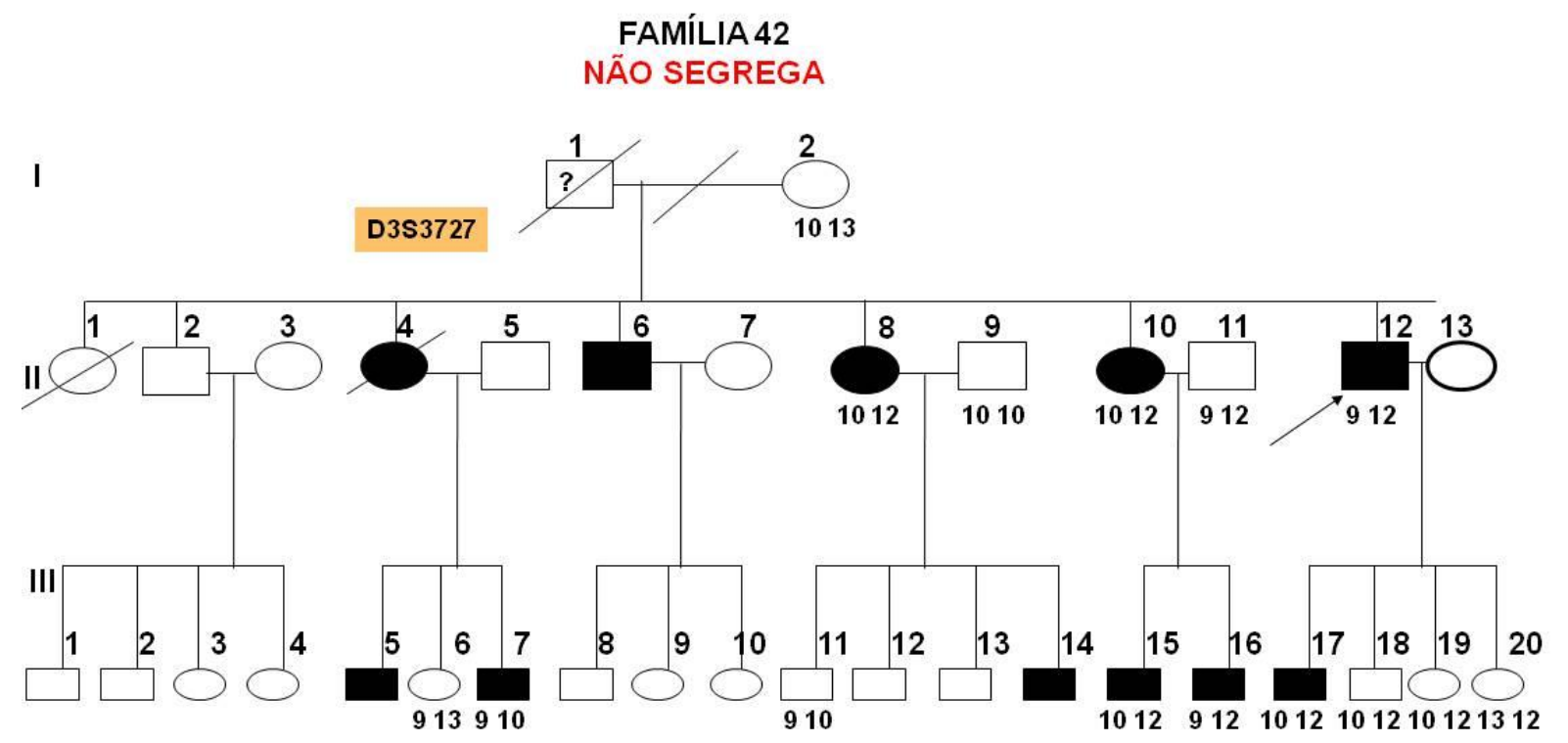

FAMÍLIA 43

SEGREGA

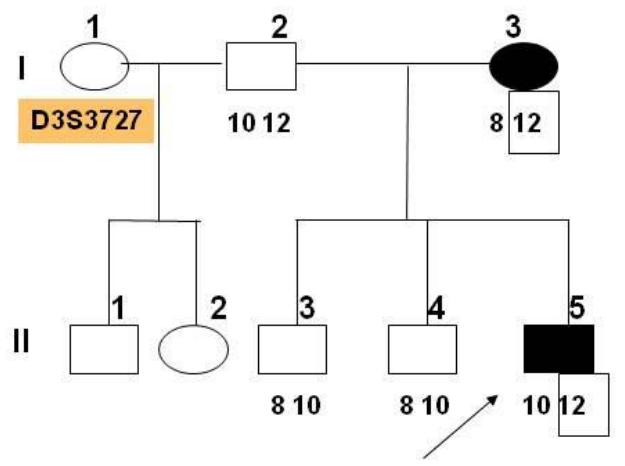


FAMÍLIA 45

NÃO SEGREGA

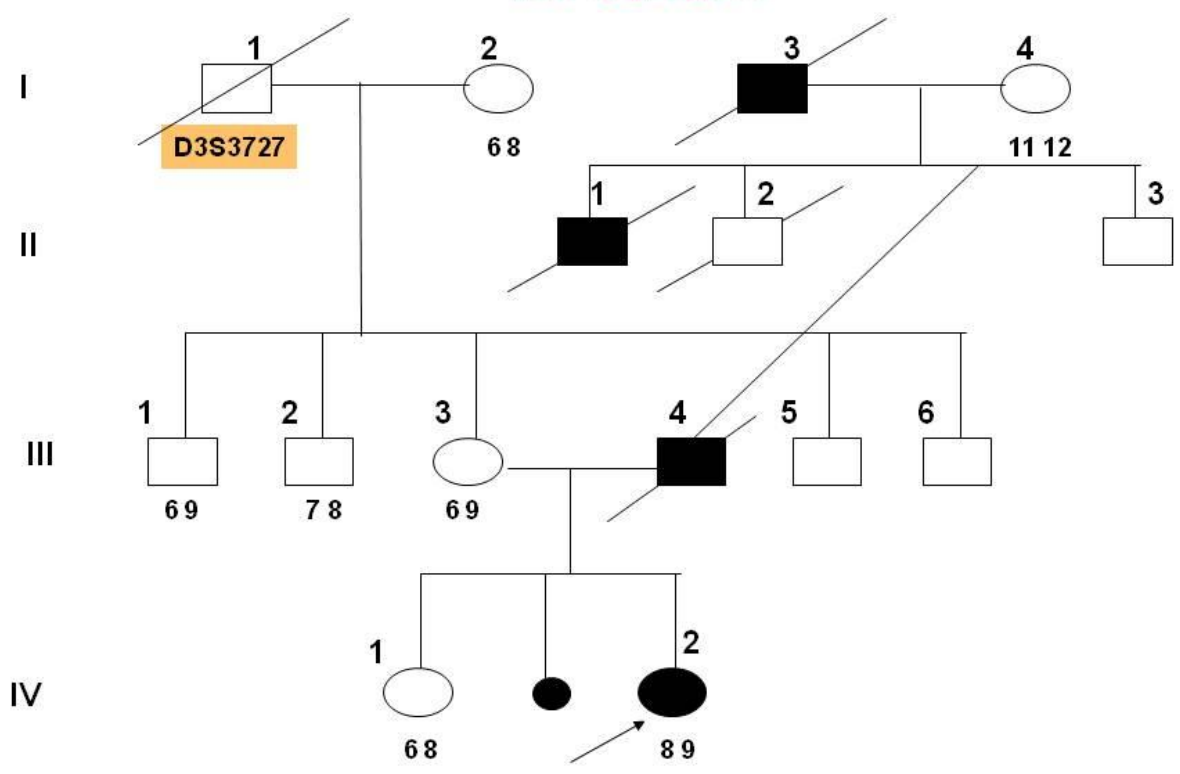

FAMÍLIA 47

EM ANDAMENTO CLÍNICO

I

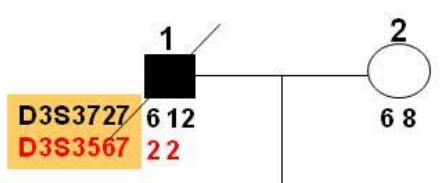

II

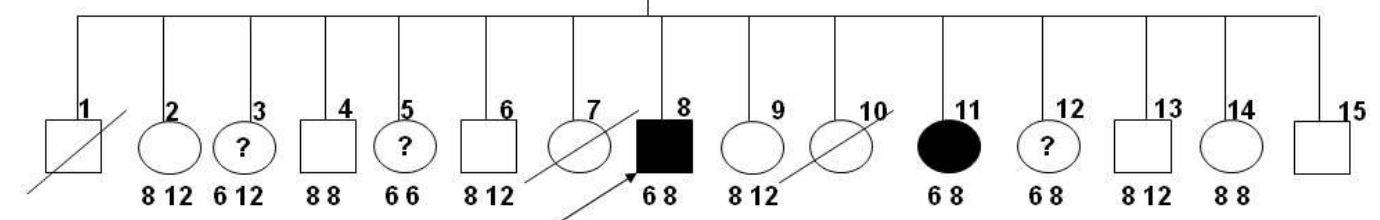

